\title{
WestVirginiaUniversity
}

THE RESEARCH REPOSITORY @ WVU

Graduate Theses, Dissertations, and Problem Reports

2009

\section{Test re-test reliability of the UNC Functional Performance Test}

\author{
N. Regina Hash \\ West Virginia University
}

Follow this and additional works at: https://researchrepository.wvu.edu/etd

\section{Recommended Citation}

Hash, N. Regina, "Test re-test reliability of the UNC Functional Performance Test" (2009). Graduate Theses, Dissertations, and Problem Reports. 2761.

https://researchrepository.wvu.edu/etd/2761

This Thesis is protected by copyright and/or related rights. It has been brought to you by the The Research Repository @ WVU with permission from the rights-holder(s). You are free to use this Thesis in any way that is permitted by the copyright and related rights legislation that applies to your use. For other uses you must obtain permission from the rights-holder(s) directly, unless additional rights are indicated by a Creative Commons license in the record and/ or on the work itself. This Thesis has been accepted for inclusion in WVU Graduate Theses, Dissertations, and Problem Reports collection by an authorized administrator of The Research Repository @ WVU. For more information, please contact researchrepository@mail.wvu.edu. 
Test Re-test Reliability of the UNC Functional Performance Test

N. Regina Hash, BA, ATC

Thesis submitted to the

College of Physical Activity and Sport Sciences

at West Virginia University

in partial fulfillment of the requirements

for the degree of

Master of Science

in

Athletic Training

Michelle A. Sandrey, PhD, ATC, Chair

Sean Bulger, Ed.D.

Jeff Erickson, MS, PT, SCS, ATC, CSCS

College of Physical Activity and Sport Sciences

Morgantown, West Virginia

2009

Keywords: Functional Performance Testing, Football, Lower Extremity, Reliability, Kinetic Chain 


\section{ABSTRACT \\ Test Re-test Reliability of the UNC Functional Performance Test}

\section{N. Regina Hash, BA, ATC}

Context: Football is a high risk contact sport in which many injuries are sustained to the lower extremity. Functional screening tests exist for football, but it is unknown if they are specifically used as criteria for return to play. The UNC Functional Performance Test has been used as criteria for return to play but reliability for this test is unknown. Objective: The purpose of this study was to establish reliability for the UNC Functional Performance Test (UNCFPT), a battery of functional skills. Design: This study was conducted as a prospective test re-test design. Setting: One site was used with only one test administrator. Data collection occurred at the athletic facilities on the campus of a division II MidAtlantic University. Patients and Other Participants: A total of 47 participants from a D-II football program were used for this study aged 18 - 23 (19.77 \pm 1.43 years), mass of 73.48 to $147.87 \mathrm{~kg}$ (101.38 $\pm 20.08 \mathrm{~kg})$, and a height of 167.6 to $198.1 \mathrm{~cm}(184.45 \pm 7.62 \mathrm{~cm})$. All participants that volunteered for the study were current players encompassing a variety of position groups and were free of a lower extremity injury within the last six months. Interventions: The participants were asked to complete the UNC Functional Performance Test of which included the shuffle box drill, figure eight test, single leg (SL) hop test for time, carioca test, and SL triple hop for distance. There was an aerobic warm-up period followed by both static and dynamic stretches prior to testing as well as a cool down period upon completion of all tasks. Testing protocol following the warm-up consisted of a demonstration of the task, 50\% effort by the subject, a thirty second rest, 75\% effort by the subject, two minute break and three maximum trials. Athletes were given thirty seconds of rest between maximal trials and additional thirty seconds before the next task was demonstrated. The examiner documented the maximal attempts in seconds for all tasks except for the SL triple jump of which data was recorded in inches. The procedure remained exactly the same for each week of testing. Data was collected at the site over two separate three week periods. For each testing session, the first week consisted of a training session followed by the second week of data collection and then another data collection a week later. Main Outcome Measures: The expectations of this study will be that the UNC Functional Performance Test will be a reliable objective functional measure and similar results will be evident throughout Weeks 2 and 3. Results: The individual components of the UNCFPT had excellent ICC and low standard error of measurement (SEM) scores indicating the tasks were reliable and precise. Little variation would exist in the results if the same person repeated the tasks multiple times. The shuffle box drill had an ICC of .933 (.880 to .963, 95\% CI) with a SEM of .202. The figure eight had an ICC score of .892 (.806 to .940, 95\% CI) with a SEM of .329. The SL hop test had the lowest ICC score of .873 (.772 to .929, 95\% CI) with a .211 SEM score. The carioca had an ICC score of .930 (.874 to .961, 95\% CI) along with a SEM score of.173. The SL triple hop had the highest ICC score of .956 (.931 to .973, 95\% CI) and SEM of 5.975 for the right side and a SEM on the left side of 5.890. Therefore, with these independent ICC and SEM scores, it can be speculated that the UNCFPT as a whole would have an approximate ICC score of .9168 (95\% CI) and have a SEM between .173 and 5.975. Due to the fact the tasks had different forms of measure (time and distance), the actual ICC and SEM could not be calculated for the UNCFPT. Conclusion: The UNC Functional Performance Test is a reliable objective functional assessment tool that can be used to aid clinicians in the return to play decision making process. It should not be used alone but should be used in conjunction with other clinical measures such as ROM, anthropometric girth, manual muscle testing and subjective pain ratings. Further research needs to be conducted on the 
validity of the UNC Functional Performance Test since excellent reliability was established in this study. 


\section{ACKNOWLEDGEMENTS}

I would like to start by thanking my family. You have always been there for me and these past two years have been no exception. I thank you for all the love, encouragement, advice, and laughs you have provided me along the way.

I would also like to thank my graduate advisor, Dr. Michelle Sandrey. The opportunities you have provided have been an immeasurable asset to my development as an athletic trainer.

Thanks to my committee members, Jeff Erickson and Dr. Sean Bulger. I am grateful for the time, effort, and energy you have put into this long process.

I would also like to thank Bob Cable. Your guidance in and out of the athletic training room has been most appreciated. It has been an honor to work with one of the best in West Virginia.

I would like to extend a special thanks to Coach Mike Lopez and the Fairmont State University Football team. Thank you for volunteering as participants and for always providing a good laugh. Best wishes throughout the upcoming season. 
TABLE OF CONTENTS

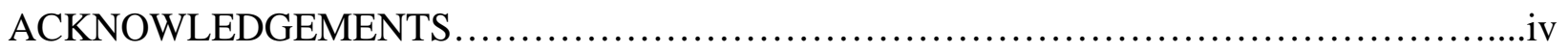

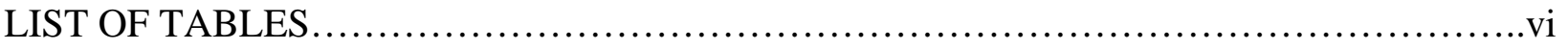

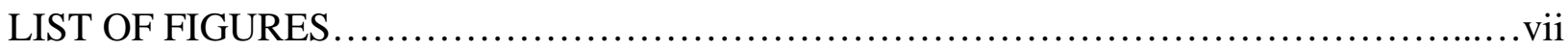

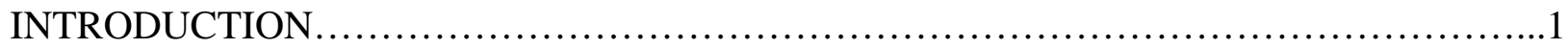

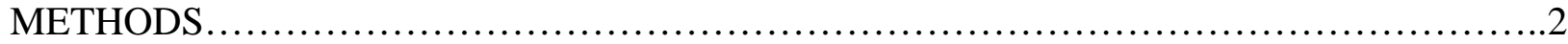

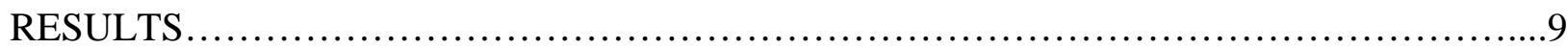

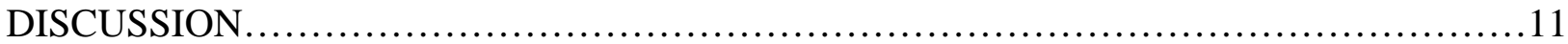

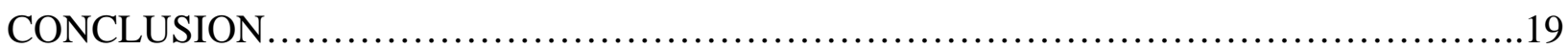

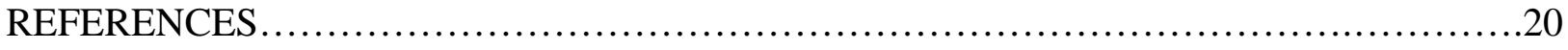

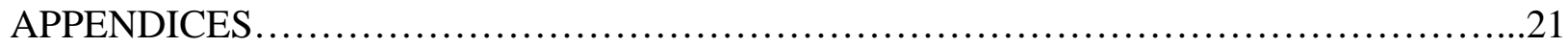

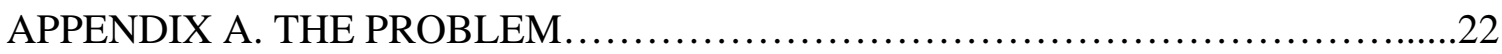

APPENDIX B. LITERATURE REVIEW ......................................31

APPENDIX C. ADDITIONAL METHODS...........................................69

APPENDIX D. ADDITIONAL RESULTS.......................................

APPENDIX E. RECOMMEDATIONS FOR FUTURE RESEARCH..................100

ADDITIONAL REFERENCES.................................................... 101 
Table

\section{LIST OF TABLES}

Table B1. Muscles Acting on the Hip and Femur 33

Table B2. Muscles Influencing the Knee................................................. 37

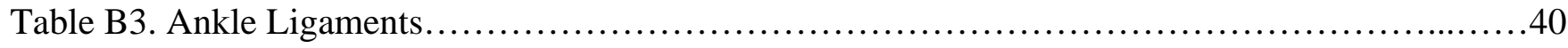

Table B4. Muscles Acting on the Foot (Talocrural and Subtalar Joints).............................41

Table B5. Intrinsic Muscles of the Foot.................................................43

Table B6. ROM Requirements of Joints for Gait...........................................47

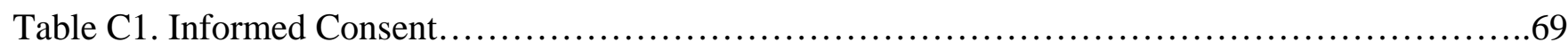

Table C2. HIPAA Form..............................................................73

Table C3. Subject Demographics....................................................... 76

Table C4. Balance Latin Square Randomization Method........................................77

Table C5. Data Collection Sheet........................................................78

Table D1. Descriptive Statistics by Position Group..........................................96

Table D2. ICC Scores, Percent of Methodological Error, and SEM of Components

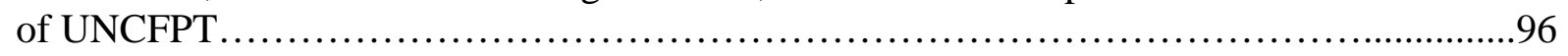

Table D3. Best Trial Descriptive Statistics by Week........................................96

Table D4. Shuffle Box Descriptive Results by Week and Position Group.............................97

Table D5. Figure 8 Descriptive Results by Week and Position Group.............................97

Table D6. Table D6. SL Hop for Distance Descriptive Results by Week and Position Group...........97

Table D7. Carioca Descriptive Results by Week and Position Group................................98

Table D8. SL Triple Hop-Right Side Descriptive Results by Week and Position Group....................98

Table D9. D9. SL Triple Hop - Left Side Descriptive Results by Week and Position Group................99 


\section{LIST OF FIGURES}

Figure

Figure C1. Standardized Warm-Up Protocol.....................................................79

Figure C2. UNC Functional Performance Test: Shuffle Box.................................91

Figure C3. UNC Functional Performance Test: Figure Eight..................................92

Figure C4. UNC Functional Performance Test: SL Hop Test (Time)..............................93

Figure C5. UNC Functional Performance Test: Carioca........................................94

Figure C6. UNC Functional Performance Test: SL Triple Hop Test (Distance)...........................95 


\section{INTRODUCTION}

Football is a complex contact sport that requires a wide variety of skills performed by athletes of various body types. Due to the variability in tasks, certain position groups are more susceptible to injury. Completed in 2007, an epidemiology report covering sixteen years of participation of fifteen college sports reported that football had the highest rate of injury in both practices and games with the majority of most incidences being ankle ligament sprains or anterior cruciate ligament injuries. ${ }^{1}$ Knee and ankle ligamentous injuries account for 17.8 and $15.6 \%$, respectively, of all injuries in the sport of football alone. $^{2}$

Over fifty percent of injuries that are classified as "time loss" occur to the lower extremity. ${ }^{1}$ Once these injuries are sustained, it is the responsibility of the certified athletic trainer, a member of the sports medicine team, to safely return the athlete to participation as quickly as possible. Functional testing allows for the clinician to stress the athlete's body in the same manner that activity would while controlling the environment. ${ }^{3}$ When using functional testing, most of the suggestions from the literature stress that normative values be used for comparisons to indicate progression to full functional activity. Factors such as gender, anthropometric characteristics, physical activity level and sport are all considered. ${ }^{4}$ Tabor et al. ${ }^{3}$ suggested that although these variables are important, their association with functionality is not well established. No matter the specificity of the criteria, the application of one single battery of functional tests or the physical demands of each sport is questionable. The concept of the kinetic chain as it relates to biomechanics will allow for functional testing of the entire lower quarter regardless of joint location. Despite the information included in the literature, there is very little on what functional tests to use to determine when the athlete is ready to return to activity. It is imperative to note that a football specific functional performance tool should evaluate forward sprinting, backpedaling, cutting, jumping, sideshuffling and kicking as they are basic components for most positions in football. 
The UNC Functional Performance Test is a battery of functional tasks that incorporates jumping in addition to speed and agility for a more comprehensive assessment of the lower extremity that encompasses all of the physical demands of football. The components include shuffle box drill, figure-8, single-leg hop test, ${ }^{5-9}$ carioca, ${ }^{10}$ and a single-leg triple hop measured for distance. ${ }^{6,11}$ This specific lower extremity functional battery was not designed specifically for the sport of football. However, clinically, it has been used in making the return to play decision.

Appropriate return to play decisions are imperative yet remain to be the most difficult aspect of athletic training. However, recognizing deficits in an athlete's normal physical capabilities is the first step in determining the most accurate assessment. If deficits go unnoticed and ultimately untreated, the initial injury will likely be exacerbated over time, or result in another injury due to compensation. An objective and reliable form of measurement needs to be implemented which has the ability to assess the individual capabilities of football athletes at baseline in order to make more accurate return to play decisions. Therefore, the purpose of this study is to establish reliability of the UNC Functional Performance Test using a test re-test design.

\section{METHODS}

This study was conducted as a prospective test re-test design to establish reliability. The components of the UNC Functional Performance Test included the shuffle box drill, figure eight test, single leg (SL) hop test, carioca test, and SL triple hop for distance. The tasks were demonstrated and performed by the subject during Week 1 only as a means of introduction to the tasks and to the testing protocol. Actual data from the maximum trials were collected at the same location during Week 2. The third data collection occurred a week later. Data was collected for a total of three weeks over two testing sessions. 


\section{Subjects}

Sixty-two subjects volunteered to be participants and only fifty-four met all inclusion criteria. Forty-seven of the fifty-four eligible participants completed this study in its entirety. All forty-seven subjects were football athletes from various position groups at one institution. The subjects were a sample of convenience from a Division-II Mid-Atlantic institution including starters and reserves. Subjects ranged in age from 18 to 23 (19.77 \pm 1.43 years), mass of 73.48 to $147.87 \mathrm{~kg}(101.38 \pm 20.08$ $\mathrm{kg})$, and height of 167.6 to $198.1 \mathrm{~cm}(184.45 \pm 7.62 \mathrm{~cm})$. The forty-seven subjects were divided into eight groups based on skill set and functional movement patterns. The groups included four on the offensive side of the ball, three on the defensive, and one group that represented special teams (Table D1). More specifically, the groups included offensive line (10), wide receivers and tight ends (12), quarterbacks (1), running backs (6), defensive tackles and defensive ends (5), linebackers (6), defensive backs (4), and special teams of which included both kickers/punters and long snappers (3). Each participant voluntarily participated, having no lower extremity pathology in the last six months, not requiring bracing, having no cardiac pathology, nor uncontrolled asthma. Each subject acted as their own control as they participated in the study for three weeks. Prior to the initiation of the study, the study was approved by the Office of Research Compliance at West Virginia University.

\section{Instruments}

The UNC Functional Performance Test (UNCFPT) is a battery of functional tasks that incorporates jumping in addition to speed and agility. The components include the shuffle box drill for time, figure 8 for time, bilateral single leg (SL) hop test for time, carioca test for time and a SL triple jump for distance. This battery of tests was developed from a prototype called the Carolina Functional Performance Index (CFPI). The CFPI included the co-contraction test, carioca test, shuttle run test and 
SL hop for time. ${ }^{12}$ It was originally designed to aid clinicians in evaluating lower-extremity functional performance. Statistical analysis from a previous study ${ }^{12}$ revealed no significant relationship between structural characteristics of height, weight, and percentage of body fat to CFPI scores or individual test scores for either gender. Furthermore, high ICC scores were reported for the co-contraction semicircular test and the carioca test for male athletes with ICC scores of 0.896 and 0.884 respectively. Female athletes also had high ICC values with the co-contraction semicircular test and the shuttle run with scores of 0.947 and 0.851 respectively. However, the CFPI has evolved over time and only two of the original components remain, the carioca and the SL hop for time. There is no reported information on established reliability or validity for the current version of the UNCFPT.

\section{Test Protocol}

The UNC Functional Performance Test is a lower extremity functional battery that has five individual components. All components of the UNCFPT were conducted on a standard gymnasium surface marked off by yards to ensure proper dimensions of the course. Four plastic cones were used as markers indicating the boundaries for the tasks. A standard tape measure was used to assess tasks measured for distance. Furthermore, a standard stopwatch was used by the administrator during both testing sessions to obtain time measurements to the nearest hundredth of a second. The stopwatch that was used was the Sportline 240 Econosport Stop Watch (Sportline, Yonkers, NY). Maximal effort on all tasks was recorded in this manner during both test and re-test.

Procedure

Research was conducted at one test site for a period of three weeks over the course of two testing sessions and adhered to the following procedures. Subjects were asked to volunteer for the study. All 
subjects completed an Informed Consent form (Table C1) and a HIPAA form (Table C2). Following the completion of those forms, subjects were also asked to complete a demographic questionnaire (Table

C3). This questionnaire was used to determine eligibility for the study. Week 1: Subjects participated in a training session. The training session included a standard dynamic warm up, a demonstration of the UNC Functional Performance Test, two submaximal trials, three maximal trials, and a cool-down. Week 2: Following the standard dynamic warm-up, a $50 \%$ and a $75 \%$ submaximal trial was performed. Three maximal effort measurements were recorded. A cool-down followed the completion of maximal attempts of all five tasks. Week 3: Test re-test measurements were obtained by following the protocol for Week 2.

For each task, the subject provided maximal effort and started behind the "start" cone. The stopwatch was started on the subject's first movement and stopped when contact was made with the final cone and recorded to the nearest .01 second. Distance was measured from the starting cone to athletes' final position of the toe measured to the nearest inch. The athlete did not have significant rest between tests as a means to more accurately assess strength and endurance. Therefore, rest did not exceed thirty seconds between maximum trials. Each new task was initiated thirty seconds after the completion of the previous task. However, a two minute rest was provided between submaximum and maximum trials for each task. Subjects received verbal instruction from the test administrator regarding which task was to be completed next, as well as a visual demonstration. The order of the tasks for each subject and for each week was randomized using the Balance Latin Square method (Table C4). The administrator confirmed that the subject did not start with the same task they started with the week before to ensure that results were independent of one another and were not impacted by fatigue.

The standard dynamic warm-up (Figure C1) required subjects to submaximally run a quarter of a mile, followed by static and dynamic stretches. Static stretches consisted of two repetitions (one on each 
side) of thirty second holds for the following muscle groups: quardriceps, hamstrings, gastrocnemius/soleus complex, hip abductors, hip adductors, and hip flexors. Dynamic stretches focused on hip abduction, adduction, extension and flexion maneuvers. The administrator at the site supervised the subjects during the warm-up period. A two minute rest period separated the submaximal and maximal attempts. The cool down period consisted of a .25 mile walk followed by the same static stretches that were described previously. The same test administrator conducted the testing for the same subjects during all three trials. The following tasks were administered during each testing session.

Box shuffle drill: This test was completed by establishing a ten by ten yard box using cones as markers indicating the corners. At each cone, the athlete changed movement patterns while facing in the same direction during the entire test. The sequence of tasks were to sprint straight ahead, sideshuffle to the left, backpedal, and then sideshuffle to the right with the athlete ending in the same position as the start point. The goal was to complete the task as fast as possible and to record the time to the nearest 01 second (Figure C2). Time, as measured by the stopwatch, started upon the first movement of the athlete and ended upon return to the start point. All three maximal trials were recorded and the best trial of the three was used for data analysis.

Figure eight test: Two cones set ten yards apart indicated the boundaries. The athlete was asked to sprint and go behind the cones in a figure eight pattern changing which side of the cone to turn on. The pattern appeared diagonal. The subject completed the task three consecutive times. This task was completed for speed and was recorded to the nearest .01 second (Figure C3). Time was initiated upon the athlete's first movement and was terminated upon return to the starting point on the third series. All three maximal trials were recorded and the best trial of the three was used for data analysis.

SL hop test (for time): Two cones were placed ten yards apart. The athlete was asked to change feet when changing directions. The subject hopped for speed on one foot all the way to the opposite 
cone, quickly changed directions in addition to switching the hopping foot and went back to the starting cone. This task was timed recorded to the nearest .01 second (Figure C4). Time started upon the athlete's first movement and ended upon crossing the starting point. All three maximal trials were recorded and the best trial of the three was used for data analysis.

Carioca test: The carioca step is a sideways movement pattern. The left foot crosses in front of the right, the right foot steps right, the left foot crosses behind the right, and the right foot steps right. The pattern was repeated in a continuous manner for fifteen yards. The athlete touched the line and returned to the starting cone completing the carioca step with a different lead foot. The athlete faced the same direction the entire time. The goal was to complete the task as fast as possible and to record the time to the nearest .01 second (Figure C5). Time was initiated upon the first movement made by the athlete and ended upon return to the starting position. All three maximal trials were recorded and the best trial of the three was used for data analysis.

SL triple hop (for distance): This test was measured for distance to the nearest inch. The athlete jumped off one foot and landed on the same foot three times before the jumping foot came in contact with the ground for the final time. This was completed bilaterally jumping as far as possible and measuring for maximal distance from the starting point on a single leg to the end position of the same foot after three consecutive jumps. As this task was considered a measurement of power, there should not have been an increased moment of foot contact with the ground between each jump (Figure C6). Distance was measured from the toe at the athlete's starting position to the position of the toe upon the completion of the third jump. The athlete was not allowed to use the hands as this would generate momentum increasing the distance covered. Hands were held behind the back while completing this task. It was also noted by the administrator which was the dominant foot. This was determined by asking each subject which leg they would kick a ball with. Their response was indicated as their dominant 
lower extremity. All three maximal trials were recorded and the best trial of the three was used for data analysis (Table C5).

Intraclass Correlation Coefficient (ICC)

The ICC is a reliability coefficient that generates a ratio ranging from 0.00 to 1.00 to estimate the consistency of performance on repeated trials. ${ }^{13}$ (A score of 0.00 indicates the measure was $100 \%$ unreliable.) In calculating the ICC, the ratio determines accurate interpretation of how much variability in the observed measure was truly a change in the participant or if it is a result of measurement error. Therefore, an ICC over 0.75 can be considered good while anything below 0.5 is poor. ${ }^{14}$ Another common scale used for reliability as described by Portney and Watkins ${ }^{14}$ is that ICC $>.75$ is good and anything less than .75 reflects moderate to poor reliability. Furthermore, Anastasi ${ }^{15}$ suggests that an ICC of .60 is the minimal acceptable score for reliability.

\section{Statistical Analysis}

ICCs or intraclass correlation coefficients were used to determine test re-test reliability of the UNC Functional Performance Test by analyzing the maximal effort measurements between trial 1 (week 2) and trial 2 (week 3). The following equation was used for the calculation of ICC as established by Shrout and Fleiss ${ }^{16}$ where BMS = between subjects mean square, EMS = between testing sessions mean square, $\mathrm{TMS}=$ trial mean square, $\mathrm{N}=$ number of total subjects, and $\mathrm{K}=$ number of testing sessions .

$$
\text { ICC }_{2,1}=[\text { BMS }-E M S] /[B M S+(K-1) E M S+(K(T M S-E M S) / N)]
$$

The SEM or standard error or measurement was used to determine the precision of the recorded measurements. The SEM demonstrates the variation in expected scores for one subject if the test were repeated multiple times. The following equation was used for SEM as described by Brown ${ }^{17}$ where $\mathrm{S}=$ the standard deviation of the test and $r_{x x}=$ reliability coefficient for the test. 


$$
\mathrm{SEM}=\mathrm{S} \sqrt{1-\mathrm{rXx}}
$$

The methodological error to determine precision of measurement and to evaluate intra-rater reliability was determined by using the formula as described by Dahlberg. ${ }^{18}$ The methodological error is represented by percent where the mean error ratio is $\mathrm{SE}^{2}=\mathrm{d}^{2} / 2 \mathrm{n}$ when $\mathrm{d}=$ difference between the measurements and $n$ = sample size. Furthermore, descriptive statistics were analyzed for all five components of the UNCFPT. Specific measures included means, standard deviations, and standard error of the mean.

\section{RESULTS}

UNC Functional Performance Test

Each component of the UNCFPT had excellent ICC scores and a relatively low standard error of the measurement (SEM). Using a two way random effects analysis of variance and the ICC $(2,1)$ formula according to Shrout and Fleiss, ${ }^{16}$ the test re-test reliability was estimated. The ICC for the shuffle box drill was .933 (.880 to $.963,95 \%$ CI) and had a SEM of .202 seconds. The figure eight had an ICC score of .892 (.806 to .940, 95\% CI) and SEM of .329 seconds. The SL hop test had the lowest ICC score of .873 (.772 to $.929,95 \%$ CI) and SEM of .211 seconds. The carioca had an ICC score of .930 (.874 to $.961,95 \%$ CI) and SEM of .173 seconds. The SL triple hop had the highest ICC score of .956 (.931 to $.973,95 \% \mathrm{CI})$. The SEM on the right (R) was 5.975 inches while the left (L) was 5.890 inches. Due to the fact all five tasks were not timed measurements, the overall ICC score and SEM for the UNCFPT cannot be accurately measured. However, it can be safe to assume that it would be close to the average of all independent ICC scores. Therefore, with these independent ICC scores, it can be speculated that the UNCFPT as a whole would have an approximate ICC score of .9168 (.873 to .956, 95\% CI) and a SEM ranging from .173 to .329 seconds and within 5.890 and 5.975 inches (Table D2). 
It is important to note that variance in ICC interpretation exists. Anastasi ${ }^{15}$ states that the minimal acceptable ICC score is .60. However, Portney and Watkins ${ }^{14}$ recommend that ICC scores greater than .75 represent good reliability and results lower than .75 depending on magnitude of deviation suggest moderate to poor reliability. Therefore, the components of the UNCFPT and the test in its entirety have excellent reliability.

Each component had some variation within results between Week 2 and Week 3. Tables D4 to D9 provide additional results including mean, standard deviation and the standard error of the mean. In this case, both the standard error of the mean and standard deviation are being reported where standard deviation will provide accurate unit variation describing the range per individual and standard error of the mean (standard deviation in relation to the sample size) is normalized and related to the normal curve not taking unit deviation into account. Standard error of the mean scores for both maximal weeks of testing ranged from .081 (SL Hop Wk 3) to 4.331 (R side SL Triple Hop Wk 2).

SEM scores for each component can be found in Table D2. Highest results for SEM were .329 seconds (Figure 8) and 5.975 in (R side SL Triple Hop). These scores are relatively low and can be interpreted as the same subject repeating this battery would not deviate more than .5 seconds or more than 6 inches from their best score on any of these tasks at any given time. Table D2 contains the methodological error listed for each component. Methodological error ranged from .011\% to 6.56\% indicating there was very little error in measurement.

\section{Positions}

As expected and in general, the offensive line was the slowest group and the quarterback and defensive backs tended to record faster results during completion of functional drills. Refer to Tables D4-D9 for additional results including descriptive statistics and differences between groups. 


\section{DISCUSSION}

The purpose of the present study was to establish test re-test reliability for the UNC Functional Performance Test in an effort to introduce an objective and reliable return to play measure for the lower extremity. It was hypothesized that the battery of tests used would be reliable resulting in high ICC scores. This hypothesis was accepted and individual components had similar ICC scores to that of previous research.

The components of the UNCFPT were pre-determined and there was no deviation in this study from the original form. Each component was significant to the overall functional assessment of the lower extremity. The shuffle box drill included forward sprinting, bilateral lateral shuffling, and backpedaling. The figure eight had an endurance component as well as cutting inducing stress upon all joints of the leg bilaterally. The SL hop test was completed for both legs (hop down on one foot and return on the opposite foot) and measured for time assessing speed and agility. The carioca placed more functional demand on the hips. The SL triple hop was measured for distance and assessed power and force production. Although this battery of tests was not specifically designed for the sport of football, it meets the demands of each position group (aside from Special Teams) and is currently being used by a D-I program. This population was used as this was the environment in which the test was introduced. It is important to note that this test can be conducted on athletes of other sports that are lower extremity dependant.

As this is the first study of this nature to evaluate a battery of tests for the lower extremity, there is one other study ${ }^{12}$ to use as a basis of comparison. However, the two tests are slightly different in content with similarities of the SL hop test and the carioca. The prototype of the UNCFPT is the Carolina Functional Performance Index (CFPI). Intraclass correlation coefficients were determined by 
$\mathrm{McGee}^{12}$ in a study evaluating reliability for the use of the CFPI by male and female athletes. In comparison to this study, the UNCFPT resulted in an ICC score of .873 (95\% CI) while the CFPI had reported values of .839 and .818 with male and female athletes respectively. Despite these differences, ICC values were considered good for both tests.

Other studies have been conducted establishing reliability for functional tasks of specific pathologies including patella ${ }^{19}$ and Achilles tendinopathy ${ }^{20}$ or criteria to return to activity ${ }^{3}$. In two studies, the ICCs were lower ${ }^{19,20}$ and methodological error was higher ${ }^{20}$ in relation to this study while, in the third study, ${ }^{3}$ the ICCs were comparable. Loudon ${ }^{19}$ examined intra-rater reliability of functional tests including anteromedial lunge, step-down, single-leg press, bilateral squat, and balance and reach for patellofemoral pain. In this test re-test design of 48 to 72 hours apart, ICC $(3,1)$ values ranged from.79 to .94 . Silbernagel ${ }^{20}$ also reported ICCs for a battery consisting of a counter movement jump (CMJ), a drop CMJ, hopping, concentric toe raises and eccentric-concentric toe raises that assessed function in subjects with Achilles tendinopathy. Results ranged from .73 to .94 with a reported methodological error ranging from 8\% to 17\%. The Lower Extremity Functional Test (LEFT), designed by Davies, is a comprehensive multidirectional test. It is comprised of eight skills of which include forward and backward running, side shuffling, carioca, figure 8 running, 45 degree and 90 degree cutting, and 90 degree crossover cutting, all of which are skills introduced during sport. ${ }^{3}$ ICC scores at different locations were .95 and .97 indicating that the LEFT was a reliable functional assessment tool for a variety of lower extremity pathologies. ${ }^{3}$

Most often in the literature, reliability has been established for individual tasks. As in this case, reliability has been reported for many of the individual components of the UNCFPT but not all. A review completed by Drouin ${ }^{6}$ reported reliability for five commonly used single-leg (SL) hop tests. These included the SL hop for distance, SL triple hop for distance, SL triple cross-over hop for distance, 
SL vertical jump, and the SL 6-m hop for time. Intraclass correlations (ICC 2,1) ranged from .66 to .99 for the five single leg tests. These results ranged from good to moderate representing good reliability of SL hop tests for consistency of measurement. The results from this study for the SL triple hop show similar reliability results to previous research, however, there is a difference noted in results for the SL hop for time. An explanation for the variation in reliability is centered on the difference in the explanation and technique of the tasks. The SL hop that is described in most of the literature is a hop for time with no change in direction nor change in feet. Clinically, most will complete the test twice, once for each side. However, the CFPI and UNCFPT SL hop is described in a manner in which both sides can be assessed simultaneously. McGee ${ }^{12}$ described the test as being modified to "include both legs in an effort to eliminate the confounding variables of dominance." It is therefore hypothesized that the change in direction and change in feet results in lower ICC scores but are still acceptable for repeatability. In both reliability studies of the UNCFPT and the CFPI, ICCs were lower than what is reported in most literature. In this study, both the SL hop for time and SL triple hop represented excellent reliability with ICC’s $(2,1)$ of .873 and .956 with standard error of measurement (SEM) values of .211 seconds and a range (representing right and left) of 5.975 to 5.890 inches, respectively. Comparatively, the study previously mentioned by Drouin ${ }^{6}$ reported ICCs in the collegiate athlete to be .92 and .97 , respectively, with SEM values of 0.06 seconds and $11.2 \mathrm{~cm}$. The variation in unit distance measured converts to an SEM of $15 \mathrm{~cm}$ on the SL triple hop. This study had a larger standard error of measurement and lower ICC but is still highly reliable even with the variation from the classic explanation of the SL hop.

Furthermore, Worrell et al. ${ }^{8}$ determined that ICCs ranging from .77 to .99 were acceptable for SL hop for distance, SL hop for time and SL agility hop as functional performance tools for ankle inversion sprains. ${ }^{8}$ In a study designed specifically for ACL reconstruction, five SL hops were investigated. ${ }^{9}$ These included the SL vertical jump, SL hop for distance, drop jump followed by double SL hop for 
distance, SL square hop, and SL side hop. The ICC scores ranged from 0.85 to $0.97 .{ }^{9}$ Lephart ${ }^{10}$ also examined the reliability of functional performance components. In examining the co-contraction semicircular test, carioca test and shuttle run, ICC scores ranged from .92 to .96. The ICC results for the carioca component of the UNCFPT were very similar with an ICC score of .930.

Additionally, Booher et al ${ }^{21}$ investigated the reliability of the SL hop for distance, SL hop for time, and the 30 meter SL agility hop. In this study, no significant differences between dominant and non-dominant extremities were observed. However, significant differences existed within the functional tests from day to day trials demonstrating that motor learning or a "practice effect" did occur. Improvements in measurements were small but were still indicative of an unstable measure. This study concluded that if multiple trials are to be performed, rest periods should be built into the protocol in an effort to prevent fatigue. Intraclass correlation scores were acceptable ranging from 0.77 to 0.97 . In establishing reliability for the UNCFPT, many of these finding were considered. The test design dictated that athletes would be tested once a week for a three week period and that they would be given adequate rest between tasks.

Furthermore, differences were noted between non-dominant and dominant legs during the SL triple hop portion of the test. Similar to the study completed by Booher, ${ }^{21}$ the differences were not significant but were noted. In most cases the non-dominant leg covered a greater distance. The differences may be explained by co-contraction. In a recent study for ACL injury prevention, Shimokochi et al. ${ }^{22}$ reported those who lean the whole body forward during landing may produce more plantar-flexor moment and less knee-extensor moment, therefore possibly increasing hip-extensor moment and decreasing knee-extensor moment production. The author suggested that leaning forward may be a technique used during single leg landing to decrease quadriceps contraction demand while increasing hamstrings co-contraction. The hamstrings work as a stabilizer in the non-dominant foot (or 
plant leg) while kicking therefore, may be more significant on the non-dominant than on the dominant foot since the SL triple hop is a repeated jump. For the purpose of this study, foot dominance was determined by asking each subject which foot they would kick a ball with.

Design considerations must also be examined. Based on the results from the Tabor ${ }^{3}$ study establishing reliability for the LEFT (Lower Extremity Functional Test), factors such as motor learning, motivation, fatigue, length of test re-test interval and examiner bias could limit the assumption that there was stability within the variables being measured. ${ }^{3}$ Motor learning was negated during this study because multiple practice performance trials were conducted prior to the first maximal attempt. Week 1 was an introduction to the test and the testing protocol. Maximum trials were not recorded during Week1 but they completed all tasks as if they were. Weeks 2 and 3 also had practice trials before maximum effort to ensure that the athlete remembered and knew what task they were being asked to perform. Furthermore, motivation was not a factor as it can significantly improve results with a retest design. The athletes were not informed of their results until the entire test was concluded. No other athletes were in the facility at the time of testing and no verbal encouragement was provided by the examiner. However, external motivation for the subject may have existed for the SL triple hop component. A piece of tape was placed on the ground indicating the final resting point for each maximal jump. The measurement was not taken until the last jump; therefore, the tape was not removed until the completion of all three trials. The examiner acted as the recorder and was aware of all collected measures which could have influenced inaccurate measurement. Furthermore, the subjects could visually see how they performed on each trial providing some source of motivation. To minimize administrator bias, the scores from the previous week were not obtainable. Knowledge of the initial scores were sealed until data analysis in an effort to make the re-test scores as accurate as possible. 
Fatigue was a factor that could not be controlled in this study, however, it had little effect on the results as these were conditions similar to game situations. The athletes at the time of the study were in the off season with heavy lifting and running requirements. Although it would have been ideal for the athletes to refrain from any strenuous activity at least two days prior to testing, this was not feasible as they were lifting or running five days a week. Exercise induced muscle injury with symptoms of delayed onset muscle soreness (DOMS) was a factor and could have altered the results. Acknowledging this and trying to keep this from impacting the re-test, the athletes were asked to come back at the same day and time for the third week of testing, therefore, the same soreness they experienced would be consistent over time. Although this was not possible for all subjects, this was followed for a majority of subjects. Furthermore, adequate rest was necessary between each trial and test components to minimize fatigue as a limiting factor. A thirty second rest interval was provided between submaximal trials followed by a two minute rest interval prior to the maximal effort. An additional thirty seconds of rest was provided between each maximum trial. This same protocol was followed for each component.

Although not part of this study, baseline testing is essential as results are individualized. If an athlete cannot reproduce the same results in a healthy state than it is unknown whether the athlete has improved from baseline following an injury. This same principal applies to all forms of baseline testing, especially those that involve return to play decisions. The significance of baseline assessment should take into account individual results. Studies ${ }^{3,20,23,24}$ have been conducted that provide guidance for clinical application as criteria to return to activity. The LEFT is a measurement that should not be used alone but should be used in conjunction with other objective measurements such as range of motion (ROM) and strength. ${ }^{3}$ Different from this study, two pathology batteries ${ }^{19,20}$ established a ratio which compared involved to uninvolved side as according to the lower limb symmetry index (LSI.) The lower limb symmetry index (LSI) has also been used in previous research as a classification measure of side- 
to-side leg difference. In a study evaluating leg function in subjects with Achilles tendinopathy, Silbernagel et al. ${ }^{20}$ described the ratio as a percent comparing the involved limb score to the uninvolved limb score. Silbernagel ${ }^{20}$ suggested that a LSI greater than $90 \%$ was considered normal and did not indicate deficits between limb sides. The UNCFPT also allows for similar comparisons by allowing for bilateral functional assessment. Another study involving a concussion assessment program argues that test re-test reliability must be greater than .90 to make accurate decisions on cognitive ability postconcussion. ${ }^{23,24}$ Although the UNCFPT does not assess cognition, high ICC scores are important if a test is being used as a criteria to return to competition.

\section{Clinical Implications}

Clinical implications for the test re-test reliability of the UNCFPT include establishing reliability as a whole collective unit and introducing an objective form of return to play measure. Although this battery is currently being used, more research needs to be completed. The components on an individual basis are a reliable means of assessing functionality and can be beneficial in the clinical setting. This tool could be used as an individual assessment for return to activity. Methodological error was low meaning that there is high intra-rater reliability in addition to acceptable and minimal variation expected with athletes on a day to day basis as determined by the standard error of measurement. Prior to its application, validity would need to be established regardless of the high test re-test reliability. Baseline testing would be essential for clinicians to accurately use this tool in an effort to have a basis of comparison for individual functionality.

Prior to returning to team training or competition, an athlete must have regained full range of motion, possess adequate coordination and maintain at least ninety percent of their original muscle strength. ${ }^{25}$ The UNCFPT is designed as a functional measure with this in mind. Currently, functional 
outcome measures that are obtained clinically are classified in three ways: 1) self-reported scoring where pain, swelling, instability, and activity level are subjectively recorded; ${ }^{26} 2$ ) performance tests that mimic a specific sporting activity and generate quantifiable data; and 3) global scoring systems that include both self-reporting and performance testing while also including range of motion. ${ }^{27}$ Although global scoring systems are the most ideal, objective measures are the most critical component of accurately allowing the athlete to return to competition therefore, explaining the need for reliable functional assessment tools.

\section{Limitations}

There were also limitations to this study. In using a football team to establish reliability, a wide range of position groups should have been used. Several position groups were represented but not all position groups were adequately portrayed due to the low number of participants. The total number of subjects was forty-seven. A larger sample size would increase power in this study. Also, subjects were representative of a D-II football population. Different results would be expected if this study was conducted at Division I football programs where size and speed is required for that level of play. Furthermore, the functional tests implemented may not be valid measurements as a whole. Specific components have been validated but no gold standard exists for comparison for the test in its entirety. Most importantly, there is no way to ensure that each participant was giving $100 \%$ maximum effort with each trial during each testing week. External sources of motivation were controlled for in an effort to achieve consistency in the testing protocol but internal factors such as sleep and nutrition could not be monitored. 


\section{CONCLUSIONS}

The data collected from this study support the conclusion that the UNC Functional Performance Test is a reliable objective measure as a lower extremity functional test when used as described. It is important to note that excellent reliability has been established for the individual components but has not been established collectively. The highest ICC was found with the SL triple hop and the lowest was the SL hop for time. Low methodological error has been reported in addition to minimal variation within subjects on a day to day basis when the test is repeated. 


\section{REFERENCES}

1. Hootman JM, Macera CA, Ainsworth BE, Martin M, Addy CL, Blair SN. Predictors of lower extremity injury among recreationally active adults. Clin J Sports Med. 2002;12:99-106.

2. Dick R, Ferrara MS, Agel J, Courson R, Marshall SW, Hanley MJ, Reifsteck F. Descriptive epidemiology of collegiate men's football injuries: National Collegiate Athletic Association Injury Surveillance System, 1988-1989 through 2003-2004. J Athl Train. 2007;42(2):221-33.

3. Tabor MA, Davies GJ, Kernozek TW, Negrete RJ, Hudson V, A multicenter study of the testretest reliability of the lower extremity functional test. J Sport Rehabil. 2002;11(3):190-201.

4. Drouin JM, Riemann BL. Lower extremity functional performance testing, part 1. Athl Ther Today. 2004;9(2).

5. Noyes FR, Barber SD, Mangine RE. Abnormal lower limb symmetry determined by function hop tests after anterior cruciate ligament rupture. Am J Sports Med. 1991;19;513-518.

6. Drouin JM, Riemann BL. Lower extremity functional performance testing, part 2. Athl Ther Today. 2004;9(3).

7. Drouin JM, Riemann BL. Lower extremity functional performance testing, part 3. Athl Ther Today. 2004;9(4).

8. Worrell T, Booher LD, Hench KM. Closed kinetic chain assessment following inversion ankle sprain. J Sport Rehabil. 1994;3:197-220.

9. Gustavsson A, Neeter C, Thomee P, et al. A test battery for evaluating hop performance in patients with an ACL injury and patients who have undergone ACL reconstruction. Knee Surg Sports Traumatol Arthrosc. 2006;14:778-788.

10. Lephart SM, Perrin DH, Fu F. Functional performance tests for the anterior cruciate ligament insufficient athlete. Athletic Train. 1991;26:44-50.

11. Hamilton RT, Shultz SJ, Schmitz RJ, Perrin DH. Triple-hop distance as a valid predictor of lower limb strength and power. J Athl Train. 2008;43(2):144-51.

12. McGee MR, Futtrell MD. Functional testing of athletes and non-athletes using the carolina functional performance index. Unpublished master's thesis. University of North Carolina Chapel Hill.

13. Drouin JM. How should we determine a measurement is appropriate for clinical practice? Athl Ther Today. 2003;8(4):56-58.

14. Portney LG, Watkins MP. Foundations of Clinical Research: Applications to Practice. East Norwalk, Conn: Appleton \& Lange; 1992. 
15. Anastasi A. Psychological Testing. $6^{\text {th }}$ ed. New York, NY: Macmillan; 1998.

16. Shrout PE, Fleiss JL. Intraclass correlations: uses in assessing rater reliability. Psychol Bull. 1979;86:420-428.

17. Brown, JD. Standard error vs standard error of measurement. JALT Testing \& Evaluation SIG Newsletter. 1999;3(1):20-25.

18. Dahlberg G. Statistical Methods for Medical and Biological Students. New York, Interscience Publications; 1940.

19. Loudon JK, Wiesner D, Goist-Foley HL, Asjes C, Loudon KL. Intrarater reliability of functional performance tests for subjects with patellofemoral pain syndrome. J Athl Train. 2002;37(3) 256261.

20. Silbernagel KG, Gustavsson A, Thomee R, Karlsson J. Evaluation of lower leg function in patients with Achilles tendinopathy. Knee Surg Sports Traumatol Arthrosc. 2006;14:1207-1217.

21. Booher LD, Hench KM, Worrell TW, Stikeleather J. Reliability of three single-leg hop tests. $J$ Sport Rehabil. 1993;2:165-170.

22. Shimokochi Y, Yong LS, Shultz SJ, Schmitz RJ. The relationships among sagittal-plane lower extremity moments: implications for landing strategy in anterior cruciate ligament injury prevention. J Athl Train. 2009;44(1):33-8.

23. Broglio SP, Ferrara MS, Macciocchi SN, Baumgartner TA, Elliot R. Test re-test reliability of computerized concussion assessment programs. J Athl Train. 2007;42(4)509-514.

24. Randolph C, McCrea M, Barr WB. Is neuropsychological testing useful in the management of sport-related concussion? J Athl Train. 2005;40:139-154.

25. Fuller CW, Walker J. Quantifying the functional rehabilitation of injured football players. $\mathrm{Br} J$ Sports Med. 2006;40(2):151-7.

26. Lysholm J, Gillquist J. Evaluation of knee ligament surgery results with special emphasis on use of a scoring scale. Am J Sports Med. 1982;10(3):150-4.

27. Munn J, Beard DJ, Refshauge KM, Lee RWY. Do functional-performance tests detect impairment in subjects with ankle instability? J Sport Rehabil. 2002;11:40-50. 
APPENDICES 


\section{APPENDIX A}

\section{THE PROBLEM}

\section{Research Question}

When using functional testing, most literature suggests that normative values be used for comparisons to indicate progression to full functional activity. Factors such as gender, anthropometric characteristics, physical activity level and sport are all considered. ${ }^{4}$ Furthermore, a performance score that is equal to or greater than $85 \%$ of the normative score is considered to be acceptable for return to play. ${ }^{7}$ However, although these criteria are specific, they do not apply to one single battery of functional tests nor does it consider the physical demands of each sport.

Regardless of sport, over fifty percent of all injuries with time lost involved the lower extremity. ${ }^{1}$ Completed in 2007, an epidemiology report covering sixteen years of participation of fifteen collegiate sports reported that football had the highest rate of injury in both practices and games with the majority of most incidences being ankle ligament sprains or anterior cruciate ligament injuries. ${ }^{1}$ Football is a complex contact sport that requires a wide variety of skills performed by athletes with various body types. Due to the variability in tasks, certain position groups are more susceptible to injury. Offensive players tend to sustain most of the injuries. Running backs sustain $20 \%$ of all injuries, while quarterbacks are at nearly $18 \%{ }^{2}$ It has also been reported that injuries are nine times more likely to be encountered in a game situation than during practice. ${ }^{2}$ The variability of body types, differences in required skills and the high occurrence of lower extremity injury in football justifies the need for indepth research to develop a reliable return to play protocol.

The primary goal of any athletic trainer is to return an athlete to a pre-functional activity level following an injury. However, the decision for return to play is often based on subjective measurements with clinician variability and can result in the premature assessment for participation. To avoid this, the 
decision should be based on functional testing as well as other variables. Functional testing, also referred to as performance testing, is designed to objectively measure all integral components of physical activity including proprioceptive function, muscle strength and power output, flexibility, pain and confidence. ${ }^{4}$, ${ }^{28}$ Other variables that should be considered are range of motion, muscle strength and endurance, neuromuscular control, anthropometric measurements, pain and swelling. ${ }^{3}$ In a controlled manner, functional testing simulates stresses that are placed on the body during participation that other tests are lacking and therefore should be used by clinicians prior to making any return to play decisions.

Clinically, there is no gold standard for functional testing which makes the decision for participation subjective regardless of the effort to obtain objective measurements. As an undergraduate athletic training student, introduction to an implemented baseline functional test very similar to preincident concussion testing with a D-1 football program, has inspired further investigation. Unfortunately, there are no reported studies in the literature to validate the theory of baseline functional testing nor all of the components of this particular battery of tests. The components of functional performance testing of interest include: shuffle box drill, figure-8, carioca, ${ }^{10}$ single-leg hop test, ${ }^{5-9}$ and a single-leg triple hop measured for distance. ${ }^{6,11}$

As an ATC, knowledge of several functional performance techniques are used with no consistency from institution to institution for objective measurement. Previous researched individual and combined components include a co-contraction semicircular test, ${ }^{10}$ carioca test, ${ }^{10}$ shuttle run test, ${ }^{10}$ anterior-lunge test, ${ }^{29}$ balance leg reach test, ${ }^{29}$ hip adduction excursion test, ${ }^{29}$ and the Lower Extremity Functional Test (LEFT). ${ }^{3}$ The literature also indicates that various unique functional programs exists, mainly designed for specific pathologies. ${ }^{19,20}$ It is unknown if these functional programs are widely accepted and practiced even after reliability has been established. Furthermore, neither functional test nor a battery of tests has been designed specifically for a particular sport. The premise behind functional 
testing is for the physical stresses of the sport to be imposed on the body to verify that the athlete is ready to counter similar forces to protect against further injury.

Appropriate return to play decisions are imperative yet remain to be the most difficult aspect of athletic training. However, recognizing deficits in an athlete’s normal physical capabilities is the first step in making the most accurate assessment. If deficits go unnoticed and ultimately untreated, the initial injury will only be exacerbated over time or result in another injury due to compensation. An objective and reliable form of measurement needs to be implemented that has the ability to assess the individual capabilities of football athletes at baseline in order to make more accurate return to play decisions. The UNC Functional Performance Test has been developed with the intent to be used as an objective return to play tool. It is unknown whether this tool has been used at other institutions. Consequently, test re-test reliability for the UNC Functional Performance Test should be established for the battery first and then followed up at multiple test sites. Therefore, the research questions that this study poses include:

1. Are there functional tests reliable and specific to the sport of football?

2. Will the shuffle box drill, figure-8, carioca, SL hop test, and a SL triple hop tests incorporated in this study as a lower extremity functional tool maintain reliability and achieve acceptable ICC scores?

\section{Experimental Hypotheses}

1. The battery of tests used to create a sport specific lower extremity assessment tool will be reliable.

2. The lower extremity functional battery will have high ICC scores for individual components. 


\section{Assumptions}

1. The functional tests that will be administered are reliable and valid.

2. The documentation of results for each individual athlete will be accurate.

3. All participants will satisfy the inclusion criteria.

4. The football athletes participating in the study will be representative of positions specific to football.

5. The participants in the study will complete each week of the research protocol with maximal effort.

6. The tests will be administered identically across each week of functional testing by the same person at the research institution.

7. The same standardized protocol for the UNC Functional Performance Test will be used during all three trial weeks.

Delimitations

1. This study drew from a population of Division II football players and cannot be generalized to the population as a whole.

2. The age demographic of $18-23$ was used to complete this study.

3. Internal factors cannot be consistently controlled for. Health, nutrition, and fatigue varied from subject to subject.

Operational Definitions

1. Agility-Term used to describe movement patterns and quickness.

2. Anthropometric Measurements-Measurements of the body. This can include girth measurements of limbs, oseteometry (bony structures), skin folds, height and weight. ${ }^{30}$

3. Carioca Test-Functional test that requires coordination. Completed by balancing weight on one leg while crossing the opposite over the weight bearing leg. Arms are often used to maintain balance. 
4. Certified Athletic Trainer (ATC)-An allied health professional that works predominantly with athletes. Performs emergency injury management, injury assessment, injury prevention and rehabilitation. An ATC graduated from an accredited athletic training program and passed the BOC certification exam.

5. Cornerback-Player that is part of the secondary defense. Typically possess speed and height and is required to complete a lot of backward movement.

6. Defensive End-Fastest and smallest members of the defensive line. Their role is to rush the quarterback on passing plays and contain the running back on running plays.

7. Defensive Tackle-Largest and strongest members of the defensive line who lines up on the interior.

8. Figure 8-Component of functional testing. A sprint test that requires sharp turning curves to allow for sudden changes of direction.

9. Flexibility-The absolute range of motion that can be obtained by a joint. Flexibility can be increased by the use of static and dynamic stretching.

10. Football-Contact sport played typically by males in which most injuries in the collegiate setting are sustained. ${ }^{2}$

11. Forty-yard Dash-Sprint that covers 40 yards. This is used to assess speed which is found to be particularly useful for skilled positions.

12. Functional Tests-Tests that are implemented in a controlled environment that allows similar stresses to be placed on the body that are produced during physical activity. ${ }^{4}$

13. Intra-class Correlation Coefficient (ICC)-Statistical measure that identifies conformity across multiple groups. ${ }^{16}$

14. Kicker-Member of a football team that is responsible for place kicking the ball during extra point attempts and kick-offs.

15. Linebacker-Defensive player that is considered to be the second line of defense.

16. Lower Extremity-Appendages that encompass the bony, muscular and tendinous structures that comprise the hip, knee, ankle and foot joints.

17. Lower Extremity Functional Test (LEFT)-Designed by George Davies in 1988 which encompasses a simultaneous evaluation of the lower extremity while completing comprehensive and multidirectional tests. ${ }^{3}$

18. Lower Quarter-Synonymous for lower extremity. 
19. National Collegiate Athletic Association (NCAA)-Governing administrative body that determines eligibility criteria of participants and enforces rules of play for all collegiate sports for member institutions only.

20. Objective Measurement-A true measurement that is collected by observation and not selfreported by the participant.

21. Offensive Linemen-Players who are typically larger in height and weight that have the responsibility of blocking in order for a pass to be completed or a run to be made. Movements are typically lateral in nature.

22. Proprioception-The body’s ability to determine a specific joints' position in space. ${ }^{28,30}$

23. Punter-Player that is responsible for punting the ball on the $4^{\text {th }}$ down as far away from the line of scrimmage as possible.

24. Quarterback-Player who makes contact with the ball every single offensive play and also has the ability to hand the ball off or run with it. Eighteen percent of all injuries in football are sustained by the quarterback. ${ }^{2}$

25. Range of Motion-Maximum amount of motion a joint can endure prior to failure. This is measured in degrees by using a goniometer. Range of motion can be limited due to pain associated with injury, bony blocks or soft tissue obstruction.

26. Reliability-Repeatability. Also describes consistency of a measurement. ${ }^{16}$

27. Running Back-A fullback or halfback that runs with the ball once the quarterback hands it off. This position group encounters the most injuries in the sport of football sustaining nearly $20 \% .^{2}$

28. Safety-Defensive player who is considered one of the hardest hitters.

29. Shuffle Box Drill-Functional test that has the athlete sprint straight ahead, side shuffle, backpedal and then side shuffle in the opposite direction to complete a box.

30. Single-leg Hop Test-Lower extremity functional test that allows for unilateral evaluation of each leg by assessing power output and proprioception. ${ }^{4-9}$

31. Single-leg Triple Jump-Functional test that is completed in a similar manner as the single-leg hop except for jumping three consecutive times. The goal is to jump for distance. ${ }^{6,11}$

32. Test-Retest Design-Reliability test that is a statistical measure. Completed by administering the same test twice, with a select amount of time between testing bouts, and then correlating the two score sets. ${ }^{16}$

33. Tight End-Member of the offensive line that has the ability to both receive the ball and block. 
34. Wide Receiver-Offensive player whose primary role is to catch throws completed by the quarterback.

Limitations

1. This study will only use one D-II football program to observe and collect data.

2. Generalizations of findings to other settings- An external validity threat will exist due to the findings from the participants will not be generalized towards a specific population.

3. Selection of participants- An external validity threat will be present based on the choice of participants as an experimentally accessible group through the institution.

4. The participants may not provide $100 \%$ effort at each testing week.

5. The functional tests implemented may not be valid measurements as a whole. Specific components have been validated but no gold standard exists for comparison for the test in its entirety.

6. Subjects may drop out of the study by injury or being cut from the team.

7. The functional tests implemented may not be specific to the demands of the sport of football.

\section{Significance of Study}

Highly prone to injury due to the contact nature of the sport, football players have many physical demands placed on them that enable them to generate force, reach great speeds and to ultimately protect themselves. Therefore, strength, range of motion, and anthropometric measurements should not be used as the only determining factors in making return to play decisions. To date, there is no standard of an objective form of measurement to determine when an athlete can safely return without causing further damage.

Functional tests are used to assess if an athlete can perform a sport specific task but this simply is not sufficient. A reliable standard needs to be implemented that will allow for the most accurate assessment of the entire lower quarter regardless of injury throughout all phases of the injury cycle. The primary goal of this study is to assess the reliability of the UNC Functional Performance Test between 
sessions. Accomplishing this will not only benefit athletic trainers from a clinical stand point but will also provide objective information as to when an athlete can safely return to participation. In ensuring proper preparation prior to return to play, exacerbation of the injury can be avoided by ultimately improving personal confidence of the athlete. For these reasons, determining the reliability of the UNC Functional Performance Test will be advantageous to a football program in its entirety. This information can easily be disseminated through future publications, presentations or workshops which will allow certified athletic trainers to perform best clinical practice on a day to day basis while using evidence based guidelines. 


\section{APPENDIX B}

\section{LITERATURE REVIEW}

Introduction

The lower quarter as it relates to this study can be defined as the joints, muscles, and ligaments that comprise the hip, tibiofemoral, patellofemoral, talocrural, subtalar, and metatarsphalangeal joints. Football places several activity demands on the lower quarter including side shuffling or lateral movements, backpedaling, forward sprinting, cutting, jumping, and kicking. These activities incorporate individual motions at each of these joints, therefore, most of the injuries that occur in the sport of football are sustained by the lower quarter and more specifically, the knee and the ankle. ${ }^{1}$ The majority of these injuries are ligamentous in nature with anterior cruciate ligament tears being the most common. When injury occurs to the lower quarter, clinicians use functional testing as a measure to determine when it is safe to return to play. Functional performance testing is measured through a one-time maximal effort performance by the athlete not only to assess sport-specific rehabilitative progress and functionality, but also to assess psychological function. ${ }^{31}$ Numerous studies have been conducted that look at reliability of lower extremity functional testing collectively and as individual components. Single tasks of single leg hops have been found reliable with ICC scores ranging from .66 to .99. Results from studies have revealed that the LEFT (Lower Extremity Functional Test) is a battery of tests that is reliable while other components of widely practiced functional tests have achieved similar results. ${ }^{3}$ These individual components include a co-contraction semicircular test, carioca test, shuttle run test, anterior-lunge test, balance leg reach test, and the hip adduction excursion test. ${ }^{3}$ Due to the variability in position in football, the approach to evaluation of functionality post-injury must be comprehensive in nature. With the advent of a comprehensive lower quarter functional testing tool, accurate return to play decisions can be made while preventing the occurrence of further injury. 
Therefore, in this literature review, anatomy and biomechanics of the joints involved in the lower quarter as it pertains to the sport of football will be discussed. Furthermore, epidemiology, etiology, and significance of functional performance testing will be discussed as well as the individual components of performance testing specific to this study including the shuffle box drill, figure-8, carioca, single-leg hop test, and a single leg triple hop. Return to play criteria will also be discussed in addition to test-retest designs and the ICC (Intra-class Correlation Coefficient).

\section{Anatomy}

Hip joint: The acetabulum of the pelvis and the head of the femur articulate to create the hip joint which is characterized as being a ball and socket joint due to the congruency these bones provide. ${ }^{32}$ More specifically, the pelvis refers to the articulation between the sacrum and the coccyx. Collectively, the sacrum is the union or fusion of five originally individual sacral vertebrae while the coccyx is composed of four coxxygeal vertebrae. ${ }^{33}$ Both the sacrum and the coccyx are considered to be innominate bones meaning they have three components; the ilium, ishium and the pubis. The location of the fusion of these components is referred to as the acetabulum. The acetabulum is a concave socket and faces forward with a downward and lateral angle. The rounded portion of the head of the femur fits into the concavity of the acetabulum by facing medially, upward and forward. ${ }^{30}$ This articulation is supported by fatty tissue, ligaments and a joint capsule. ${ }^{30}$ Shape alone does not allow for the congruency of the hip. Nearly ten percent of the acetabular articular area is provided by the acetabular labrum, a fibrocartilagnous material. ${ }^{34}$ Collectively, the functions of the pelvis are to support the spine and trunk while also transferring weight to the lower extremities. ${ }^{30}$

Lined with a synovial memebrane, the joint capsule obtains support from numerous ligaments. Protecting from anterior translation of the femur, the iliofemoral and pubofemoral ligaments work 
together. The ishiofemoral ligament is responsible for controlling posterior translation. ${ }^{33}$ As the strongest ligament of the entire body, the iliofemoral ligament prevents hyperextension, controls external rotation and adduction of the thigh, and restricts rotation of the pelvis during backward rolling of the femoral head while weight bearing. ${ }^{30,35}$ The pubofemoral ligament blends in with the medial portion of the iliofemoral ligament and limits excessive hip extension and abduction. ${ }^{33}$ The ishiofemoral works in the opposite direction by preventing excessive internal rotation and adduction of the thigh. ${ }^{30.32}$ Although the ligamentum teres provides little support from excessive translation, it serves a great purpose by transporting nutrient vessels to the head of the femur. ${ }^{30}$

Many muscles act on the hip and femur from a variety of directions to generate multiple movements. Located on the anterior side are the iliacus and the psoas major. The tensor fasciae lata, gluteus maximus, medius and minimus make up the lateral and posterior muscle of the hip. ${ }^{30,36}$ Six mucles comprise the lateral or external rotators. They are the gemellus superior and inferior, obturator externus and internus, piriformis and the quadratus femoris. ${ }^{32,36}$ On the medial side, the adductor muscle group includes the adductor longus and brevis, adductor magnus, gracilis and the pectineus. ${ }^{32,36}$ Table B1 describes the origin, insertion, nerve and action of all muscles that act on the hip and femur.

Table B1. Muscles Acting on the Hip and Femur ${ }^{30,32,33,36}$

\begin{tabular}{lllll}
\hline Muscle & Origin & Insertion & Nerve & Action \\
\hline Iliacus & Iliac Fossa & $\begin{array}{l}\text { Lesser trochanter of } \\
\text { femur }\end{array}$ & Femoral & $\begin{array}{l}\text { Internally (medially) } \\
\text { rotate femur; flex hip }\end{array}$ \\
Psoas Major & T12-L5 vertebral bodies & $\begin{array}{l}\text { Lesser trochanter of } \\
\text { femur }\end{array}$ & Lumbar plexus & $\begin{array}{l}\text { Internally (medially) } \\
\text { rotate femur; flex hip }\end{array}$ \\
Tensor Fascia Lata & Iliac crest & Lateral tibial condyle & Superior gluteal & $\begin{array}{l}\text { Internally (medially) } \\
\text { rotate femur; abduct; } \\
\text { flex hip }\end{array}$ \\
& Ilium and sacrum & $\begin{array}{l}\text { Gluteal tuberosity of } \\
\text { femur, fascia lata }\end{array}$ & Inferior gluteal & $\begin{array}{l}\text { Abduct; externally } \\
\text { (laterally) rotate femur; } \\
\text { extend hip }\end{array}$ \\
Glueteus Medius/ Minimus & Ilium & $\begin{array}{l}\text { Femoral greater } \\
\text { trochanter }\end{array}$ & Superior gluteal \\
abduct
\end{tabular}




\begin{tabular}{|c|c|c|c|c|}
\hline Gemellus Superior/Inferior & Body of ischium & $\begin{array}{l}\text { Obturator internus } \\
\text { tendon }\end{array}$ & Sacral plexus & Externally (laterally) rotate \\
\hline Obturator Externus & $\begin{array}{l}\text { Anterior margin of } \\
\text { obturator foramen }\end{array}$ & $\begin{array}{l}\text { Femoral greater } \\
\text { trochanter }\end{array}$ & Obturator & Externally (laterally) rotate \\
\hline Obturator Internus & $\begin{array}{l}\text { Posterior margin of } \\
\text { obturator foramen }\end{array}$ & $\begin{array}{l}\text { Femoral greater } \\
\text { trochanter }\end{array}$ & Sacral plexus & $\begin{array}{l}\text { Externally (laterally) rotate } \\
\text { abduct }\end{array}$ \\
\hline Piriformis & $\begin{array}{l}\text { Anterior lateral portion } \\
\text { of sacroiliac region }\end{array}$ & $\begin{array}{l}\text { Femoral greater } \\
\text { trochanter }\end{array}$ & $\begin{array}{l}\text { S1-S2 Ventral } \\
\text { rami }\end{array}$ & $\begin{array}{l}\text { Externally (laterally) rotate } \\
\text { abduct }\end{array}$ \\
\hline Quadratus Femoris & Ischial tuberosity & $\begin{array}{l}\text { Femoral inter- } \\
\text { trochanteric ridge }\end{array}$ & Sacral plexus & $\begin{array}{l}\text { Externally (laterally) rotate } \\
\text { adduct }\end{array}$ \\
\hline Adductor Longus/Brevis & Pubis & $\begin{array}{l}\text { Posterior shaft of } \\
\text { femur }\end{array}$ & Obturator & $\begin{array}{l}\text { Externally (laterally) rotate } \\
\text { adduct, flex hip }\end{array}$ \\
\hline Adductor Magnus & Ischium & $\begin{array}{l}\text { Posterior shaft of } \\
\text { femur }\end{array}$ & Obturator; tibial & $\begin{array}{l}\text { Anterior: externally } \\
\text { (laterally) rotate femur; } \\
\text { adduct, flex hip } \\
\text { Posterior: extend hip }\end{array}$ \\
\hline Gracilis & Pubis & $\begin{array}{l}\text { Medial aspect of } \\
\text { proximal tibia }\end{array}$ & Obturator & $\begin{array}{l}\text { Internally (medially) } \\
\text { rotate tibia; adduct femur; } \\
\text { flex knee }\end{array}$ \\
\hline Pectineus & Pubis & $\begin{array}{l}\text { Posterior aspect of } \\
\text { proximal femur }\end{array}$ & Femoral & $\begin{array}{l}\text { Externally (laterally) rotate } \\
\text { adduct; flex hip }\end{array}$ \\
\hline
\end{tabular}

Peripheral nerves innervating the muscles of the hip and femur originate at a variety of location. The ventral rami of nerves L1-L4 and some fibers from T2 intersect to form the lumbar plexus. ${ }^{32,{ }^{33}}$ Five nerve roots divide into anterior and posterior divisions. These original five nerves of the lumbar plexus are the iliohypogastric, ilioinguinal, genitofemoral, lateral femoral cutaneus, femoral saphenous and obturator nerve. ${ }^{32}$ The sacral plexus is the result of the junction between the ventral rami of nerves L4, L5, and S1 to S4. Anterior and posterior divisions occur here as well from six original nerve roots. ${ }^{32,33}$ The sacral plexus is comprised of the superior and inferior gluteal nerves, perforating cutaneous nerve, posterior cutaneous nerve, tibial nerve, common peroneal nerve, sciatic nerve, pudendal nerve and the coccygeal nerve. ${ }^{32}$ Refer to Table B1 for specific muscles and nerve innervations. 
The arterial supply to the pelvis region and lower limb originates at the right and left common iliac arteries. ${ }^{32,33}$ These two arteries then feed into internal and external iliac arteries. The internal iliac artery has seven branches. The most important of these branches for the gluteal muscles are the superior and inferior gluteal arteries. The obturator artery supplies the adductor muscles of the medial thigh. ${ }^{32}$ Furthermore, the external iliac artery divides into four branches. One of these is the femoral artery, which is further divided into the deep and circumflex femoral arteries. These supply the hamstring muscles and femur, respectively. ${ }^{32,33}$ The remaining branches of the external iliac artery supply distal structures of the lower extremity.

The venous drainage of the lower limb and pelvic regions is a result of both deep and superficial veins. The drainage begins at the most distal portion of the lower extremity, the toes, and proceeds proximally, following the path of blood to the inferior vena cava. ${ }^{32}$ There are nine deep and three superficial veins in the lower extremity. ${ }^{33}$ The femoral vein, and internal and external iliac veins are of particular importance. As a continuation of the popliteal vein, the femoral vein receives drainage from the deep thigh muscles and from the femur. ${ }^{32}$ Furthermore, the femoral and great saphenous veins merge into the external iliac vein. Following the internal iliac artery and distribution, the internal iliac vein follows the same course and drains the gluteal muscles and the medial muscles of the thigh along with other structures. ${ }^{32}$

Tibiofemoral joint: The knee joint complex also referred to as the tibiofemoral joint forms the middle link in the kinetic chain for the lower extremity. This incorporates the articulation of the tibia and femur which is considered to be very incongruent. ${ }^{33}$ For this reason, the knee in the extended position is said to be the most stable because this is where the articular surfaces are most congruent and the ligaments are taut. ${ }^{37}$ However, the muscles and ligaments provide the knee with static and dynamic stability. Arguably the most important component is the knee extensor mechanism that consists of the 
quadriceps group, the patellofemoral joint, and the tendon group connecting these elements. ${ }^{33}$

Additionally, the knee is surrounded by a joint capsule that contains a synovial membrane. Menisci or fibrocartilaginous discs are found between both sets of femoral and tibial condyles. They serve two main purposes by assisting in shock absorption and deepening the joint surface for a more stable articulation. $^{33}$

Furthermore, both internal and external ligaments provide the knee with stability. The external ligaments are the patellar ligament, fibular collateral ligament, tibial collateral ligament, oblique popliteal ligament and the arcuate popliteal ligament. ${ }^{33}$ The patellar ligament is the distal portion of the quadriceps tendon on the anterior segment of the knee. It is significant in maintaining accurate patellar alignment. ${ }^{37}$ Also known as the lateral collateral ligament, the fibular collateral ligament connects the fibular head to the lateral epicondyle of the femur. The tibial collateral ligament, also known as the medial collateral ligament, is much weaker and is injured more often. ${ }^{33}$ There is a direct attachment by the medial collateral ligament to the medial meniscus. On the posterior aspect is the oblique popliteal ligament which originates off the posterior portion of the medial tibial condyle where there is a connection with the joint capsule. ${ }^{33}$ Also contributing to the posterior stability of the knee is the arcuate popliteal ligament. After coming off the fibular head, the structure spreads over the posterior aspect of the knee. ${ }^{33}$ The cruciate ligaments are the intra-articular ligaments of the knee. The anterior cruciate ligament, or ACL, is relatively weak and has a very poor blood supply. In originating from the anterior intercondylar area of the tibia and attaching to the posterior portion of the lateral femoral condyle, the function is to limit posterior translation of the femur on the tibia. The posterior collateral ligament, or PCL, prevents anterior movement of the femur on the tibia. These two ligaments cross over one another within the joint capsule. ${ }^{33}$ In the knee, plica are embryological remnants that have remained in some individuals after birth. In most cases, the plica are reabsorbed by the time of birth. In some cases 
however, these plica can still be present in the knee and become thickened, which can be a source of knee pain. $^{38}$

Patellofemoral joint: The patellofemoral joint is the articulation between the patella and the femur. ${ }^{32,38,39}$ Although the patella is a sesamoid bone and is embedded within a tendon, the patella articulates with the patellofemoral grove on the femur. In an effort to maintain proper tracking and assist with stability, several forces act on the patella. ${ }^{32}$ Twenty-four bursae surround the knee and the patellofemoral joint and aid in decreasing friction between the moving surfaces. With both the knee and the patellofemoral joint, this friction is being generated by the tendons that run parallel to the bones and pull lengthwise across the joint during knee movements. ${ }^{33}$ Ligamentous stability in the patellofemoral joint is from the medial and lateral patellar ligaments, which run from the patella to the tibia and fibula. $^{33}$

The muscles that control motion at the knee can be separated into three groups including the anterior compartment of the thigh, posterior compartment of the thigh, and the posterior compartment of the leg. The anterior compartment of the thigh contains the quadriceps femoris muscle group and the sartorius. The posterior compartment of the thigh is comprised of the hamstring muscle group. The hamstrings are made up of the biceps femoris, semimembrinosus and semitendinosus. The posterior compartment of the leg consists of the popliteus muscle. Actions and innervations of the muscles acting on the knee as well as their origin and insertion are described in Table B2.

Table B2. Muscles Influencing the Knee. ${ }^{32,33}$

\begin{tabular}{lllll}
\hline Muscle & Origin & Insertion & Nerve & Action \\
\hline Rectus Femoris & $\begin{array}{l}\text { Anterior inferior } \\
\text { iliac spine }\end{array}$ & Tibial tuberostiy & Femoral & Extend knee; flex hip \\
Vastus Lateralis & $\begin{array}{l}\text { Posteriolateral shaft } \\
\text { of femur }\end{array}$ & Tibial tuberosity & Femoral & Extend knee \\
Vastus Medialis & $\begin{array}{l}\text { Linea aspera of } \\
\text { femur }\end{array}$ & Tibial tuberosity & Femoral & Extend knee \\
\hline
\end{tabular}




\begin{tabular}{|c|c|c|c|c|}
\hline Vastus Intermedius & $\begin{array}{l}\text { Anterior shaft of } \\
\text { femur }\end{array}$ & Tibial tuberosity & Femoral & Extend knee \\
\hline Sartorius & $\begin{array}{l}\text { Anterior superior } \\
\text { spine of ilium }\end{array}$ & $\begin{array}{l}\text { Medial portion of } \\
\text { tibial tuberosity }\end{array}$ & Femoral & $\begin{array}{l}\text { Flex hip; medially rotate } \\
\text { femur, laterally rotate } \\
\text { tibia }\end{array}$ \\
\hline Biceps Femoris & $\begin{array}{l}\text { Long head: ischial } \\
\text { tuberosity } \\
\text { Short head: posterior } \\
\text { midshaft of femur }\end{array}$ & Fibular head & $\begin{array}{l}\text { Long head: tibial } \\
\text { Short head: } \\
\text { common peroneal }\end{array}$ & $\begin{array}{l}\text { Flex knee, extend hip, } \\
\text { externally rotate leg }\end{array}$ \\
\hline Semimbranosus & Ischial tuberosity & $\begin{array}{l}\text { Medial condyle of } \\
\text { tibia; collateral } \\
\text { ligament }\end{array}$ & Tibial & $\begin{array}{l}\text { Flex knee; extend hip, } \\
\text { internally rotate tibia }\end{array}$ \\
\hline Semitendinosus & Ischial tuberosity & Tibial tuberosity & Tibial & $\begin{array}{l}\text { Flex knee, extend hip, } \\
\text { internally rotate tibia }\end{array}$ \\
\hline Popliteus & $\begin{array}{l}\text { Lateral femoral } \\
\text { condyle }\end{array}$ & $\begin{array}{l}\text { Posterior proximal } \\
\text { tibia }\end{array}$ & Tibial & $\begin{array}{l}\text { Flex knee, internally } \\
\text { rotate tibia, unlock knee } \\
\text { to allow for flexion }\end{array}$ \\
\hline
\end{tabular}

The quadriceps femoris group consists of four muscles that merge into a single quadriceps, or patellar, tendon. The tendon becomes the patellar ligament distally and then continues over the patella and inserts on the tibial tuberosity. ${ }^{32}$ As a fibrous sheath, fascia encircles the thigh and is responsible for tightly binding the muscles. The fascia combines with the gluteus maximus and the tensor fascia lata to form the iliotibial band on the lateral aspect of the thigh, ${ }^{32}$ Starting at the iliac crest and extending down to the lateral condyle of the tibia, the iliotibial band distally continues and inserts on the lateral border of the patella, the lateral retinaculum, and Gerdy’s tubercle of the tibia. ${ }^{32}$ The pes anserine is the common aponeurosis of the semitendinosus, sartorius, and gracilis muscles and is located medial and slightly distal to the tibial tuberosity. ${ }^{40}$

The roots of the lumbar and sacral plexus are the nerve supply to the muscles acting on the knee. The femoral nerve originates from posterior divisions of nerve roots L2, L3, and L4. ${ }^{32}$ The tibial nerve is an anterior division of L4, L5, S1-S3. ${ }^{32}$ The common peroneal nerve comes from posterior divisions of L4, L5, S1, and S2. The common peroneal nerve and the tibial nerve merge proximally to form the sciatic nerve. ${ }^{32}$ Refer to Table B2 for specific muscle neural innervations. 
The external iliac artery and corresponding branches are the primary arterial supply to the muscles influencing the knee. The deep femoral artery supplies the hamstring muscles, while the circumflex femoral artery supplies both the femur itself and the hamstring muscles. The femoral artery provides the quadriceps femoris muscle group and the sartorius. ${ }^{32,33}$ The popliteal artery supplies the popliteus muscle on the posterior aspect. ${ }^{32}$

Similar to the arterial supply, the venous drainage of the muscles acting on the knee and thigh comes from a combination of deep and superficial veins. Drainage initiates at the toes and continues proximally following the flow of blood towards the inferior vena cava. The popliteal vein, femoral vein, and the great and small saphenous veins are the most significant of the nine deep and three superficial veins in the lower extremity. ${ }^{32,33}$

Talocrural joint: The talocrural joint of the ankle is referred to as the true ankle mortise. The articulations between the distal and medial aspects of the tibia and fibula and the superior dome of the talus comprise this joint. ${ }^{41}$ The ligaments of the ankle function to provide a stable base of support for the ankle especially during weight bearing moments. These ligaments can be classified into one of three groups including medial, lateral and syndesmotic. The attachment and function of the primary ankle ligaments are described in detail in Table B4. On the lateral aspect, there are three primary ankle ligaments which include the anterior talofibular ligament, calcaneofibular ligament, and the posterior talofibular ligament. ${ }^{41}$ The anterior talofibuluar resists inversion while the foot is plantarflexed. This is the weakest of all of the ligaments of the ankle and the most commonly injured. ${ }^{41}$ The calcaneofibular ligament crosses both the talocrural and subtalar joints and is most taut in dorsiflexion. ${ }^{41}$ The posterior talofibular is the strongest ligament working to prevent inversion. Other lateral ligaments include the cervical and bifurcate of which attach to the anterior process of the calcaneus. ${ }^{41}$ The four ligaments on the medial aspect of the ankle are the deltoid ligaments. The medial, lateral and posterior talocalcaneal 
ligaments support the capsule while the interosseus ligament binds the bones together. ${ }^{33}$ The main function of the medial talonavicular ligament is to decrease eversion of the foot. ${ }^{42}$ The plantar aponeurosis is the most superficial fascia that acts as connecting tissue covering the plantar muscles. Originating from the posterior aspect of the calcaneus, the fascial structure branches out into five bands that split again to enclose the tendons of the phalanges. ${ }^{33}$

Table B3. Ankle Ligaments ${ }^{30,32,33}$

\begin{tabular}{|c|c|c|c|}
\hline Ligament & Proximal Attachment & Distal Attachment & Function \\
\hline Anterior Talofibular* & Lateral malleolus & Talar neck & $\begin{array}{l}\text { Primary restraint against } \\
\text { plantarflexion; internal } \\
\text { rotation of foot; inversion }\end{array}$ \\
\hline Calcaneofibular* & Tip of lateral malleolus & $\begin{array}{l}\text { Lateral surface of } \\
\text { calcaneus }\end{array}$ & Prevents inversion \\
\hline Posterior Talofibular* & Lateral malleolar fossa & Lateral tubercle of talus & Prevents inversion \\
\hline Lateral Talocalcaneal* & Posteriolateral talus & Posteriolateral calcaneus & $\begin{array}{l}\text { Prevents excessive inversion } \\
\text { and supination }\end{array}$ \\
\hline Cervical & Talar neck & $\begin{array}{l}\text { Calcaneal cervical } \\
\text { Tubercle }\end{array}$ & Aids in preventing inversion \\
\hline Anterior tibiotalar\# & Inferior medial malleolus & $\begin{array}{l}\text { Superior posterior } \\
\text { portion of navicular }\end{array}$ & Prevents eversion \\
\hline Tibionavicular\# & Inferior medial malleolus & $\begin{array}{l}\text { Sustenaculum tali of } \\
\text { calcaneus and navicular }\end{array}$ & Prevents eversion \\
\hline Tibiocalcaneal\# & Inferior medial malleolus & $\begin{array}{l}\text { Sustentaculum tali of } \\
\text { calcaneus }\end{array}$ & Prevents eversion \\
\hline Posterior Tibiotalar\# & Inferior medial malleolus & $\begin{array}{l}\text { Medial tubercle of talus, } \\
\text { sustentaculum tali of } \\
\text { calcaneus }\end{array}$ & Prevents inversion \\
\hline
\end{tabular}

* Lateral Ligament

\# Medial (Deltoid) Ligament

Motions generated in the sagital plane such as plantarflexion and dorsiflexion occur at this joint. 33, 43 Plantarflexion is produced by the muscles in the posterior compartment of the leg. ${ }^{30}$ Dorsiflexion is generated by the muscles of the anterior compartment of the leg. ${ }^{30}$ Muscles acting on the talocrural joint are found in detail in Table B4 including origin, insertion, nerve and action. 
Table B4. Muscles Acting on the Foot (Talocrural and Subtalar Joints). ${ }^{32,33,44}$

\begin{tabular}{|c|c|c|c|c|}
\hline Muscle & Origin & Insertion & Nerve & Action \\
\hline $\begin{array}{l}\text { Extensor Digitorum } \\
\text { Longus }\end{array}$ & $\begin{array}{l}\text { Lateral condyle of } \\
\text { tibia, shaft of fibula, } \\
\text { interosseus } \\
\text { membrane }\end{array}$ & $\begin{array}{l}\text { Middle, distal } \\
\text { phalanges II-V }\end{array}$ & Deep peroneal & $\begin{array}{l}\text { Extends toes II-V; } \\
\text { dorsiflexes, everts foot }\end{array}$ \\
\hline $\begin{array}{l}\text { Extensor Hallicus } \\
\text { Longus, }\end{array}$ & $\begin{array}{l}\text { Medial aspect of } \\
\text { fibula; interosseus } \\
\text { membrane }\end{array}$ & Distal phalynx I & Deep peroneal & $\begin{array}{l}\text { Extends hallux; } \\
\text { dorsiflexes, } \\
\text { everts foot }\end{array}$ \\
\hline Peroneus Tertius & Distal shaft of fibula & Metatarsal V & Deep peroneal & $\begin{array}{l}\text { Dorsiflexes, } \\
\text { everts foot }\end{array}$ \\
\hline Tibialis Anterior & $\begin{array}{l}\text { Lateral tibia, } \\
\text { interosseus } \\
\text { membrane }\end{array}$ & $\begin{array}{l}\text { Medial cuneiform } \\
\text { metatarsal I }\end{array}$ & Deep peroneal & Dorsiflexes, inverts foot \\
\hline Gastrocnemius & $\begin{array}{l}\text { Medial, lateral } \\
\text { femoral epicondyles }\end{array}$ & Calcaneus & Tibial & $\begin{array}{l}\text { Flex knee, plantarflex } \\
\text { foot }\end{array}$ \\
\hline Soleus & $\begin{array}{l}\text { Proximal one-third } \\
\text { of tibia and fibula }\end{array}$ & Calcaneus & Tibial & Plantarflex foot \\
\hline Plantaris & Distal femur & Calcaneus & Tibial & $\begin{array}{l}\text { Flex knee; plantarflex } \\
\text { foot }\end{array}$ \\
\hline $\begin{array}{l}\text { Flexor Digitorum } \\
\text { Longus }\end{array}$ & Midshaft of tibia & $\begin{array}{l}\text { Distal phalanges } \\
\text { II-V }\end{array}$ & Tibial & $\begin{array}{l}\text { Flex toes II-V; } \\
\text { plantarflex and invert } \\
\text { foot }\end{array}$ \\
\hline $\begin{array}{l}\text { Flexor Hallicus } \\
\text { Longus }\end{array}$ & Fibular shaft & Distal phalynx I & Tibial & $\begin{array}{l}\text { Flex hallux; plantarflex } \\
\text { and evert foot }\end{array}$ \\
\hline Tibialis Posterior & $\begin{array}{l}\text { Proximal half of } \\
\text { tibia, fibula, } \\
\text { interosseus } \\
\text { membrane }\end{array}$ & $\begin{array}{l}\text { Navicular } \\
\text { cuneiforms, } \\
\text { metatarsals II-V }\end{array}$ & Tibial & $\begin{array}{l}\text { Plantarflex and invert } \\
\text { foot }\end{array}$ \\
\hline Peroneus Brevis & Fibular shaft & Base of metatarsal V & Superficial peroneal & Plantarflex and evert \\
\hline Peroneus Longus & $\begin{array}{l}\text { Proximal half of } \\
\text { tibia, lateral condyle } \\
\text { of tibia }\end{array}$ & $\begin{array}{l}\text { Medial cuneiform, } \\
\text { metatarsal I }\end{array}$ & Superficial peroneal & $\begin{array}{l}\text { Plantarflex and evert } \\
\text { foot }\end{array}$ \\
\hline
\end{tabular}

The posterior compartment muscles of the leg are supplied by the tibial nerve. The tibial nerve is a posterior division of the sacral plexus. ${ }^{32}$ The posterior tibial and fibular arteries provide the blood supply. ${ }^{32,33}$ The venous drainage is supplied by the posterior tibial and fibular veins, as well as the small saphenous vein. ${ }^{32,33}$ Refer to Table B3 for specific muscle neural innervations. 
Subtalar joint: The articulations between the under surface of the talus and the superior surface of the calcaneus create the subtalar joint, a plane type synovial joint. ${ }^{32,33,45}$ Although the joint capsule itself is weak, it is supported by the medial, lateral, posterior and interosseus talocalcaneal ligaments.

The subtalar joint uses eversion and inversion motions at the foot to convert torque between the leg (internal and external rotation) and the foot (pronation and supination) ${ }^{33,45}$ There are multiple muscles in both the anterior, posterior and medial compartments that control these motions. These muscles along with their origin, insertion, action and nerve supply are described in detail in Table B4.

Several nerves innervate the muscles that influence motion at the subtalar joint. The superficial and deep peroneal nerve as well as the tibial nerve are three such nerves. ${ }^{32,33}$ Refer to Table B4 for specific muscles and neural innervation. The posterior tibial and fibular arteries supply the blood to the subtalar joint. ${ }^{32,33}$ Likewise, the venous drainage is similar to the arterial supply and is supplied by the posterior tibial and fibular veins. ${ }^{32,33}$

Metatarsophalengeal joint (MTP Joint): The MTP joint is the articulation between the five metatarsal bones and the bases of the proximal phalengeal bones ${ }^{33,40,43}$ Collateral ligaments protect this joint medially and laterally. ${ }^{33}$ These ligaments check and prevent excessive varus and valgus forces. Limiting excessive extension of the phalanges, the plantar ligament is on the plantar aspect of the joint.

The intrinsic muscles acting on the foot can be divided into two groups, a dorsal group and a ventral group. The dorsal group only has one layer, but the ventral muscle group has four layers. The intrinsic muscles of the foot, along with their origin, insertion, action and nerve supply is described in detail in Table B5. 
Table B5. Intrinsic Muscles of the Foot. ${ }^{32,33}$

\begin{tabular}{|c|c|c|c|c|}
\hline Muscle & Origin & Insertion & Nerve & Action \\
\hline $\begin{array}{l}\text { Extensor Digitorum } \\
\text { Brevis }\end{array}$ & $\begin{array}{l}\text { Dorsal aspect of } \\
\text { Calcaneus }\end{array}$ & $\begin{array}{l}\text { Tendons of extensor } \\
\text { digitorum longus }\end{array}$ & Deep peroneal & Extend toes \\
\hline $\begin{array}{l}\text { Flexor Digitorum } \\
\text { Brevis }\end{array}$ & $\begin{array}{l}\text { Calcaneus, plantar } \\
\text { aponeurosis }\end{array}$ & $\begin{array}{l}\text { Middle phalanges } \\
\text { II-V }\end{array}$ & Medial plantar & Flex toes II-V \\
\hline $\begin{array}{l}\text { Abductor Digiti } \\
\text { Minimi }\end{array}$ & $\begin{array}{l}\text { Calcaneus, plantar } \\
\text { aponeurosis }\end{array}$ & Proximal phalynx V & Lateral plantar & $\begin{array}{l}\text { Abduct; flex small toe; } \\
\text { support medial } \\
\text { longitudinal arch }\end{array}$ \\
\hline Abductor Hallicus & $\begin{array}{l}\text { Calcaneus, plantar } \\
\text { aponeurosis }\end{array}$ & Proximal phalynx I & Medial plantar & $\begin{array}{l}\text { Flex hallux; support } \\
\text { medial longitudinal arch }\end{array}$ \\
\hline Quadratus plantae & $\begin{array}{l}\text { Calcaneus, plantar } \\
\text { aponeurosis }\end{array}$ & $\begin{array}{l}\text { Tendons of flexor } \\
\text { digitorum }\end{array}$ & Lateral plantar & Flex toes \\
\hline Lumbricals & $\begin{array}{l}\text { Tendon of flexor } \\
\text { digitorum longus }\end{array}$ & $\begin{array}{l}\text { Extensor tendons } \\
\text { to digits II-V }\end{array}$ & Lateral, medial plant & $\begin{array}{l}\text { Flex meta-tarsophalangeal } \\
\text { joints; extend inter- } \\
\text { phalangeal joints }\end{array}$ \\
\hline Adductor Hallicus & Metatarsals II-IV & Proximal phalynx I & Medial plantar & Adduct hallux \\
\hline $\begin{array}{l}\text { Flexor Digiti } \\
\text { Minimi Brevis }\end{array}$ & $\begin{array}{l}\text { Cuboid; plantar } \\
\text { aponeurosis }\end{array}$ & Proximal phalynx I & Lateral plantar & Flex $\mathrm{V}$ toe \\
\hline $\begin{array}{l}\text { Flexor Hallicus } \\
\text { Brevis }\end{array}$ & $\begin{array}{l}\text { Cuboid, plantar } \\
\text { aponeurosis }\end{array}$ & Proximal phalynx I & Medial plantar & Flex hallux \\
\hline $\begin{array}{l}\text { Dorsal Interosseus } \\
\text { Muscle (four } \\
\text { muscles) }\end{array}$ & $\begin{array}{l}\text { Each has two heads } \\
\text { coming off of the } \\
\text { adjacent metatarsal }\end{array}$ & $\begin{array}{l}\text { Proximal phalanges } \\
\text { II-IV }\end{array}$ & Lateral plantar & Abduct toes II-IV \\
\hline $\begin{array}{l}\text { Plantar Interosseus } \\
\text { Muscle (three } \\
\text { muscles) }\end{array}$ & $\begin{array}{l}\text { Medial aspect of } \\
\text { metatarsals III-V }\end{array}$ & $\begin{array}{l}\text { Proximal phalanges } \\
\text { III-V }\end{array}$ & Lateral plantar & Adduct toes III-V \\
\hline
\end{tabular}

Three arches, the medial and lateral longitudinal arches and the transverse arch, are typically found in the foot. Of the three, the medial longitudinal arch is the largest. These arches are considered to be a fully integrated working unit. The arches interact to enhance the dynamic function of the foot. ${ }^{42}$ The longitudinal arches attach posteriorly to the calcaneus and the metatarsal heads anteriorly. The medial arch of the foot is higher and the lateral arch is lower. The talus rests at the top of the arch and is considered to be the "keystone" of the arch. ${ }^{33,46}$ The reference as "keystone" is made because all weight transferred from the body to the heel or the forefoot must pass through the talus. The transverse 
arch is different than the other two in that it runs perpendicular to the longitudinal arches. It is best visualized at the midfoot as the tarsometatarsal joints. The "keystone" of the transverse arch is the middle cuneiform bone. ${ }^{33,46}$

The arches serve two main functions. It is imperative that there is weight acceptance and response to changes in surfaces. Overall, the arches must work to dampen impact and rotation. ${ }^{46,47}$ The arches must allow distribution of weight through the foot and allow for the conversion of the flexible foot to a rigid lever to aid with stability. ${ }^{47}$ The integrity and strength of the arches is maintained by the shape of the interlocking bones, the actions of the involved muscles, the strength of the plantar ligaments, (especially the calcaneonavicular ligament and the long and short plantar ligaments) and the plantar aponeurosis. ${ }^{33}$ The plantar fascia provides support to the longitudinal arch of the foot and is divided into three slips. The central slip is the longest and the thickest. As the central slip continues down the length of the foot, the tendon divides into two slips on the medial and lateral sides. ${ }^{39}$

Branches of the lumbar plexus innervate the intrinsic muscles of the foot. The deep peroneal nerve branches from the common peroneal nerve, and the medial and lateral plantar nerves are a continuation of the tibial nerve. ${ }^{32}$ Refer to Table B5 for specific neural innervation. The arterial supply of these muscles is provided by the medial and lateral plantar arteries in addition to the digital arteries. The deep plantar arch and digital veins provide venous drainage for the intrinsic muscles of the foot. ${ }^{32}$ Biomechanics

Abnormalities and poor biomechanics have frequently been identified as factors influencing injury to the lower limb during physical activity. ${ }^{48}$ There are two areas of biomechanics including kinematics and kinetics. Kinematics describes motion without regard to the forces responsible for the motion being generated. ${ }^{46}$ Motion is referred to as the location, duration and magnitude of a force. Conversely, kinetics is the study of the forces that produce motion or maintain equilibrium. ${ }^{46}$ The lower 
body forms a kinetic chain that can be thought of as a continuum. It starts at the toes and continues proximally. This chain is a series of joints linked together. In being linked, motion generated at one joint will directly impact and cause motion at the adjacent joint. The role of the kinetic chain can cause compensatory properties or an injury to occur above or below the joint associated with a malalignment. $^{38,40}$

Movements that take place at the ankle and foot are transferred to the knee and then transferred again to the hip, pelvis and spine. However, abnormal forces cannot be distributed nor absorbed by the tissues resulting in injury. ${ }^{49}$ The role of the kinetic chain justifies explaining kinematics and kinetics of the lower quarter together as one cohesive unit.

Kinematics: Range of motion (ROM) is influenced by structural elements including bony and soft tissue blocks, as well as whether the motion is performed actively or passively. ${ }^{50}$ The motions of the hip, a ball and socket joint, are generated by the femoral head moving in the concavity of the acetabulum. This articulation allows for three degrees of freedom where flexion, extension, adduction, abduction, medial and lateral or external rotation occurs. ${ }^{48,50}$ The hip is capable of being flexed to 90 degrees with the knee extended, and to 120 degrees when the knee is flexed. Hip extension has a range of 10-30 degrees. The femur can be abducted 45-50 degrees, and adducted 20-30 degrees. With the hip

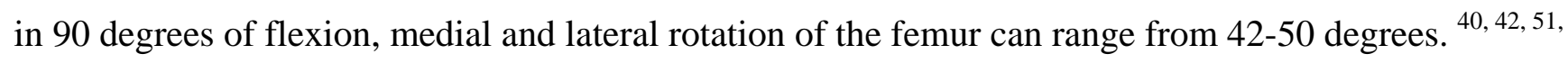
52

The tibiofemoral and patellofemoral joints are collectively referred to as the knee. The normative knee flexion values are between 130-140 degrees. The normal knee extension value should be close to 0 degrees. ${ }^{42}$ The patella itself has the ability to complete multiple motions as a sesamoid bone. The tightness of the quadriceps muscle dictates the exent in which the patella is capable of flexion, extension, medial tilt, lateral tilt and rotation. The patella also raises and lowers in the trochlear grove of 
the femur as the knee completes flexion and extension activities. Different parts of the patella make contact with the femur as the degree of knee flexion increases. As flexion increases, the contact area on the patella moves upward and outward until only the lateral facets of the patella are in contact with the femur. ${ }^{30,46,53}$ Furthermore, at 90 degrees of knee flexion, the largest contact area of the patella is across the medial and lateral facets. In full flexion (135-145), the far medial portion is in contact with the femur. ${ }^{46,53,54}$ Contrarily, in moments of extension, the inferior pole of the patella makes contact with the femur in addition to the suprapatellar fat pad. ${ }^{39}$

The subtalar joint has three articulations and this limits the mobility of the joint due to the bony congruencies. Motion of the talus on the calcaneus is a "twisting" motion that can occur as long as the articulating facets can simultaneously produce motions across the surfaces in opposite directions. ${ }^{44,46}$ This result is a triplanar motion of the talus resulting in pronation and supination. ${ }^{43,44,46}$

Talocrural joint motions occur in the sagital plane and are referred to as dorsiflexion and plantarflexion. ${ }^{43,48,55,56}$ Maximum dorsiflexion of the talocrural joint occurs during the stance phase of

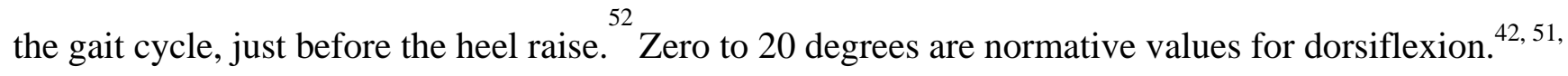
${ }^{52,57}$ Ten degrees of dorsiflexion is necessary for normal locomotion while more is required for running. ${ }^{40,52,58}$ Normal plantarflexion values are 0-45 degrees ${ }^{42,38}$ and in some studies ${ }^{51}$ as high as 60 degrees. There is no bony block in this direction which will allow for more motion in the plantarflexed position.

A closed kinetic chain is described as when the joint is maximally congruent, and when the ligaments and capsule are taut. ${ }^{39,46}$ An open kinetic chain is described as any position outside of the confines of maximal congruencey. ${ }^{39,46}$ Open kinetic chain or non weight bearing supination consists of plantarflexion, adduction, and inversion. ${ }^{51,52,59}$ Closed chain or weight bearing supination consists of inversion, dorsiflexion, and abduction. ${ }^{51,52,59}$ Alternatively, open kinetic chain pronation consists of 
dorsiflexoin, abduction, and eversion. ${ }^{51,52,59}$ Closed chain pronation is comprised of eversion, plantarflexion, and adduction. ${ }^{51,52,59}$ Subtalar joint pronation can be measured from 0-16 degrees, ${ }^{42,59 \text {, }}$ ${ }^{60,61}$ while subtalar joint supination can be measured from 0-32 degrees. ${ }^{42,59,60,61}$

The metatarsophalengeal joint provides a variety of motions including flexion, extension, adduction, and abduction. All of these motions are necessary, however, flexion and extension are more available than abduction and adduction. Seventy to ninety degrees of extension, and twenty to fourty degrees of flexion are available at the $1^{\text {st }}$ metatarsophalangeal joint. ${ }^{38,42,52}$ Flexion is the most essential motion at the MTP joint. ${ }^{42,43}$ In the weight bearing position, the MTP must be able to rotate over the toes through extension when rising up on the toes during walking or running. This concept is referred to as the metatarsal break. ${ }^{42,43}$ The angle which the metatarsal break occurs ranges from 54-73 degrees of toe extension. This amount is required in the normal foot so gait will not be disrupted. ${ }^{42}$

Kinetics: The gait cycle encompasses all motions that occur from the point of initial contact of one lower extremity to the point at which the same extremity contacts the ground again. ${ }^{42,43}$ Gait is divided into two phases; stance and swing. Stance phase is when the foot is on the ground, while the swing phase initiates as soon as the toe of one extremity leaves and ends at heel strike. Swing phase is further divided into early and late swing. Early swing includes an acceleration phase and a toe-off, or push off. Late swing includes deceleration and the preparation for heel strike. ${ }^{42,48}$ Table B6 describes the ROM required at each joint in the lower extremity to maintain normal biomechanics during gait. Table B6. ROM Requirements of Joints for Gait. ${ }^{42,43,44,62}$

\begin{tabular}{llll}
\hline Joint & Heel Strike Phase & Mid-Stance Phase & Toe-Off Phase \\
\hline Hip & $30^{\circ}$ flexion & Neutral position & $10-20^{\circ}$ extension \\
Knee & $0-15^{\circ}$ flexion & Neutral position & $30-40^{\circ}$ flexion \\
Talocrural & $0-15^{\circ}$ plantar-flexion & $10^{\circ}$ dorsiflexion & $20^{\circ}$ plantarflexion \\
Subtalar & $6^{\circ}$ pronation & $12^{\circ}$ supination & supinatioin \\
$1^{\text {st }}$ MTP & No movement & No movement & $65^{\circ}$ extension \\
\hline
\end{tabular}


The external rotators of the hip act as pelvic stabilizers throughout the entire gait cycle. However, they function at heel strike by decelerating the hip and assisting in hip external rotation. ${ }^{42} \mathrm{Hip}$ adductors also decelerate the hip at heel strike and, aid in internal rotation of the hip when flexed to 30 degrees. The gluteus maximus is at peak activity at heel strike by eccentrically decelerating hip flexion and hip internal rotation. ${ }^{42}$ Furthermore, the hamstrings act as stabilizers at heel strike while the quadriceps eccentrically control knee flexion. ${ }^{42}$ The talocrural and subtalar joints are stabilized by the temporary activation of the peroneus longus, allowing the foot to load from the lateral to medial side creating a pronating motion. The extensor hallicus longus assists in decelerating the foot after heel strike. ${ }^{43}$ The tibialis posterior decelerates subtalar joint pronation and lower leg internal rotaion eccentrically at heel strike. ${ }^{43}$ Pronation is necessary to allow greater mobility of the transtarsal joint by making the surfaces parallel. This in turn allows for dorsiflexion and increases the width of the crosssectional arch of the foot, ultimately allowing for greater flexibility. ${ }^{43,62}$

In the stance phase, the hip abductors function as primary stabilizers of the hip and limit pelvic tilt. ${ }^{46,63}$ The iliopsoas contributes during the stance phase by eccentrically decelerating internal rotation of the hip and pelvic rotation. ${ }^{46,63}$ Tibial internal rotation and subtalar joint pronation are decelerated by the eccentric contraction of the soleus during the late contact period. The soleus also assists in knee extension during midstance by eccentrically decelerating forward momentum of the tibia. ${ }^{43,46,62,64}$ The gastrocnemius eccentrically decelerates femoral rotation during late contact and maintains knee flexion tension at midstance ${ }^{46,64}$ The peroneus longus is the most active muscle during midstance, assisting in ankle plantarflexion and stabilizing the base of the first ray. Pronation and supination are crucial in decreasing the forces at foot contact. ${ }^{45,65}$ At heel strike, the tibialis posterior concentrically supinates the subtalar joint and assists in external rotation of the leg. ${ }^{43,46,51,62}$ Subtalar supination allows the 
transtarsal joints to become more rigid. This consequently makes the cross-sectional arch taller and more rigid. $^{43,51,55,62}$

In order to achieve proper gait, the knee must flex, as well as the hip. Therefore, the hamstrings and iliopsoas fire simultaneously. ${ }^{46}$ The peroneus brevis contracts to stabilize the lateral foot. ${ }^{48}$ Intrinsic flexor muscles contribute to forefoot rigidity, and the windlass mechanism is tightened as metatarsophalengeal flexion proceeds. ${ }^{43}$ The windlass mechanism is described as a locking of the medial longitudinal arch, which increases stability of the foot during toe off. On push off, the calcaneus raises and the toes extend. These actions raise the longitudinal arch, and in effect lock the arch to increase stability. $^{40,43,46,51,66}$

However, in the sport of football, walking is not a component. Other motions must be considered. These include sprinting, cutting, backpedaling, sideshuffling (or lateral movements), kicking and jumping. Different positions in the sport of football have different tasks. In general, quarterbacks will sprint straight ahead, backpedal and cut in an attempt to complete a pass or run with the ball. Wide receivers will have to jump for height, sprint straight ahead and cut while trying to obtain an open position to receive the ball. On the other hand, running backs will complete forward and lateral movements with some jumping for distance components. The offensive linemen and tight ends will also complete lateral and forward movements while blocking opponents. On the defensive side of the ball, corners and safeties will sprint straight ahead, laterally and also complete backpedaling while reading a pass. Linebackers’ responsibilities include lateral and forward movements in addition to cutting while the defensive linemen have tasks that require forward movement and backpedaling. Kickers and punters must kick the ball in a specified manner.

Running: Running is a more complex movement than walking. A key feature of walking is that one or both feet have direct contact with the ground at all times while running allows for the individual 
to be airborne for a short period of time. ${ }^{67}$ Due to the fact that both feet are simultaneously off of the ground, running can be considered a series of leaps which results in an impact that is a multiple of the participants' body weight. ${ }^{67}$ In walking, over $60 \%$ of movement occurs in the stance phase. However, as speed increases with running, less time is spent in the stance phase which drastically increases the rate of injury at landing due to the increased necessity of shock absorption. ${ }^{67}$ Divided into three phases, running also allows for a greater distance to be covered in a shorter period of time.

Phase 1 is the stance phase and is subdivided into landing, mid-stance, and push-off. This phase occurs when one foot is in contact with the ground. At heel strike, in an effort to maintain the center of gravity (COG), the pelvis rotates 40 degrees anteriorly through the adductors and abductors. ${ }^{67}$ The quadriceps are in extension while the hamstrings eccentrically stabilize. The ankle is in dorsiflexion at impact but the foot must remain flexible to help absorb shock. The foot will then supinate slightly in an attempt to increase stability. The ground reaction force can equal up to 1.5 to 5 times the individuals' body weight at heel strike. ${ }^{67}$ However, fast runners may never land on the heel but will land on the forefoot. Mid-stance is a moment in which the foot pronates to allow for flexibility in pushing off. The tibia internally rotates on the talus while the quadriceps contract. Furthermore, the hip and knee fall into alignment with the ankle while the hip displaces laterally approximately one inch to help maintain the COG. ${ }^{67}$ During the push-off phase, the gluteus maximus and hamstrings contract to extend the hip while the muscles in the anterior compartment of the ankle (posterior tibialis and the peroneals) push the foot off the ground. ${ }^{67}$

The second phase is the swing phase. The first component of the swing phase is acceleration in which the hip flexors move the leg off the ground. The knee flexes to approximately 65 degrees and the ankle dorsiflexes so the foot can clear the ground. ${ }^{67}$ The hip will rotate anteriorly so the opposite hip can become a fulcrum. The leg then decelerates by the eccentric contraction of the hamstrings in 
preparation for heel strike while the peroneals stabilize the ankle. ${ }^{67}$ The float phase is the third stage of running in which the athlete is airborne.

Cutting: Cutting is a motion that is described as a maneuver that includes a sharp deceleration in conjunction with a change in direction. Typically, the knee undergoes a moment of internal rotation, valgus, and relative extension of approximately 0 to 30 degrees. ${ }^{68}$ The ACL is fully loaded when in these positions which corresponds to the high number of ACL injuries that occur as a result of this mechanism. ${ }^{68}$ The nature of sport dictates that some maneuvers are going to be unanticipated which will call for a rapid and unexpected reaction. (This unplanned reaction can also be generated in a similar manner due to an external force such as contact with another player.) These unanticipated motions result in increased moments of varus/valgus and internal/external rotation moments at the knee. ${ }^{69}$ Previous studies suggest that these extreme moments are as much as $100 \%$ greater than cutting maneuvers that are preplanned and thought through. ${ }^{69}$

The Central Nervous System (CNS) provides a variety of neural strategies to counterbalance the external loads the knee endures during cutting tasks. One example is "selected activation" of muscles with moment arms that are best able to counter the external load. Activation of the gracilis to counter an external valgus moment, or co-activation of the medial hamstrings and medial quadriceps to oppose external valgus loading will occur. Another option of the CNS is generalized co-contraction involving co-activation of hamstring and quadriceps muscles without any selectivity of specific muscles. Besier et al ${ }^{69}$ examined the differences in muscle activation during pre-planned and unplanned cutting tasks. It was found that co-contraction of flexor and extensor muscle groups were evident during the preplanned and unplanned cutting tasks. However, during unplanned moments, a generalized co-contraction strategy was predominantly used. Furthermore, muscle activation levels increased by $10-20 \%$ when the maneuvers were unanticipated. ${ }^{69}$ 
Backpedaling: Backpedaling is also referred to as retro-running and has gained popularity as a training tool among many sports. Current trends suggest that running backwards can help build stronger and more balanced leg muscles through maximizing quadriceps strength. ${ }^{70}$ Forward running is predominantly characterized by the muscle activation of the hamstrings which propels the body forward. The quadriceps muscles are not as active because their main function is to support the force of the foot when striking the ground. Backpedaling allows for the opposite to happen; the hamstrings aid in absorbing most of the impact while the quadriceps extend the knee to generate the backward motion. ${ }^{70}$

Kicking: There are three phases in kicking of which include the back swing, leg cocking and acceleration. During the back swing, the striking foot leaves the ground and achieves maximal hip extension. The leg cocking phase incorporates maximal flexion of the knee. The force of the kick is contingent on leg acceleration until contact with the ball occurs. ${ }^{67}$ Muscle groups must serve as agonists and antagonists for kicking to occur. The agonist group generates the motion across the joints while the antagonist muscle group works to slow down the agonist group. During back swing, the hamstrings and hip extensors act as agonists while the quadriceps and hip flexors reduce the rate of knee flexion. Likewise, just prior to ball contact, the quadriceps and hip flexors are the agonists while the hamstrings and hip extensors slow down the rate of knee extension. ${ }^{67}$ The muscle groups that are in an eccentric contraction or are acting as antagonists are most commonly injured during that particular phase of the kick. ${ }^{67}$

Jumping: There are four components of jumping of which include foot plant, ascent, descent and landing. ${ }^{67}$ During foot plant or take-off, one or both feet are in contact with the ground. The ground reaction force produced is enough to elevate the body that corresponds with Newton's third law. This law states that every action has an equal and opposite reaction. ${ }^{67}$ The hamstrings, quadriceps, gastrocsoleus complex and hip flexors contract to create a downward force. All joints of the lower extremity 
that make up the kinetic chain (the hip, knee and ankle) are in flexion initially and transition to extension to generate an upward motion. ${ }^{67}$ The ascent is the period of time in which the athlete leaves the ground and moves against the forces of gravity. Once peak elevation is met, the return to the ground or downward period is referred to as the descent. ${ }^{67}$ The landing requires eccentric control from all muscle groups of the lower extremity of which include the abdomen, hips, thighs, legs and feet. The hip, knee and ankle are all in a flexed position so the muscles can absorb the shock and transfer it up the kinetic chain instead of being absorbed by the joints themselves. Optimal landing positions vary depending on sport and position. ${ }^{67}$

Forces: Static and dynamic analysis of forces acting on a joint are important components of kinetics. Static refers to a body at rest or at a constant speed while dynamic refers to a body in motion. During an erect bilateral stance, the hips are in neutral with the center of gravity (COG) posterior to the axis for flexion and extension of the hip. The posterior positioning creates a slight extension moment of force which contributes to the posterior tilt of the pelvis on the femoral heads. Body weight is transferred through the sacroiliac joint and pelvis in the frontal plane. ${ }^{71}$ The magnitude of this force on each femoral head is one-half of two-thirds of total body weight. (This is calculated in this manner because each lower extremity is approximately one-sixth of an individuals' body weight.) However, this force increases proportionally to the amount of muscle activity being generated if the stabilizing muscles surrounding the hip are contracted. ${ }^{72}$ Overall, the joint reaction force (JRF) at the hip depends on the positioning of the upper extremities, the posture of the spine, and the inclination of the pelvis. ${ }^{72}$

The two main factors that influence magnitude of force during dynamic periods on the tibiofemoral joint are acceleration of the leg and mass moment of inertia. ${ }^{72}$ Following heel strike JRF can range from two to three times the individuals body weight with the eccentric contraction of the hamstrings. The beginning of the stance phase is characterized by knee flexion which generates JRF of 
up to two times body weight with the contraction of the quadriceps. The late stance phase prior to pushoff can generate JRF of two to four times body weight and is associated with the contraction of the gastrocnemius. The late swing phase is associated with the contraction of the hamstrings and results in a JRF approximately equal to body weight. ${ }^{72}$ The JRF transitions from the medial to the lateral plateau during the gait cycle. During the stance phase, the JRF is sustained by the medial plateau while the lateral plateau sustains most forces during the swing phase. The JRF during the stance phase are much greater and are accommodated by the medial plateau structurally in that the cartilage is three times thicker and also has a larger surface area. The menisci also sustain JRF and help distribute the stress evenly. $^{72}$

The forces at the patellofemoral joint are associated with knee flexion. ${ }^{72}$ The COG of the body above the knee is approximately above the center of rotation of the patellofemoral joint. The COG moves further away from the COR during knee flexion. ${ }^{72}$ Furthermore, knee flexion impacts the angle between the patellar tendon and the quadriceps tendon. This angle becomes smaller during flexion resulting in a greater magnitude of JRF. With activities requiring 90 degrees of knee flexion, JRF reaches two and half to three times body weight. ${ }^{72}$

Forces imposed on the foot and ankle can exceed $120 \%$ to $275 \%$ of bodyweight with walking and running, respectively. ${ }^{72}$ The tarsal joints sustain the majority of the load specifically on the medial column. This consists of the talus, navicular, cuneiforms and metatarsals one through three. The distribution of pressure imposed on the foot is $60 \%$ heel, $8 \%$ midfoot, $28 \%$ forefoot, and $4 \%$ toes. ${ }^{72}$ The distribution of forces will change depending on type of shoe-wear. Furthermore, running and walking both generate numerous forces between the foot and the ground. These forces include vertical, anteroposterior shear, medial and lateral shear, and rotational torque. ${ }^{72}$ Vertical force is generated during both heel strike in early stance and in late stance just prior to push-off. Anteroposterior shear 
force is created by the deceleration of the foot as a forward shear force is placed by the foot on the ground immediately followed by backward shear force on the ground during late stance while pushingoff. The body's COG is medially placed over the foot which results in lateral displacement of a mediallateral shear force. As the tibia internally rotates and the foot pronates in the early stance phase, rotational torque is generated followed by the external rotation of the leg and supination of the foot. ${ }^{72}$

\section{Epidemiology}

Regardless of sport, over fifty percent of all injuries that resulted in time lost involved the lower extremity. ${ }^{1}$ Completed in 2007, an epidemiology report covering sixteen years of participation of fifteen college sports reported that football had the highest rate of injury in both practices and games with the majority of most incidences being ankle ligament sprains or anterior cruciate ligament injuries. ${ }^{1}$ Knee and ankle ligamentous injuries account for 17.8 and $15.6 \%$, respectively, of all injuries in the sport of football alone. Muscle and tendon injuries of the lower extremity account for nearly $10 \% .{ }^{2}$ Likewise, an epidemiology study in the NFL or National Football League also concluded that the most common injury during training camp was a knee sprain, followed by hamstring strains and contusions. ${ }^{73}$ This study revealed that muscle strains are the most common injury type during practice. ${ }^{73}$

Offensive players tend to sustain injuries most often with running backs sustaining $20 \%$ of all injuries while quarterbacks are at nearly $18 \%{ }^{2}$ It has also been reported that injuries are nine times more likely to be encountered in a game situation than during practice. ${ }^{2}$ More specifically, the rate of injury per 1000 athlete-exposures was greater during high school competitions (12.04) than during practices (2.56). Likewise, the rate of injury per 1000 athlete-exposures was also greater during collegiate competitions (40.23) than during practices (5.77). ${ }^{74}$ Therefore, a positive correlation exists indicating that as competition level increases the rate of injury also increases. 
Furthermore, injuries were reported by $36.5 \%$ of the players, with $14.4 \%$ reporting more than one injury in a season in a boys youth program ranging from fourth to eighth grade. ${ }^{75}$ The injury rate increased with each succeeding grade from 14.3 per 1000 A-Es (95\% CI = 12.1, 16.9) in grades 4 and 5 to 21.7 per $1000 \mathrm{~A}$-Es $(95 \% \mathrm{CI}=17.2,27.3)$ in grade 8 . A total of $58.6 \%$ of all injuries were considered non-time-loss injuries. Overall, it was concluded that youth football players sustained more non-time loss injuries than time loss injuries. ${ }^{75}$

Time of year also influences the epidemiology of injury in football. Data was collected that compared fall games to fall practices as well as to spring practices. 54.7, 50.8, and 55.7 were recorded, respectively for the percentage of injuries that were sustained to the lower extremity. ${ }^{2}$ This suggests that fall practices are much less intense because this is the "in-season” period in which games are being played.

According to Krackow, ${ }^{76}$ one explanation for the high number of injuries in football is the number of exposures that a player experiences over the course of a complete season. A player is exposed to collisions not only in games but practices as well. The athlete participating in practices and games is exposed to collision on almost every play of everyday and "there appears to be a direct relationship between the amount of contact a player gives or receives and the incidence of injury.” ${ }^{76}$ Therefore, the more plays an athlete is in, the increased chance of becoming injured.

\section{Etiology}

Football is a very physical contact sport resulting in several mechanisms of injury. In the epidemiological study by Dick et al., ${ }^{2}$ the most frequent mechanisms of injury listed were being blocked below the waist, tackling and being tackled, blocked and being blocked, contact with playing surface, stepped on/fallen on/kicked, sprinting or running, blocking a kick, non-contact with a rotational 
component, overuse and being clipped. The majority of ACL ruptures were a result of noncontact with a rotational component occurring nearly $30 \%$ of the time with being blocked, blocking and being tackled all resulting in nearly $10 \%$ of ACL injuries each. ${ }^{2}$ Non-contact with a rotational component was also the leading mechanism for meniscal injuries. However, PCL injuries occurred most often while being tackled nearly $20 \%$ of the time. ${ }^{2}$

Injury mechanisms can be categorized into extrinsic, those caused by forces generated outside the athlete such as a direct blow, and intrinsic, those caused by forces generated within the athlete's body. ${ }^{77}$ In general, extrinsic mechanisms tend to cause more tissue damage because the forces generated are usually greater. Several factors have been correlated with an increased risk of injury. Player position is a factor, with those handling the ball, running backs and quarterbacks, having the highest relative risk. ${ }^{78,79}$ On the defensive side of the ball, linebackers and defensive backs are the most vulnerable. ${ }^{78}$ Most injuries occur in the third quarter of a game and in the first half of the season. Other factors include the playing surface and a player's size and speed. ${ }^{79}$

Tyler et al ${ }^{80}$ completed a study that examined body mass index and weight in relationship to ankle sprains occurring in the sport of football. Most of the reported sprains (15 of 24) were non-contact. Injury incidence was higher in athletes with previous ankle injuries (2.60 vs 0.39). Body mass index was identified as a risk factor with injury incidence of 0.52 for players with a normal body mass index, 1.05 for players at risk of overweight, and 2.03 for overweight players. Furthermore, injury incidence was 0.22 for normal-weight players with no previous ankle sprain compared with 4.27 for overweight players who had a previous sprain. They concluded that an overweight player who had a previous ankle sprain was 19 times more likely to sustain a non-contact ankle sprain than the likelihood of a normalweight player with no previous ankle sprain. ${ }^{80}$ This is imperative to consider for the sport of football 
due to the size of many of the participants. It can be inferred that excess weight not only influences injury at the ankle but also up the kinetic chain.

Injuries sustained by the hip are approximately accountable for $2.5 \%$ of all injuries in the sport of football with most being classified as contusions. ${ }^{77}$ Direct trauma from a fall can result in a soft tissue contusion over bony prominences. Common sites for contusions are the greater trochanter, the ischial tuberosity, and the iliac crest. Traumatic posterior hip subluxation is an injury often misdiagnosed as a sprain or strain. The mechanism is usually a fall on a flexed knee with the hip flexed and adducted. Acetabular labrum tears are correlated with twisting mechanisms. ${ }^{77}$

The knee is the most injured joint in the sport of football with up to $36.5 \%$ of all injuries. ${ }^{77}$ The most common site of knee injuries is the MCL followed by the meniscus and then the ACL. The most susceptible players are linemen, running backs, and linebackers. Linemen are particularly susceptible to MCL injuries from side blocks to the knee or from a player rolling onto the lateral leg, both of which result in extreme valgus stress. ${ }^{77}$ ACL tears are the most common knee injury requiring surgery. Receivers and defensive backs are susceptible to noncontact ACL injury from rapid deceleration and cutting. Other mechanisms include valgus, varus, or hyperextension as a result of contact. Running backs are vulnerable to contact injuries while being tackled. ${ }^{77}$ Although very rare, PCL tears do occur in football. The most common mechanism is a direct blow to the anterior tibia with the knee flexed, but injury can occur with any combination of hyperflexion/extension, varus, or valgus stress. ${ }^{77}$ Acute meniscal tears often result from a twisting mechanism. These are often associated with ligamentous injury. Medial meniscal tears are up to four times more common than lateral meniscal tears among football players. ${ }^{77}$ Ankle injuries are very prominent in the sport of football. The most common mechanism is supination of the foot or inversion with plantar flexion while cutting, resulting in injury to the lateral ligaments. ${ }^{77}$ 


\section{Functional Performance Testing}

Functional outcome measures are used to determine physical capabilities to aid in the return to play decision making process. Outcome measurements should quantify an athletes' physical ability and accurately verify that rehabitiation can safely be terminated. ${ }^{25}$ However, functional outcome measures that are obtained clinically are classified in three ways: 1) self-reported scoring where pain, swelling, instability, and activity level are subjectively recorded; ${ }^{26}$ 2) performance tests that mimic a specific sporting activity and generate quantifiable data; and 3) global scoring systems that include both selfreporting and performance testing while also including range of motion. ${ }^{27}$ Although global scoring systems are the most ideal, objective measures are the most critical component of accurately allowing the athlete to return to competition. According to Beardmore et al., ${ }^{81}$ when making return to play decisions, it seems as if “...greater emphasis [has been placed] on clinical recovery and anatomical healing than the ability of an injured part to withstand the stresses and demands of the sport.” Functional performance testing is an objective and observable measure that involves full weight bearing and sport specific tasks that challenge the site of injury. ${ }^{82}$ Assessment is measured through a one-time maximal effort performance by the athlete not only to assess sport-specific rehabilitative progress, but also psychological function. ${ }^{31}$

Functional performance testing allows for assessment of the neurophysiologic integrity of a muscle or a muscle group. ${ }^{83}$ The neuromuscular system is imperative in sport due to the constant changes in positioning and velocity the limb is undergoing to produce a series of motions. This function is achieved through the interaction of afferent neurologic input which has the ability to cause change through an efferent output that will produce the muscular response. ${ }^{83}$ For this reason, isokinetic measurements should not be used alone in making return to play decision because it may not assess normal muscular function adequately. Isokinetic measurements can not measure both acceleration and 
deceleration simultaneously which are a result of multiple concentric, eccentric, and static contractions in the lower extremity. ${ }^{83}$ Furthermore, a discrepancy exists in the literature concerning the efficacy of isokinetic testing. A positive correlation has been documented by some authors between isokinetic peak torque and functional maneuvers such as running, cutting and hopping. However, other authors report no correlation between isokinetic results and functional activities such as sprinting, jumping and agility drills. ${ }^{83}$

Functional performance testing has been verified as a re-injury prevention tool and should be used clinically. A study completed by Hagglund et al. ${ }^{84}$ provided a ten step guide of a rehabilitative program to aid coaches in making return to play decisions where medical coverage was not provided. The basic components of the functional tests included a straight forward jog, figure eight jog, zig-zag jog, jog with ninety degree turns, jog with 180 degree turns, jog with 360 degree turns and sport specific tasks increasing in difficulty after successful completion of the previous. Coaches were not given a specific number of repetitions to determine progress but were asked to evaluate symptoms of the athlete both during the exercise and on the following day. Furthermore, the athletes were not eligible to compete until they had participated in at least one team training session without pain or swelling. Compared to the control group where no functional testing was performed to assess return to play ability, a sixty-six percent reduction in rate of re-injury was recorded with the greatest preventative effect seen within the first week of activity. This indicates that premature return to play was an important factor contributing to the rate of re-injury. Therefore, functional performance testing is clinically advantageous in making accurate return to play decisions.

Based on the movement patterns and demands of the sport of football, there is not one test or a collective series of tests discussed in the literature that allows for assessment of total function of the lower extremity. A functional performance tool that incorporates straight ahead sprinting, backpedaling, 
cutting, lateral side shuffle and jumping is integral for football that will encompass all lower extremity demands of every position. However, several but only individual components have been identified as being reliable and valid.

Furthermore, most functional tests developed for the lower extremity have been centered around ACL reconstruction to evaluate functional deficits. ${ }^{85}$ Augustsson et al ${ }^{86}$ suggests that a more comprehensive evaluation of lower-extremity function after ACL reconstruction can be achieved by performance testing under non-fatigued and fatigued test conditions. This should be considered when using any of the following components of functional testing for any injury that may impact the kinetic chain.

Single-leg (SL) hop tests: Drouin ${ }^{6}$ reviewed five commonly used single-leg (SL) hop tests that are individual components of lower extremity functional testing. These included the SL hop for distance, SL triple hop for distance, SL triple cross-over hop for distance, SL vertical jump, and the SL 6-m hop for time. Intraclass correlations (ICC) ranged from .66 to .99 for the five single leg tests. These ratios demonstrate that consistency is present through repeated trials. Also evaluating reliability, Worrell et al. ${ }^{8}$ determined that ICCs were acceptable for SL hop for distance, SL hop for time and SL agility hop as functional performance tools for ankle inversion sprains with scores ranging from .77 to $.99 .{ }^{8}$ In a study designed specifically for ACL reconstructed individuals, five SL hops were investigated. ${ }^{9}$ These included the SL vertical jump, SL hop for distance, drop jump followed by double SL hop for distance, SL square hop, and SL side hop. The ICC scores ranged from 0.85 to $0.97 .^{9}$

Noyles et al ${ }^{5}$ investigated the sensitivity rates for several single-leg hop tests. It was found that the sensitivity rate for the cross-over hop was $58 \%$ and for the timed hop was $49 \%$. Both of these studies evaluated each jump as a single test item. It was suggested that a battery of functional single-leg tests would provide more accurate information on bilateral deficiencies of the lower limb than these 
individual tests. Functional tests were unable to identify the athletes' specific functional limitation such as strength and balance deficits. O'Donnell et al ${ }^{87}$ investigated the hop test used to determine progress in ACL deficient patients. Subjects were asked to perform a hop for distance on each leg which would allow for assessment of strength. A bilateral comparison noted a significant strength deficit in the involved leg with a sensitivity of 20 to $60 \% .{ }^{87}$

Hamilton et al. ${ }^{11}$ examined the triple hop for distance (THD) for validity. They predicted that THD would result in a better method for predicting leg strength and power while decreasing postural balance errors during the assessment. The variance in vertical jump height was predicted by THD 69.5\% of the time while also predicting variance in strength $56.7 \%$ and $58.8 \%$ of the time in hamstring and quadriceps, respectively. However, there was no correlation with the Balance Error Scoring System (BESS). They also concluded that THD requires minimal space, time and equipment and should be used in clinical practice. ${ }^{11}$

Furthermore, Booher et al ${ }^{21}$ investigated the reliability of the SL hop for distance, SL hop for time, and the 30 meter SL agility hop. No significant differences between dominant and non-dominant extremities were observed. However, significant differences existed within the functional tests from day to day trials demonstrating that motor learning or a "practice effect" did occur. Improvements in measurements were small but are still indicative of an unstable measure. This study concluded that if multiple trials are to be performed, rest periods should be built into the protocol in an effort to prevent fatigue. ICC scores were acceptable ranging from 0.77 to 0.97 .

Running tasks and proprioceptive challenges: Lephart also examined the reliability of functional performance components. In examining the co-contraction semicircular test, carioca test and shuttle run, ICC scores ranged from .92 to $.96 .{ }^{10}$ Furthermore, Greenberger et al..$^{29}$ looked at the reliability of the 
anterior lunge test, balance leg reach and hip adduction excursion test and verified that ICC scores ranged from .73 to .91 .

Comprehenisve battery: George Davies developed a multidirectional and comprehensive battery of tests in 1988 that would assess the integrity of the lower extremity. ${ }^{3}$ This test was referred to as the LEFT or Lower Extremity Functional Test. It was comprised of eight skills of which included forward and backward running, side shuffling, carioca, figure 8 running, 45 degree and 90 degree cutting, and 90 degree crossover cutting all of which are stresses introduced during sport. Tabor et al. ${ }^{3}$ examined the reliability of these tests as a single test using a test-retest design. ICC scores at different locations were .95 and .97 indicating that the LEFT was a reliable functional assessment tool for a variety of lower extremity pathologies. ${ }^{3}$ However, the authors acknowledge that the LEFT should only be used in conjunction with other objective measurements including goniometric, anthropometric and isokinetic measurements in addition to subjective data from the athlete. ${ }^{3}$ Furthermore, a series of hops referred to as the multiple hop test designed by Riemann et al. ${ }^{88}$ to assess postural control, has also been found reliable with ICC scores ranging from 0.87 to 0.97 in healthy and unhealthy subjects, respectively.

Test batteries have been created for the evaluation of specific pathologies in addition to a means for objective measures of lower limb function. A battery was designed by Silbernagel et al. ${ }^{20}$ that allowed for evaluation of different aspects of muscle-tendon function in association with Achilles tendinopathy. The test battery consisted of three jump tests, a counter movements jump (CMJ), a drop counter movement jump (drop CMJ) and hopping, and two strength tests, concentric toe-raises, eccentric-concentric toe-raises and toe-raises for endurance. Excellent reliability was found between test days 1-2 and 2-3 for all tests with ICC scores ranging from 0.76-0.94 except for the concentric toeraise test at days $2-3$. Reliability was reported as fair with an ICC score of 0.73 . The sensitivity of the test battery at a $90 \%$ capacity was 88 . Furthermore, the individual test sensitivity in the test battery 
ranged from 33 to $48 \%$, compared to the whole test battery with a sensitivity of $88 \%{ }^{20}$ These results confirm that the test battery evaluated the different functions as intended and the test battery sets a higher demand on the patients than each individual test.

A functional test battery for Patellofemoral Pain Syndrome (PFPS) was also examined for reliability. ${ }^{19}$ The five components included anteromedial lunge, step-down, single-leg press, bilateral squat, balance and reach. ICC scores ranged from .79 to .94, while SEM scores ranged from .38 to .68. More specifically, the highest ICC was found with the stepdown test and the lowest ICC with the bilateral squat test. As pain level decreased, the number of repetitions performed increased for all unilateral tasks. The bilateral squat correlated the least with the VAS (or Visual Analog Scale) and resulted in the lowest reliability. This result was concluded by the authors to be a direct consequence of the bilateral nature of the test. Weight distribution was not monitored, therefore subjects could shift weight to the uninvolved limb to avoid overloading the involved side. ${ }^{19}$ It can then be concluded that unilateral functional testing of the involved side is the most conclusive for PFPS functional performance.

Furthermore, functional performance deficits in patients with functional ankle instability have been noted through some of the components of a unilateral hop-test battery. The components of the battery included the figure-of-8 hop, side hop, up-down hop, and a single hop. Docherty et al. ${ }^{89}$ found that a positive relationship existed between functional ankle instability and performance deficits on the side hop and figure-of-8 hop. However, they concluded that a relationship did not exist between functional ankle instability and frontal-plane functional-performance activities. ${ }^{89}$ It can then be concluded that tasks that are multi-planar are a more accurate assessment of functional performance.

After examining individual components and functional performance batteries, it must be noted that current research by Keyas et al. ${ }^{90}$ indicated that most functional tasks are only indicative and 
comparable to quadriceps strength. In comparing knee strength and functional stability before and after ACL reconstruction, the shuttle run, side step, carioca, single and triple hop tests had significant positive correlations with quadriceps strength. However, there was no correlation with any of the tasks pre or post operatively with hamstring strength. ${ }^{90}$ This suggests that a larger variety of tasks are required to provide a better objective and more comprehensive measurement of total function prior to return to play.

Return to play criteria: Insufficient rehabilitation and premature return to play are risk factors for recurrence of injury. ${ }^{84}$ Prior to returning to team training or competition, an athlete must have regained full range of motion, possess adequate coordination and maintain at least ninety percent of their original muscle strength. ${ }^{25}$ Other factors to consider are pain, balance and functional performance. ${ }^{13}$ Saal ${ }^{91}$ further believes the ability to run and sustain contact without pain is more indicative of return to play than just functional performance. No intake of pain medication and player education about preventive measures and future risks are essential components to the return to play decision. ${ }^{91} \mathrm{~A}$ consensus statement generated by team physicians states that safe and timely return of an injured athlete to practice or competition is dependent on the status of the chronic or acute injury. The athlete should pose no undue risk to the safety of other participants or himself, have fully restored sport specific skills, is psychosocially ready to return, and has the ability to perform safely with equipment modification including bracing and orthoses in addition to the ability to comply with the governing athletic bodies. ${ }^{92}$ All of these criteria must be met. For these reasons, functional performance testing is a key component in making return to play decisions.

UNC Functional Performance Test: The UNC Functional Performance Test is a battery similar to the LEFT but incorporates jumping in addition to speed and agility for an even more comprehensive assessment of the lower extremity that encompasses all of the physical demands of football. The components include the shuffle box drill for time, figure 8 for time, bilateral SL hop test for time, 
carioca test for time and a SL triple jump for distance. Some of these components have reliability established already as discussed in the previous section while others have not. This test is not intended to be the only functional assessment tool as it remains necessary to bilaterally compare and maintain at least 90\% strength and ROM of the uninvolved side from baseline prior to return to play.

This test has previously been introduced as the Carolina Functional Performance Index (CFPI) but has been modified since. The original components included the co-contraction test, carioca test, shuttle run test and SL hop for time. It was originally designed to aid clinicians in evaluating lowerextremity functional performance but not for a specific sport. A normative index was determined for males and females with only the carioca test and co-contraction. The index was intended to be used for comparison at baseline pre-injury and post-injury to track rehabilitative progress. ${ }^{12}$

Test Re-test Design, ICC, and SEM

Test re-test reliability is a research design that examines a test's consistency among different administrations. The same test is given to a group of subjects on at least two separate occasions in order to generate a coefficient for reliability. Scores that each athlete receives on the first administration should be very similar if not the same as scores on the second trial. ${ }^{93} \mathrm{~A}$ high positive correlation is expected if the results are similar. However, a major concern with test-retest reliability is the learning or practice effect. ${ }^{93}$ This is especially true when the two trials are close together in time. After being introduced to a specific task, remembering what to do the next time can create variations in time or the overall result. ${ }^{93}$ This can create an inaccurately high reliability coefficient as the athletes may respond to the next trial based on their previous experience instead of responding naturally to the challenges from the test itself. 
Reliability means that the measure is free from error and will consistently measure a specific characteristic. On the other hand, validity means that the measure is an accurate assessment of the characteristic intended to measure. ${ }^{13}$ Therefore, a measure can not be valid if it is not reliable and vice versa. Clinical measures should only vary on a day to day basis if a real change is actually and physiologically taking place. However, no measurement is 100 percent reliable and measurement error needs to be factored in. ${ }^{13}$ An observed score is in actuality the true score of the physiological change plus or minus the measurement error. For these reasons, the typical approach to establishing reliability is through the intra-class correlation coefficient (ICC) and the standard error of measurement (SEM). ${ }^{16,94}$

The ICC is reliability coefficient that generates a ratio ranging from 0.00 to 1.00 that estimates the consistency of performance on repeated trials. ${ }^{13}$ (A score of 0.00 indicates the measure was 100\% unreliable.) In calculating the ICC, the ratio will allow accurate interpretation of how much variability in the observed measure was truly a change in the participant or if it is a result of measurement error. Therefore, an ICC over 0.75 can be considered good while anything below 0.5 is poor. ${ }^{14}$ However, the ICC provides a limited clinically meaningful interpretation. ${ }^{94}$ For this reason, additional information is required for clinical practice.

The following equation is used for the calculation of ICC as established by Shrout and Fleiss ${ }^{16}$ where BMS $=$ between subjects mean square, EMS = between testing sessions mean square, TMS = trial mean square, $\mathrm{N}=$ number of total subjects, and $\mathrm{K}=$ number of testing sessions.

$$
\text { ICC }_{2,1}=[\text { BMS -EMS]/[BMS + (K-1)EMS + (K(TMS-EMS)/N) }]
$$

The SEM is used to assess the precision of the measurement by estimating measurement error. ${ }^{13}$ In using the SEM in conjunction with the ICC, measurement precision can be obtained which will allow for appropriate decisions for clinical application. The SEM or standard error or measurement was used to determine the precision of the recorded measurements. The SEM demonstrates the variation in 
expected scores for one subject if the test were repeated multiple times. Reported as a standard deviation, the SEM is based off a normal distribution which will represent the range for estimated

measurement error. ${ }^{13}$ The following equation was used for SEM as described by Brown ${ }^{17}$ where $\mathrm{S}=$ the standard deviation of the test and $\mathrm{r}_{\mathrm{xx}}=$ reliability coefficient for the test.

$$
\mathrm{SEM}=\mathrm{S} \sqrt{1-\mathrm{rXx}}
$$

\section{Summary}

The lower extremity is comprised of a variety of bony articulations that are essential to perform a wide range of tasks. The kinetic chain connects all of the joints in an effort to protect the body and to make it as efficient as possible. When a component in the chain becomes injured or weak, it impacts the integrity of the rest of the chain. Compensations occur that can lead to muscular imbalances and joint instability that will ultimately impact functionality of the entire lower extremity.

There are many different functional tasks that exist that can prepare an athlete for return to play but they can also be used to ensure the athlete has the proper flexibility and strength to protect themselves during sport prior to full participation following an injury. Many tasks focus on jumping which helps with the transfer of force improving both concentric and eccentric muscle strength. Other tasks evaluate speed and endurance as well as the ability to confidently cut and pivot. However, it is noted that these functional tasks alone do not dictate when an athlete is ready for participation. Other clinical measures need to be used in conjunction with functional performance tools which include ROM, anthropometric measurement, manual muscle testing and subjective pain assessments. With the many tasks that have been identified for specific pathologies, very few authors have actually tested functional skills in the form of a battery that are specific to a sport. Further studies need to be conducted testing the clinical relevance of functional objective measures as reliable return to play criteria. 
APPENDIX C

ADDITIONAL METHODS

Table C1. Informed Consent

\section{CONSENT AND INFORMATION FORM}

Test Re-test Reliability of the UNC Functional Performance Test

Principal Investigator: Sandrey, Michelle

Department: Physical Education

Tracking Number: H-21388

Study Title:

Test Re-test Reliability of the UNC Functional Performance Test

Co-Investigator(s):

N. Regina Hash, BA, ATC

Sponsor

\section{Contact Persons}

For more information about this research, you can contact N. Regina Hash,ATC at (919) 619-7055 or at nhash@mix.wvu.edu or, the principle investigator, Michelle A. Sandrey, PhD, ATC at (304) 293-3295 Ext. 5220 or at msandrey@mail.wvu.edu. For information regarding your rights as a research subject, you may contact the Executive Secretary of the Review Board at (304) 293-7073.

For information regarding your rights as a research subject, you may contact the Office of Research Compliance at (304) 293-7073.

\section{Introduction}

I, , have been invited to participate in this research study, which has been explained to me by N. Regina Hash, ATC. She is conducting this research under the primary investigator Michelle A. Sandrey, PhD, ATC to fulfill the requirements for a master's thesis in Athletic Training in the College of Physical Activity and Sport Sciences at West Virginia University.

\section{Purposes of the Study}

The purpose of this study is to establish reliability for a lower extremity functional test battery that has components specific to the sport of football. The battery being used is the UNC Functional Performance Test in which the subjects will be asked to demonstrate maximal effort during each testing session for three weeks. Fairmont State University expects to enroll approximately seventy-five subjects from the football team. This study will be conducted at Fairmont State University, 1201 Locust Ave, Fairmont, WV, 26554.

$\overline{\text { Version }} \quad \overline{\text { Date }} \quad \overline{\text { Time }}$




\section{Description of this Study}

\section{Orientation Procedures}

The purpose of this study will be explained to me in depth at an orientation meeting. You will be given an informed consent form as well as a HIPAA form explaining my rights as a research subject. You will also be asked to complete a demographic/inclusion criteria questionnaire. If you are one of the eligible subjects, you will be contacted by the principal researcher and will schedule a time for my testing. You will be asked for your full cooperation and to put forth maximal effort. Your involvement in this will initially take thirty minutes for a training session. This will be followed by meeting with the researcher once a week for twenty minutes over a two week period. Including the training session, you will be part of a three week study. The end of the third testing session will conclude my participation.

\section{Interventions}

You will be asked to complete the UNC Functional Performance Test of which has five components. These tasks include the shuffle box drill, figure eight test, single leg (SL) hop for time, carioca test and SL triple hop for distance. Testing will be administered and supervised by the principal investigator at Fairmont State Univeristy, 1201 Locust Ave, Fairmont, WV 26554. Prior to testing, the device and procedures will be explained to your satisfaction. You will complete the standard warm-up protocol in which you will submaximally run a quarter of a mile followed by a series of static stretches and dynamic flexibility exercises. Static stretches will consist of two repetitions of thirty second holds, one repetition on each side, for the following muscle groups: quardriceps, hamstrings, gastrocnemius/soleus complex, hip abductors, hip adductors, and hip flexors. You will be asked to stretch your quad by standing on one leg while the other leg will be bent. You will stretch your hamstrings by standing and reaching down towards your toes. You will also be asked to stretch your gastroc and soleus by standing with one foot behind the other and leaning forward. You will do this with a straight leg and with a bent knee to target both muscle groups. In order to stretch your hip abductors, you will be asked to sit on the ground with one leg out and draw the opposite leg in while rotating your torso in the opposite direction. You will stretch your hip adductors by completing a lunge maneuver, or a side step with a squat. You will be asked to kneel to stretch your hip flexors in which you will be on one knee and lean forward as far as possible. The dynamic flexibility exercises that you will be asked to complete include lateral hip swings, forward hip swings, hurdle maneuver, side lunges and forward lunges. You will be asked to complete the hip swings and hurdle maneuver for thirty seconds. You will complete both series of lunges over a distance of twenty yards.

The shuffle box drill will require that you complete a sequence of skills in which you will sprint straight ahead, sideshuffle to the left, backpedal, and then sideshuffle to the right in a box pattern. The figure eight drill will require that you sprint and go behind cones in a figure eight pattern changing which side of the cone you will turn on. The pattern will appear diagonal. The single leg hop for time will require that you change feet when changing directions. You will hop for speed on one foot to one cone, quickly change directions in addition to the hopping foot and go back to the starting cone. The carioca step is a sideways movement pattern. Your left foot crosses in front of the right, the right foot steps right, the left foot crosses behind the right, and the right foot steps right. You will complete this pattern continuously for fifteen yards and come back to the starting cone with the opposite lead foot. Lastly, you will

\section{$\overline{\text { Version }} \quad \overline{\text { Date }} \overline{\text { Time }}$}


complete the single leg triple hop for distance in which you will jump off one foot and land on the same foot three times before both feet come in contact with the ground. You will not be allowed to use your hands. A two minute rest period will separate the submaximal and maximal attempts. You will be given thirty seconds rest between each task. Following the completion of all five tasks, results will be recorded on a data sheet. If all data has been correctly recorded, your testing session will be completed. At this time you will be asked by the primary researcher for any questions or comments. The cool down period will consist of a . 25 mile walk followed by the same static stretches that will be completed during the warm-up. There will be no need for you to repeat the dynamic exercises at this time.

\section{Risks and Discomforts}

There are no known or expected risks from participating in this study. The only known or expected discomfort may be mild muscle soreness in your lower extremity. However, stretching and warm-up will be performed prior to and after testing. Should any injury occur, you understand that $\mathrm{N}$. Regina Hash, ATC will provide first aid and make any necessary medical referral at your expense.

\section{Alternative}

You do not have to participate in this study.

I understand that I do not have to participate in this study. No negative actions will be taken against me if I choose not to participate.

\section{Benefits}

You understand that this study is not expected to be of direct benefit to you, but the knowledge gained may be of benefit to others.

\section{Financial Considerations}

You will receive no financial remuneration for completing this study.

\section{Confidentiality}

You understand that any information about you obtained as a result of your participation in this research will be kept as confidential as legally possible. Identifying information on the informed consent form and demographic/history questionnaire will be kept confidential by assigning a code number to each informed consent form and demographic/injury history questionnaire. You understand that your research records and test results, just like hospital records, may be subpoenaed by court order or may be inspected by the study sponsor or federal regulatory authorities (including the FDA if applicable) without my additional consent. In any publications that result from this research, neither your name nor any information from which you might be identified will be published without my consent.

$\overline{\text { Version }} \quad \overline{\text { Date }} \quad \overline{\text { Time }}$




\section{Voluntary Participation}

Participation in this study is voluntary. You understand that you are free to withdraw your consent to participate in this study at any time and that such refusal to participate will not affect your future care, your employee status at Fairmont State University, or your class standing or grades. Refusal to participate or withdrawal will involve no penalty to you. You have been given the opportunity to ask questions about the research, and you have received answers concerning areas you did not understand. In the event new information becomes available that may affect your willingness to continue to participate in this study, this information will be given to you so you may make an informed decision about your participation. Upon signing this form, you will receive a copy.

I willingly consent to participate in this research.

$\overline{\text { Signature of Subject }} \longrightarrow$ Date Time

$\overline{\text { Signature of Principle Investigator }} \quad$ Date $\quad$ Time




\section{Test Re-test Reliability of the UNC Functional Performance Test}

\section{Principal Investigator: Sandrey, Michelle \\ Department: Physical Education \\ Tracking Number: H-21388}

\section{Study Title:}

Test Re-test Reliability of the UNC Functional Performance Test

\section{Co-Investigator(s):}

N. Regina Hash, BA, ATC

\section{Sponsor}

Subject's Name:

ID Number:

We know that information about you and your health is private. We are dedicated to protecting the privacy of that information. Because of this promise, we must get your written authorization (permission) before we may use or disclose your protected health information or share it with others for research purposes. This form gives that permission. It also helps us make sure that you are correctly told how this information will be used or disclosed. Please read the information below carefully before signing this form. Please ask any questions you may have about this form or its uses. You can decide to sign or not to sign this authorization form. However, if you choose not to sign this authorization form, you will not be able to take part in the research study. Whatever choice you make about this research study, it will not have an effect on your access to medical care.

\section{USE AND DISCLOSURE COVERED BY THIS AUTHORIZATION}

DO NOT SIGN A BLANK FORM. You or your authorized representative should thoroughly read the information below before signing this form.

Who will disclose, receive, and/or use the information?

This form will authorize the following person(s), class(es) of persons, and/or organization (s) to disclose, use, and receive the information*: WVU, Michelle A. Sandrey, PhD, ATC and N. Regina Hash, BA, ATC.

*If, during the course of the research, one of the companies or institutions listed above merges with, or is purchased by, another company or institution, this authorization to use or disclose protected health information in the research will extend to the success or company or institution.

What information will be used or disclosed?

A self-report demographic history that includes information on position group, height, weight, and past medical history involving injury to the lower extremity. 


\section{SPECIFIC UNDERSTANDINGS}

By signing this research authorization form, you give permission for the use and/or disclosure of your protected health information described above. The purpose for the uses and disclosures you are authorizing is to carry out the research study explained to you during the informed consent process. It is also to ensure that the information relating to the research is available to all parties who may need it for research purposes. Your protected health information may be used as necessary for your research-related treatment or to collect payment for your research related treatment (when applicable). It may also be used to run the business operations of the institution.

This information may be redisclosed or used for other purposes if a recipient described in this form is not required by law to protect the privacy of the information. You have a right to refuse to sign this authorization. Your health care outside the study, the payment for your health care, and your health care benefits will NOT be affected if you do not sign this form. However you will NOT be able to take part in the research study described in this authorization if you do not sign this form.

If you sign this authorization, you will have the right to cancel it at any time, except to the extent that UHA or UHA Affiliated, WVU, WVU Hospitals has already taken action based upon your authorization or needs the information to complete analysis and reports of data for this research study. To cancel this authorization, please write to the Principal Investigator, Michelle A. Sandrey, at: Mailbox \# PO Box 6116.

You will be allowed to see or copy the information described on this form as long as the research is in progress, but you have a right to see and copy the information upon completion of the research in accordance with hospital policies.

The members and staff of any Institutional Review Board (IRB) that oversees this research study. The Principal Investigator: Michelle A. Sandrey, Phd, ATC, the Co-Investigator: N. Regina Hash, ATC, Members of UHA or UHA Affiliated, WVU, WVU Hospitals, administrative staff responsible for administering clinical trials and other research activities, including the Clinical Trials, Office/Office of Research and other -research activities, including the Clinical Trials, Office/Office of Research and Sponsored Programs.

You have a right to receive a copy of this form after you have signed it.

Expiration Date: None

THE SUBJECT OR HIS/HER AUTHORIZED REPRESENTATIVE MUST BE PROVIDED WITH A COPY OF THIS FORM AFTER IT HAS BEEN SIGNED. 


\section{SIGNATURE}

I have read this form and all of my questions about this form have been answered. By signing below, I acknowledge that I have read and accept all of the above.

Signature of Subject or Authorized Representative

Date

Print Name of Subject or Authorized Representative

Print Name of Individual Explaining this Research Authorization Form

\section{CONTACT INFORMATION}

The contact information of the subject or authorized representative who signed this form should be filled in below.

Address:

Telephone

Daytime:

Evening: 
Code:

Age:

Position:

Year in School: Freshman / Sophomore / Junior / Senior / Graduate Student

Year on Field:

Height:

Weight:

Injury History

1. Have you had a lower extremity injury within the past six months? Yes/No

If yes, Please

explain:

2. Have you had surgery to the lower extremity within the past six months? Yes/No

If yes, Please

explain:

3. Have you had any neurological disorders within the past six months? Yes/No

If yes, please

explain:

4. Have you had any vestibular (balance) disorders within the past six months? Yes/No

If yes, please

explain:

5. Have you had visual disorders within the past months? Yes/No

If yes, please

explain:

6. Are you currently involved in any of the following physical activities?

Weight Training/Cardiovascular Training/Other

If yes, please explain what physical activity you are involved in and how often you are involved in each activity: 
The Balance Latin Squre is a matrix in which the same number is not repeated in each row nor each column. For the purpose of this study, the first row indicated a pre-assigned test component with the first column representing an arbitrary number assigned to a subject. (The components were assigned task \#s based on the order of their appearance. Task \#1 was the shuffle box, \#2 was the figure 8, \#3 was the SL hop for time, \#4 was the carioca, and \#5 was the SL triple hop.) The row that started with the subjects' number indicated the order in which the subject completed the tasks. Once all five numbers had been used, the subjects were reassigned to numbers 1-5 again.

\begin{tabular}{|l|l|l|l|l|}
\hline 1 & 2 & 3 & 4 & 5 \\
\hline 1 & 2 & 3 & 4 & 5 \\
\hline 2 & 3 & 4 & 5 & 1 \\
\hline 3 & 4 & 5 & 1 & 2 \\
\hline 4 & 5 & 1 & 2 & 3 \\
\hline 5 & 1 & 2 & 3 & 4 \\
\hline
\end{tabular}

For example, subject \#3 would start with test component \#4 first and then complete \#5. The third task for this participant would be task \#1 and would then finish with tasks \#2 and \#3. 
Table C5. Data Collection Sheet

\section{Data Collection Sheet for UNC Functional Performance Test}

Subjects Number:

Age:

Position:

Height:

Weight:

Dominant Lower Extremity: Right / Left

Week: 2 / 3

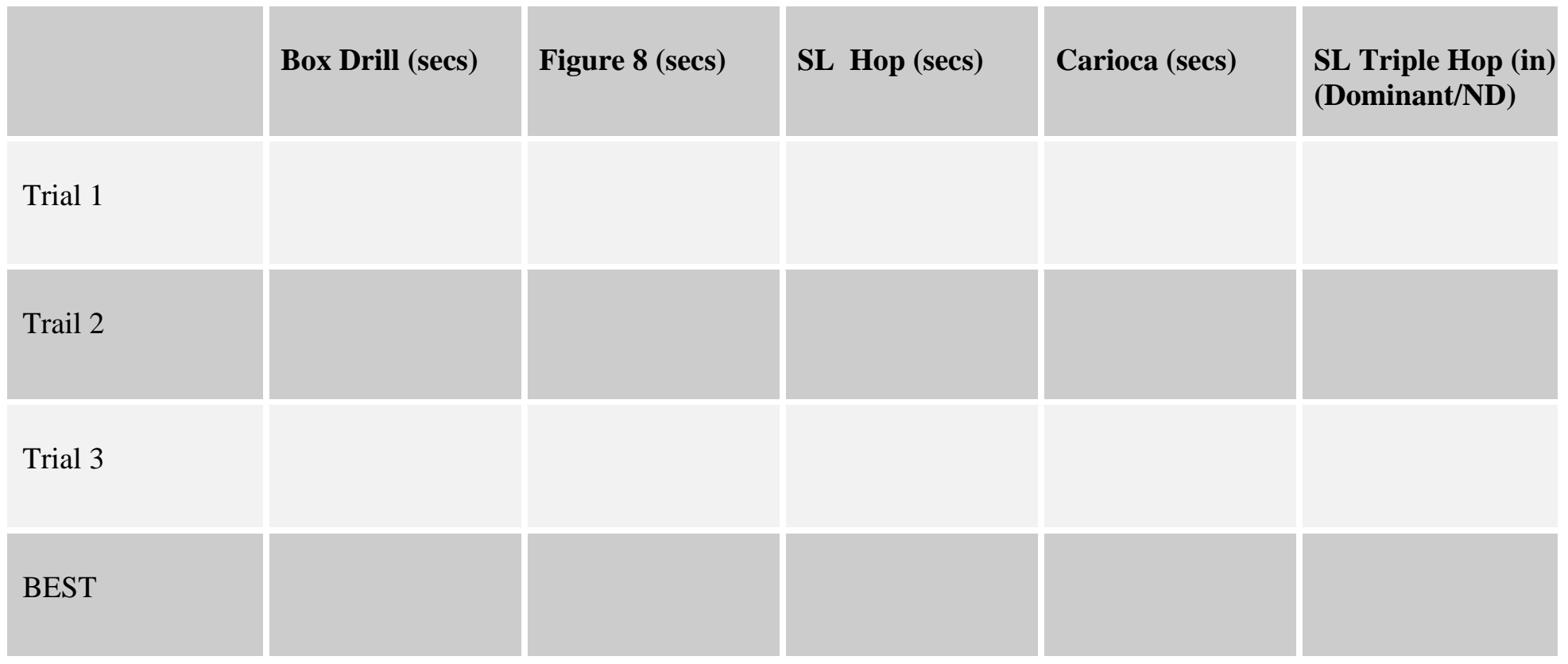

Comments: 
Figure C1. Standardized Warm-up Protocol

1. Athlete jogged $1 / 4$ of a mile.

2. Static stretches were completed following the jog. All stretches consisted of two repetitions of a static hold of thirty seconds, one repetition on each side, for the following muscle groups:

- Quadriceps

- Hasmstrings

- Gastroc/Soleus Complex

- Hip Abductors

- Hip Adductors

- $\quad$ Hip Flexors

3. Dynamic flexibility exercises were then completed by the athlete. Maneuvers included the following and were completed for thirty seconds:

- Hip Abduction to Hip Adduction

- Hip Flexion to Extension

- Hurdler Maneuver

- Deep Side Lunge to Right and Left (covering 20 yards)

- Forward Lunge (covering 20 yards) 
Specific Instructions for Static Stretches:

Quadriceps:

1. The athlete was instructed to stand up and lift one leg up by bending at the knee so that the heel was touching the buttocks.

2. The knees were kept together and hips were pushed forward.

3. This was held for thirty seconds and then the athlete was asked to switch legs and repeat.

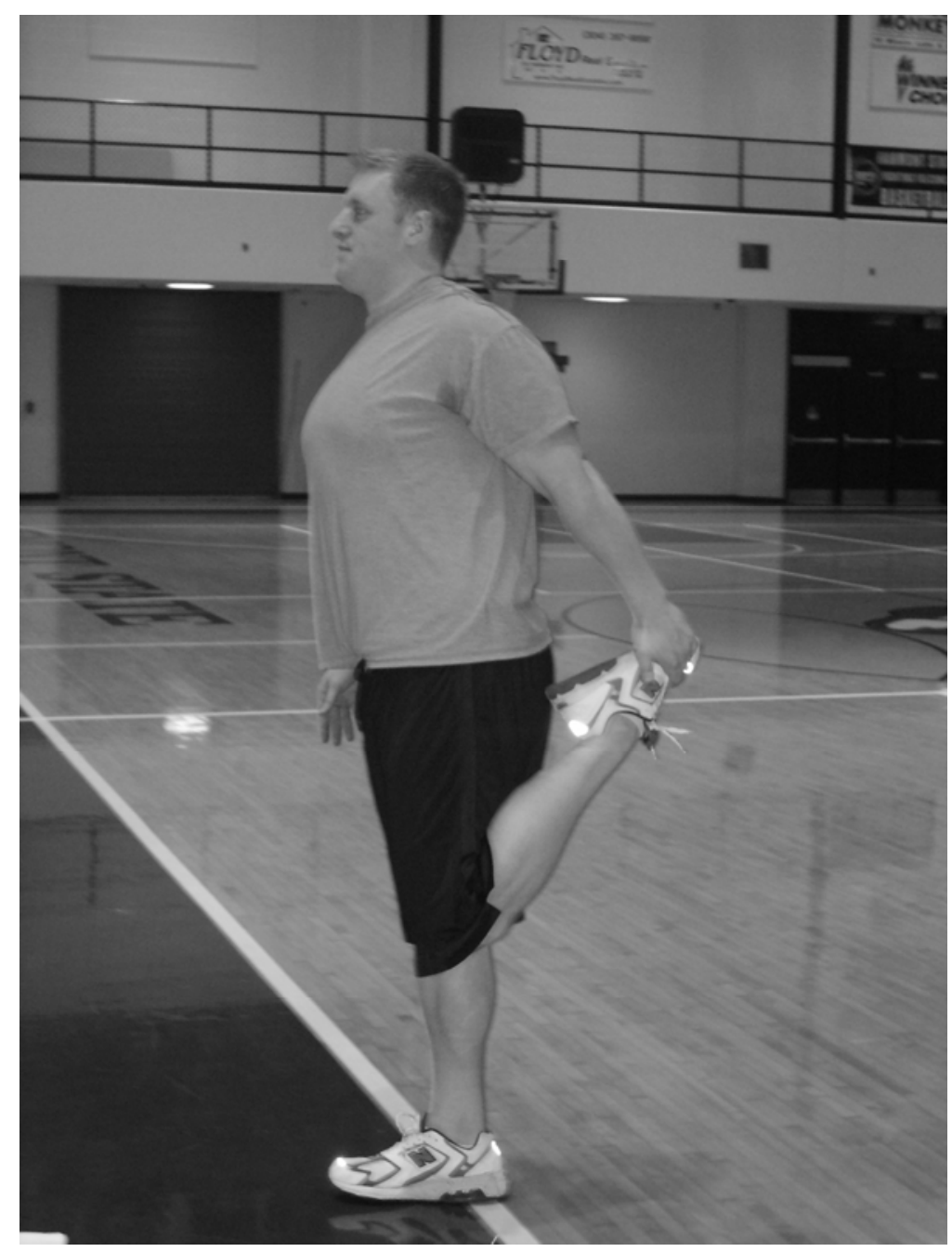




\section{Hamstrings:}

1. The athlete kept one leg bent and one leg straight. Weight was on the bent leg.

2. The head remained in an upright position and the back stayed straight.

3. This was held for thirty seconds and then the athlete was asked to switch legs and repeat.

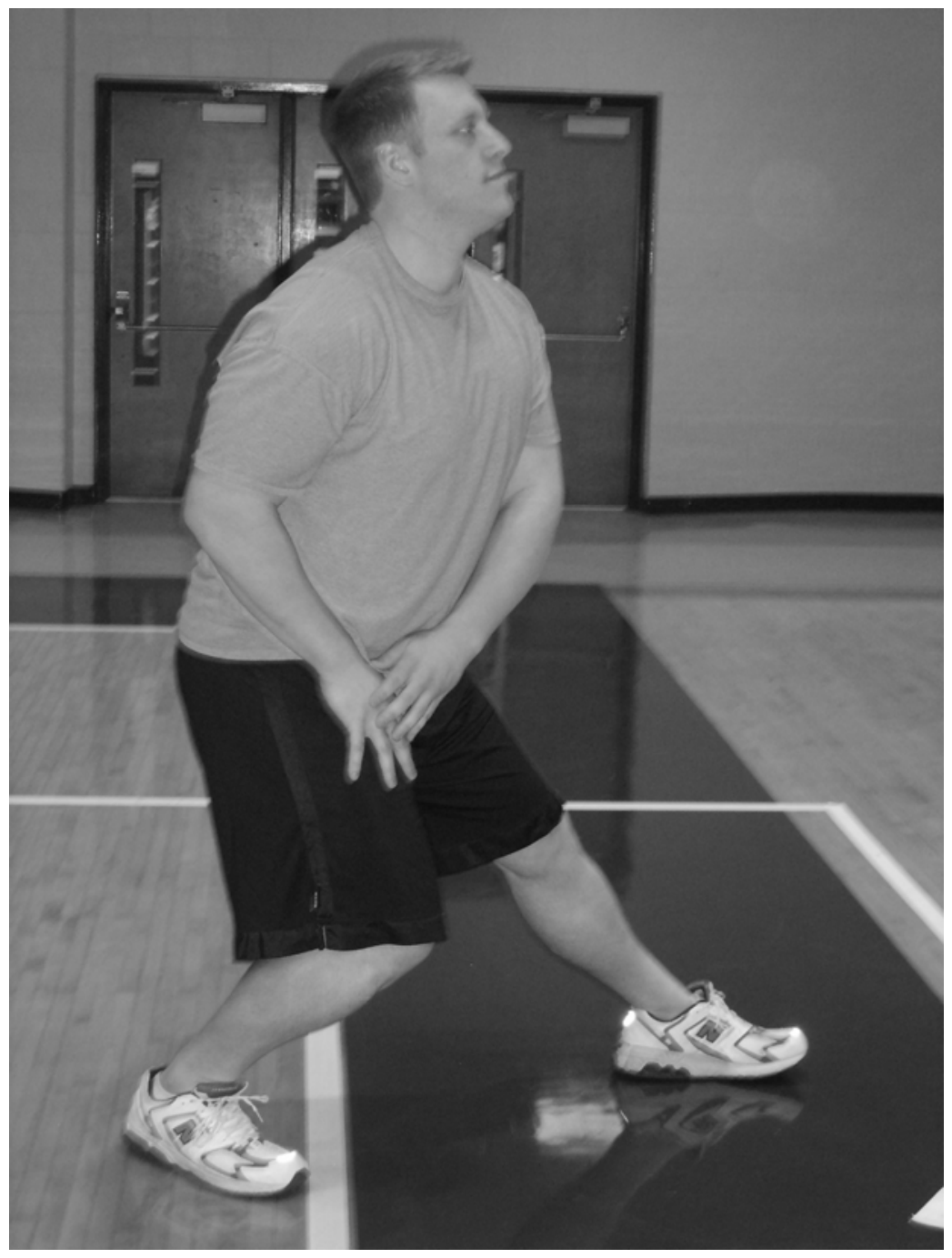




\section{Gastroc/Soleus Complex:}

1. The athlete leaned on the wall or another item for balance and placed one foot forward and the knee bent and placed one foot back with the knee straight. The back heel was kept on the floor while the front knee was bent.

2. This was held for thirty seconds and then the athlete modified this position by bending the back knee. Upon completion of these two stretches, the athlete was instructed to switch which foot was forward and which foot was back and repeat.

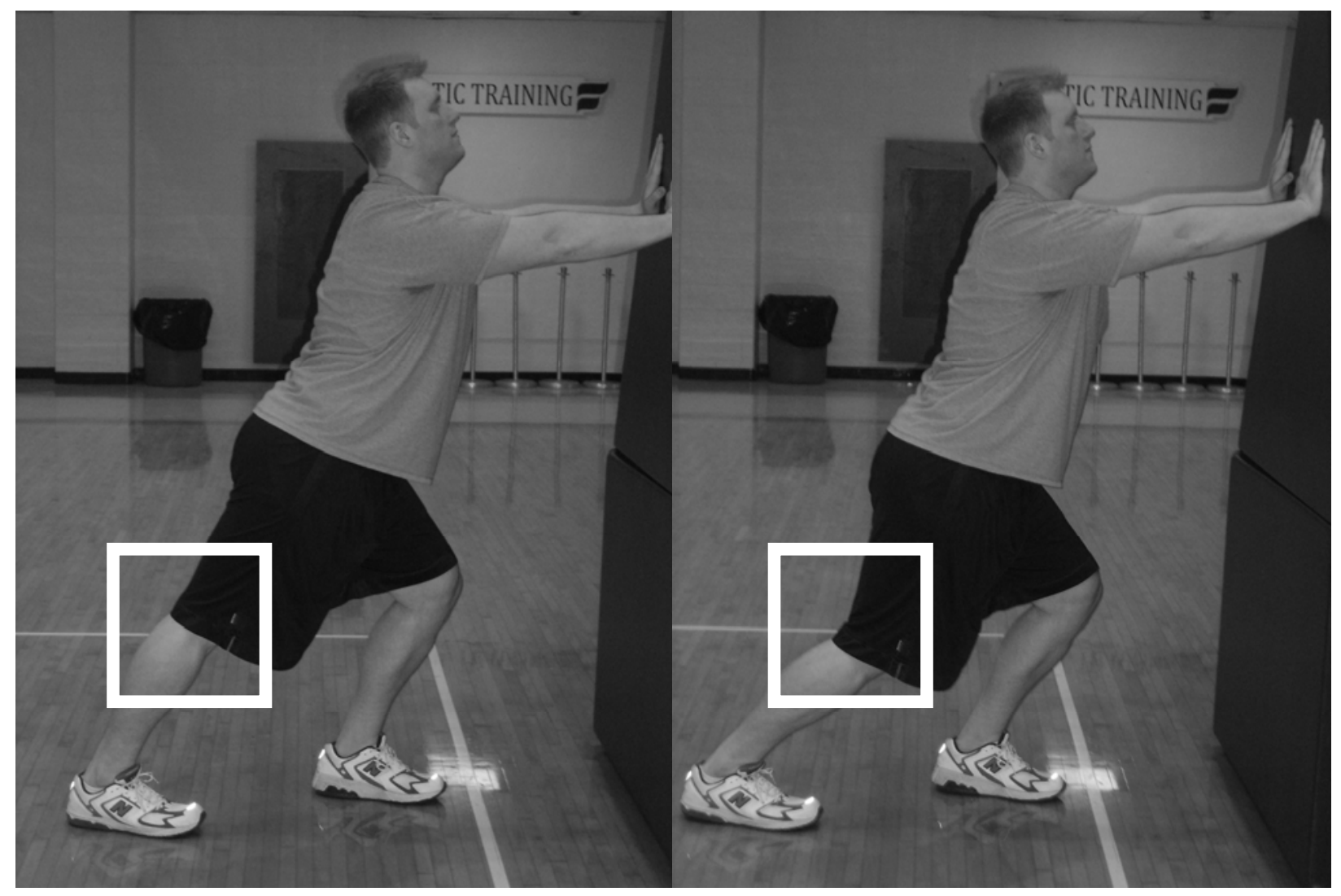




\section{Hip Abductors}

1. The athlete sat with both legs out in front.

2. The athlete then brought one leg over the other and then rotated the torso in the opposite direction.

3. This was held for thirty seconds and then the athlete was asked to switch legs and repeat.

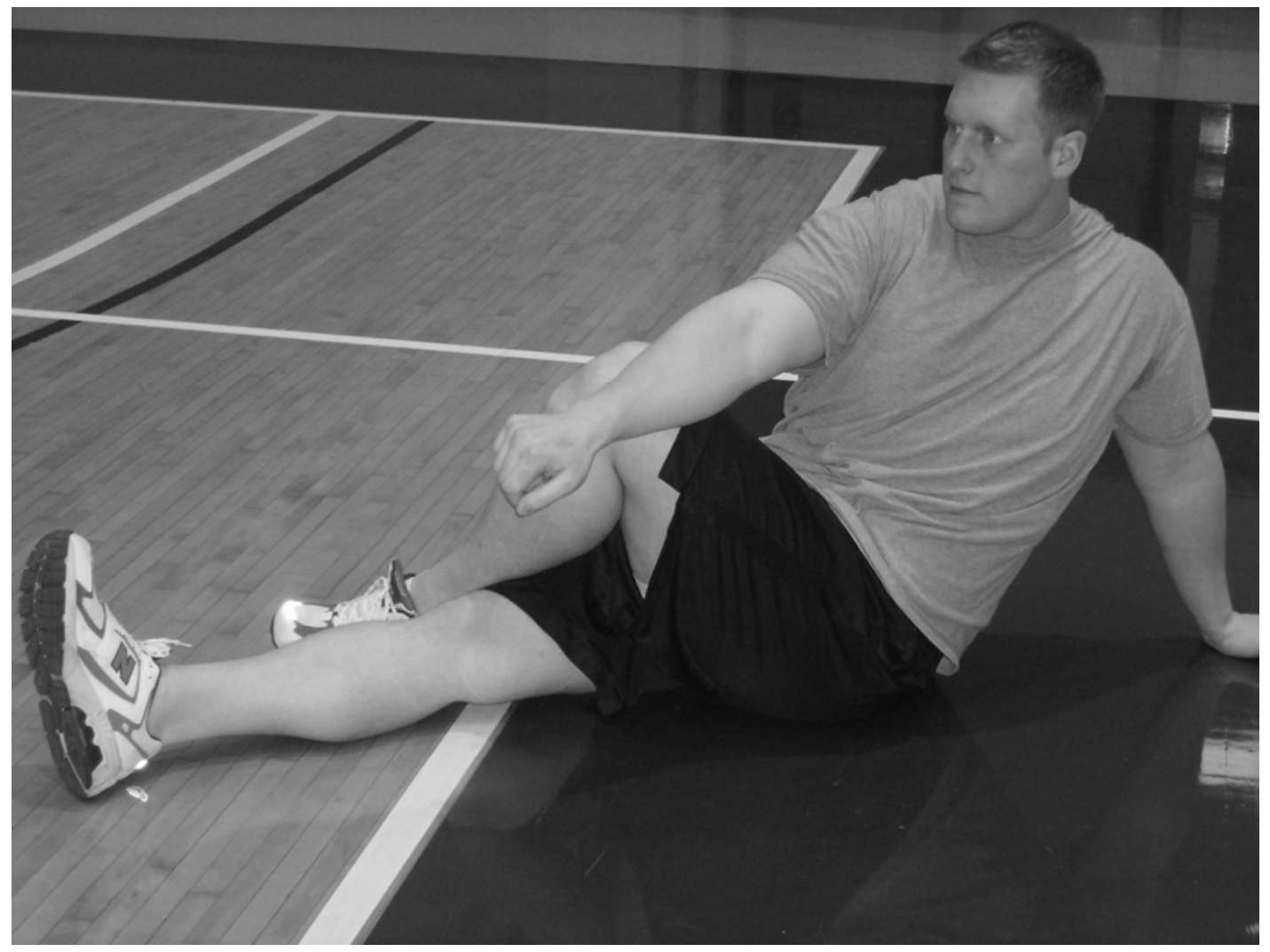




\section{Hip Adductors}

1. This stretch began with one leg straight and the opposite leg bent. Both feet were pointed straight ahead.

2. The athlete slowly moved in a sideways motion toward the bent leg until a stretch was felt in the straight leg groin area.

3. This was held for thirty seconds and then the athlete was instructed to switch legs and repeat.

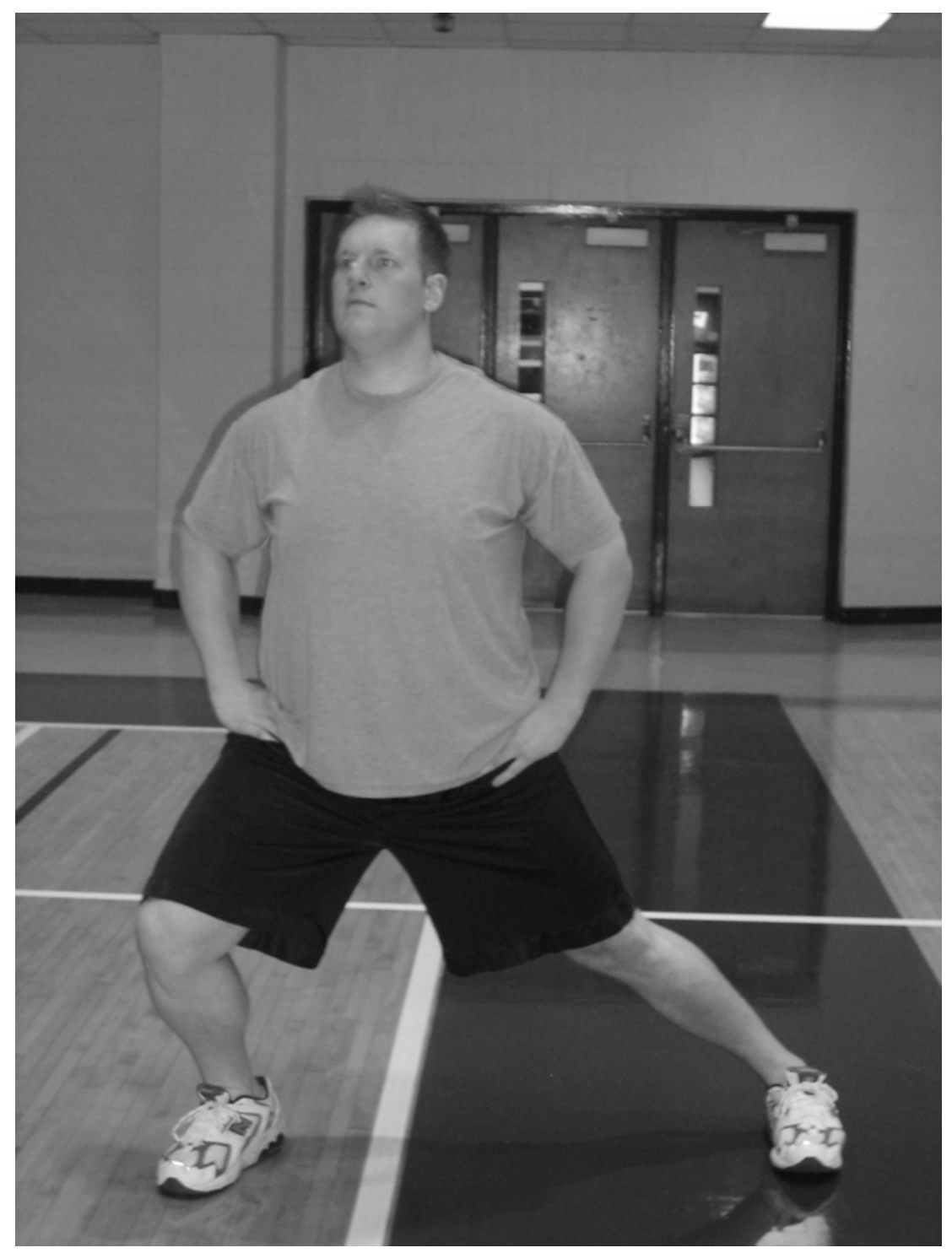




\section{Hip Flexors}

1. This stretch was completed by kneeling on one leg and pushing the hips forward.

2. The front foot was kept stationary and an arch was not present in the back.

3. This was held for thirty seconds and then the athlete was asked to switch legs and repeat.

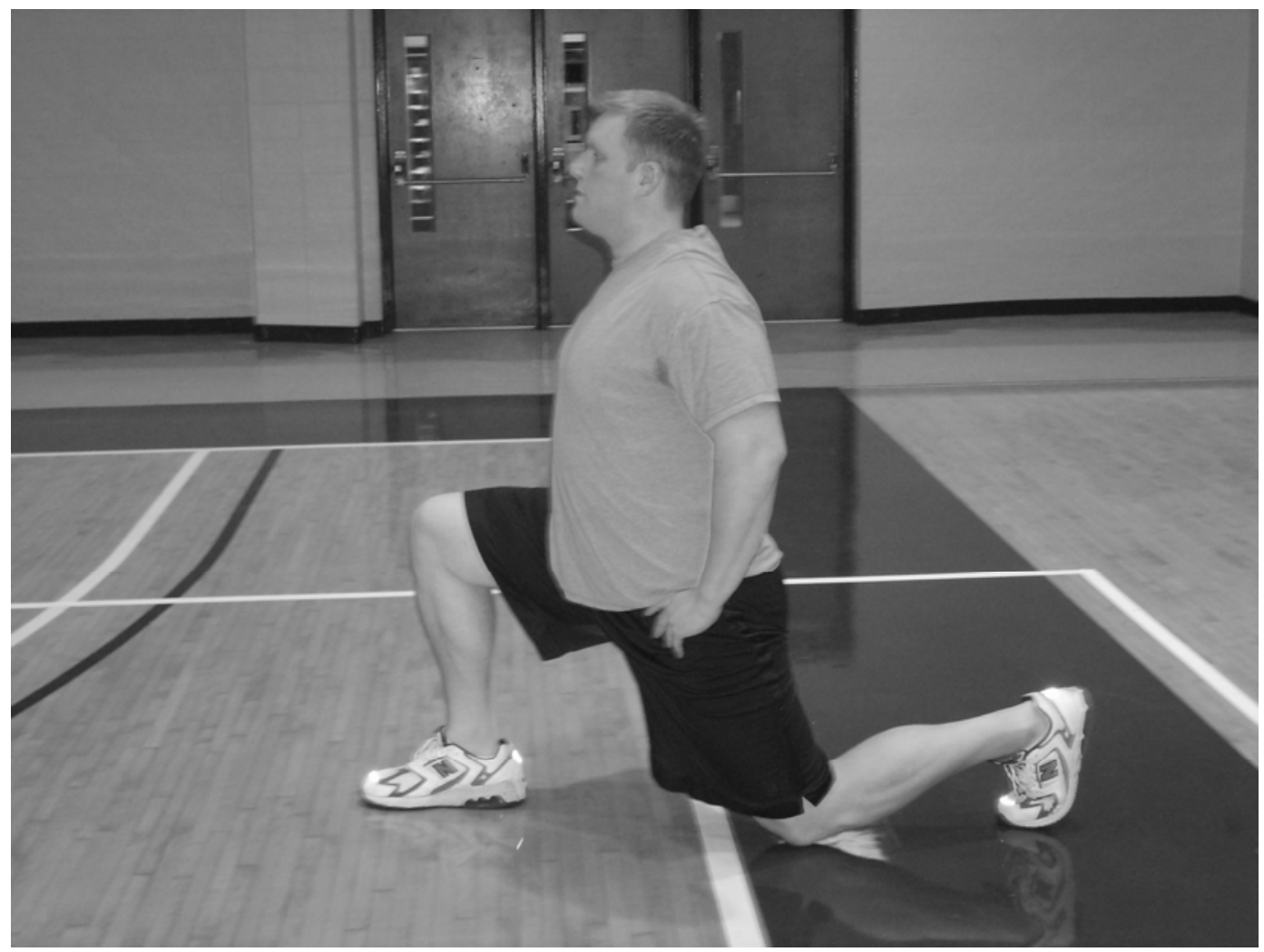


Specific Instructions for Dynamic Flexibility Exercises:

Hip Abduction to Adduction:

1. Subject started by standing on one leg with upper extremity supported against a wall for balance.

2. The non-stance leg was then swung back and forth between hip abduction and adduction.

3. This was completed continuously for thirty seconds.

4. The athlete then switched legs and repeated the same motion for thirty seconds.

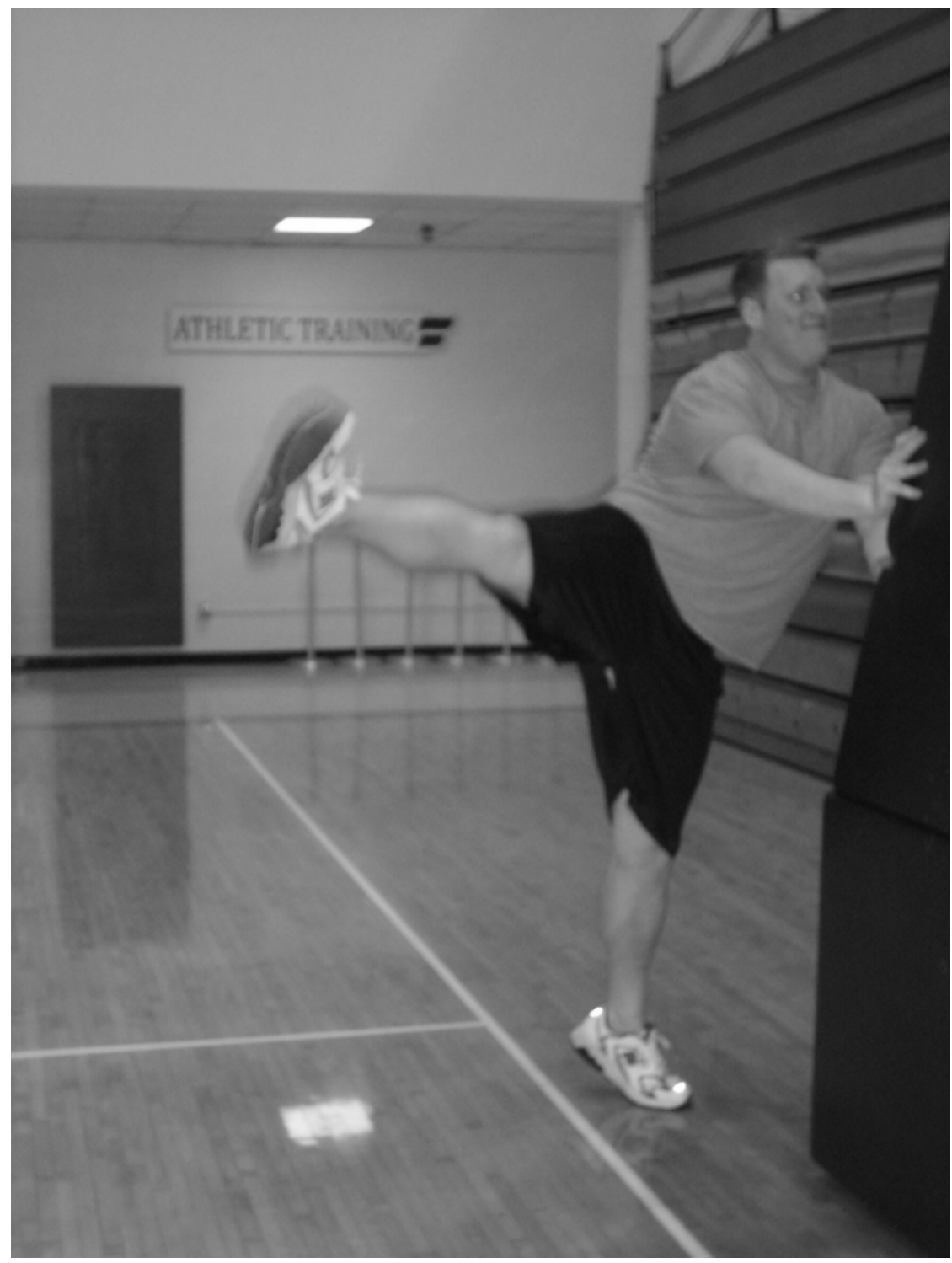




\section{Hip Flexion to Extension:}

1. Subject started by standing on one leg with upper extremity supported against a wall for balance.

2. The non-stance leg was swung back and forth between hip flexion and hip extension.

3. This was completed continuously for thirty seconds.

4. The athlete then switched legs and repeated the same motion for thirty seconds.

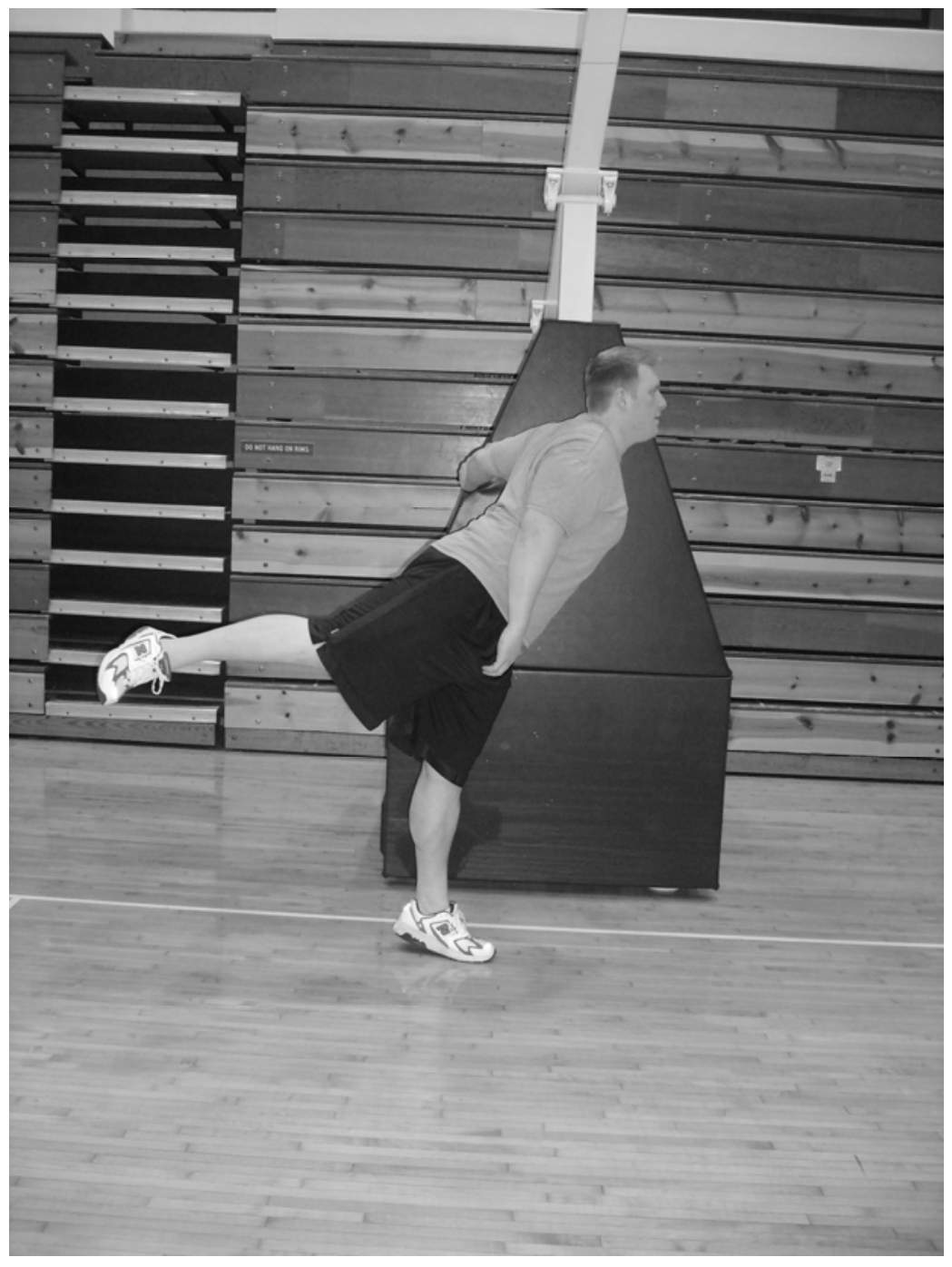


Hurdler Maneuver “Open and close the gait”:

1. The athlete marched forward bringing lead leg up into hip flexion and abducted hip.

2. The ankle remained dorsiflexed until the leg came back to midline.

3. When stepping forward, the athlete switched extremities and continued with same movement pattern.

4. Avoiding excessive trunk lean and maintaining alignment of stance leg were important.

5. This was completed continuously for thirty seconds.

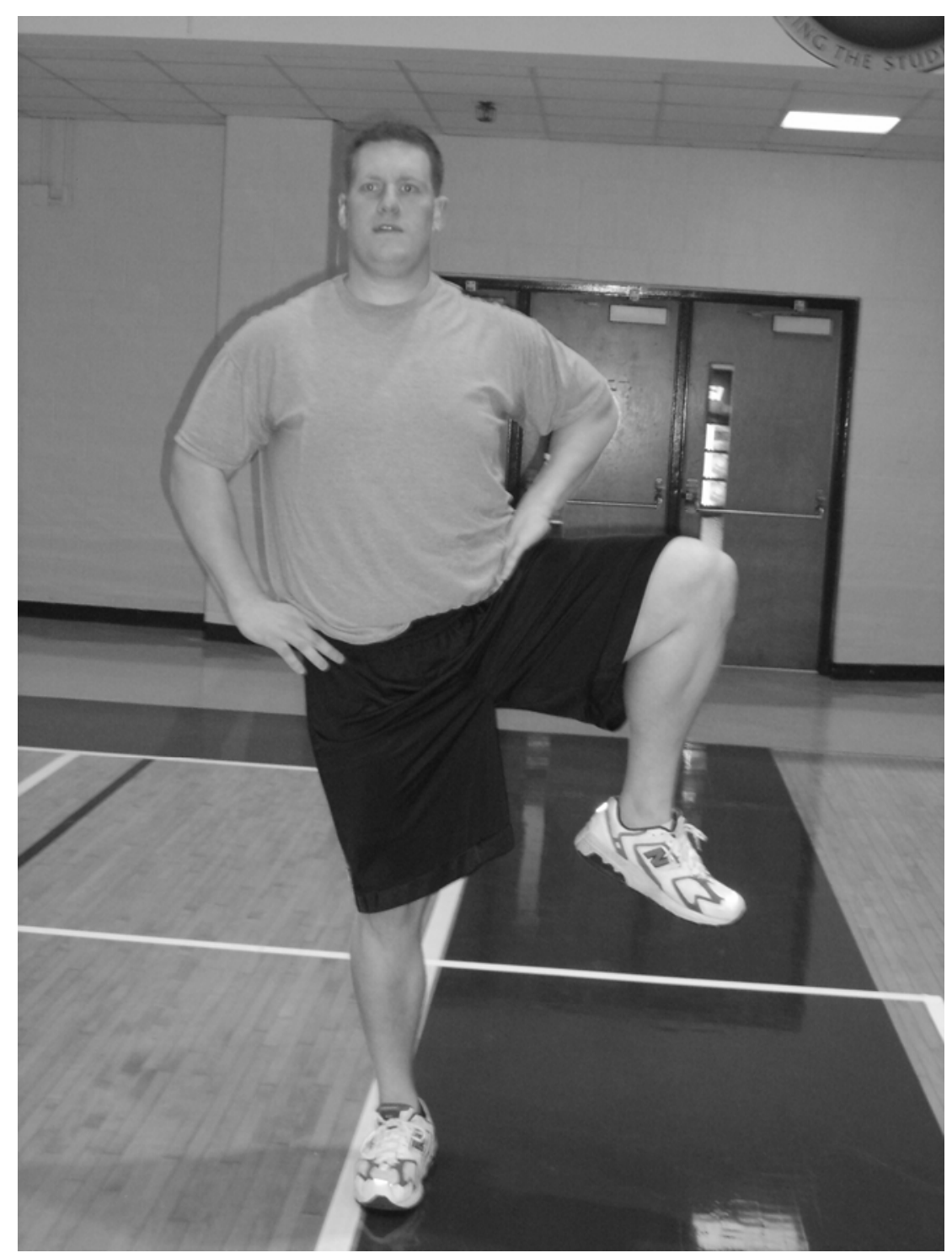


Side Lunge:

1. Athlete started from a standing position and took a large step to the right with the right foot and lowered himself into a deep squat.

2. The athlete then returned immediately to a standing position and stepped again with the right foot and continued with same movement pattern. This was continued for twenty yards.

3. The athlete then changed directions while facing the same way with lead foot now being the opposite as before. This was again continued for twenty yards.

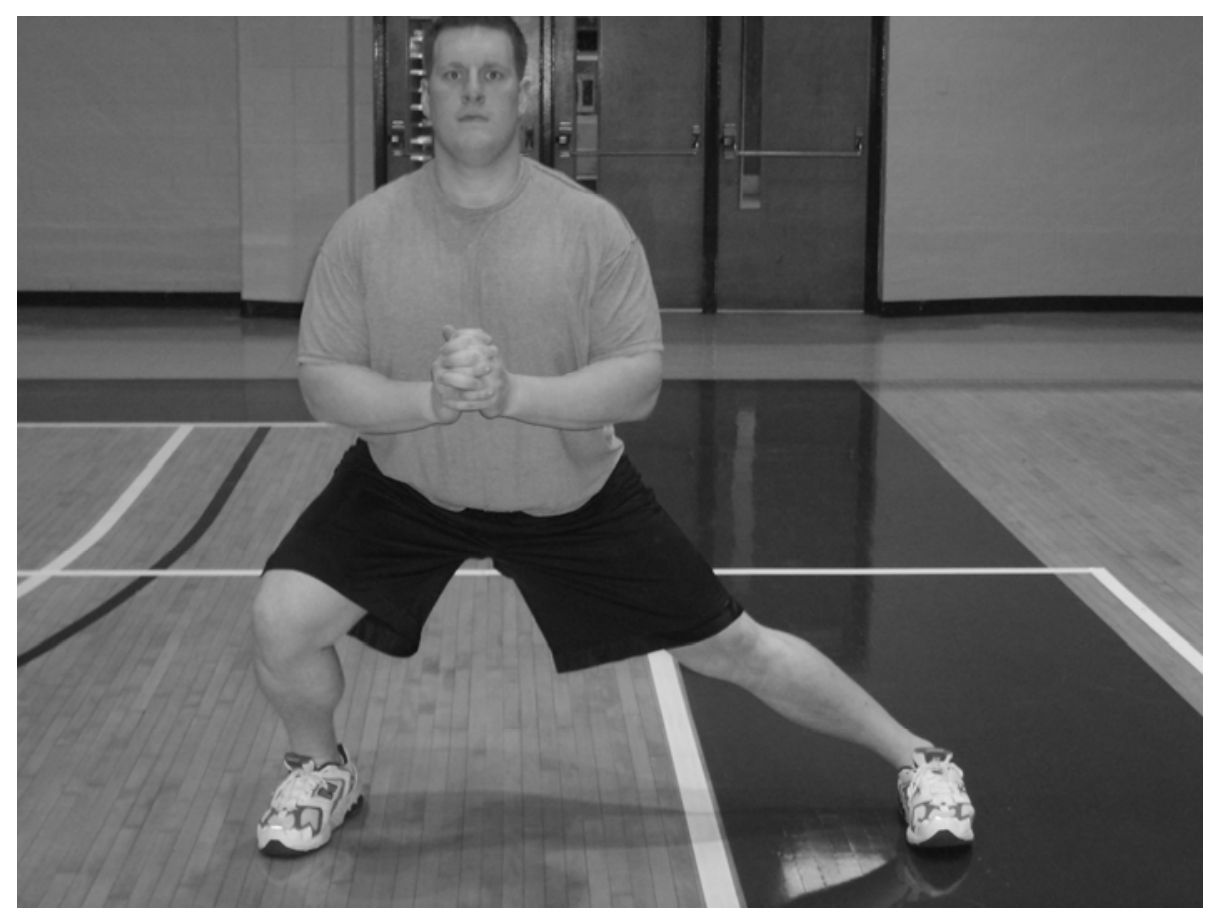




\section{Forward Lunge:}

1. The athlete started from a standing position and took giant steps forward.

2. With contact of each foot, the athlete lunged as far forward as they could each time.

3. This same pattern was continued for twenty yards.

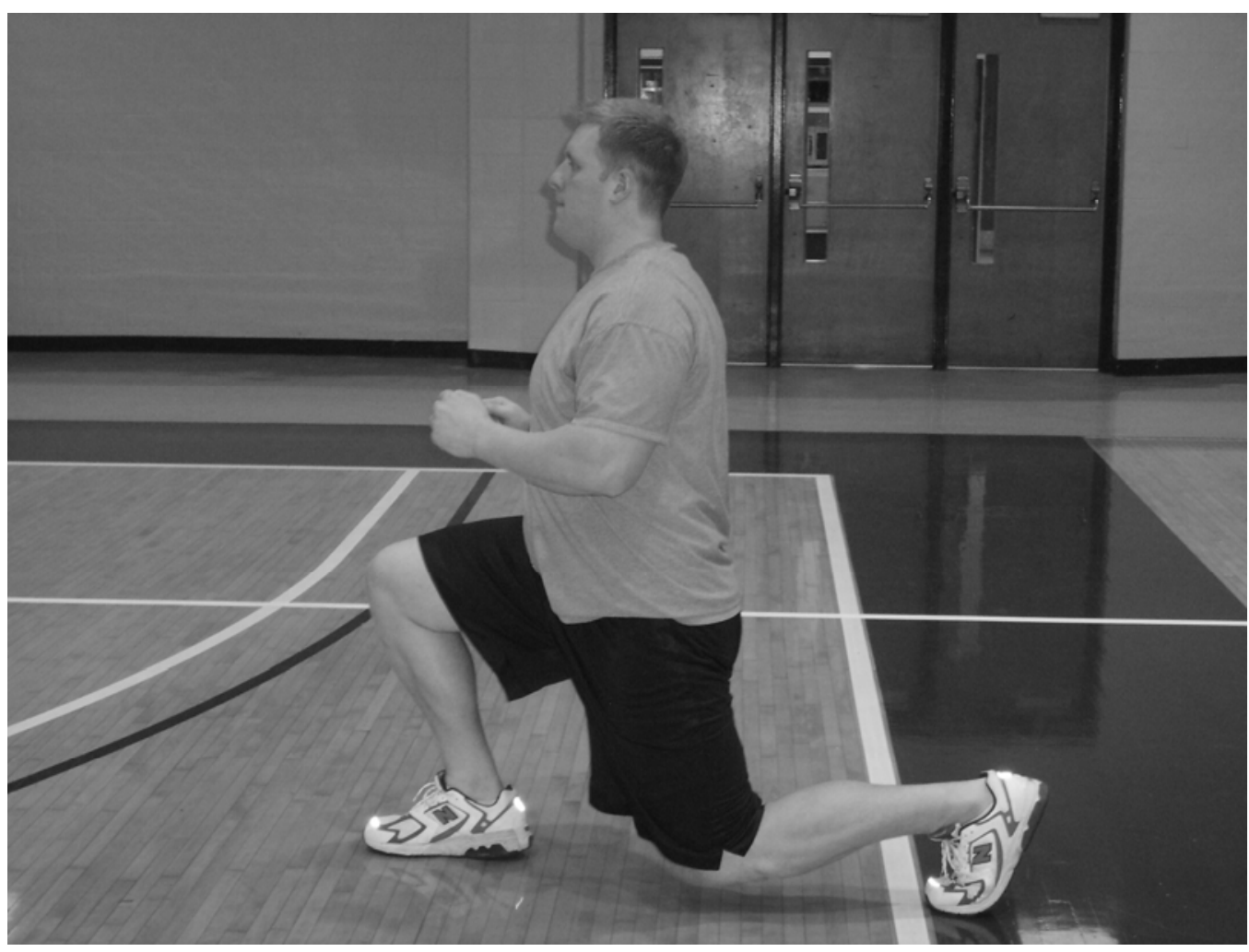



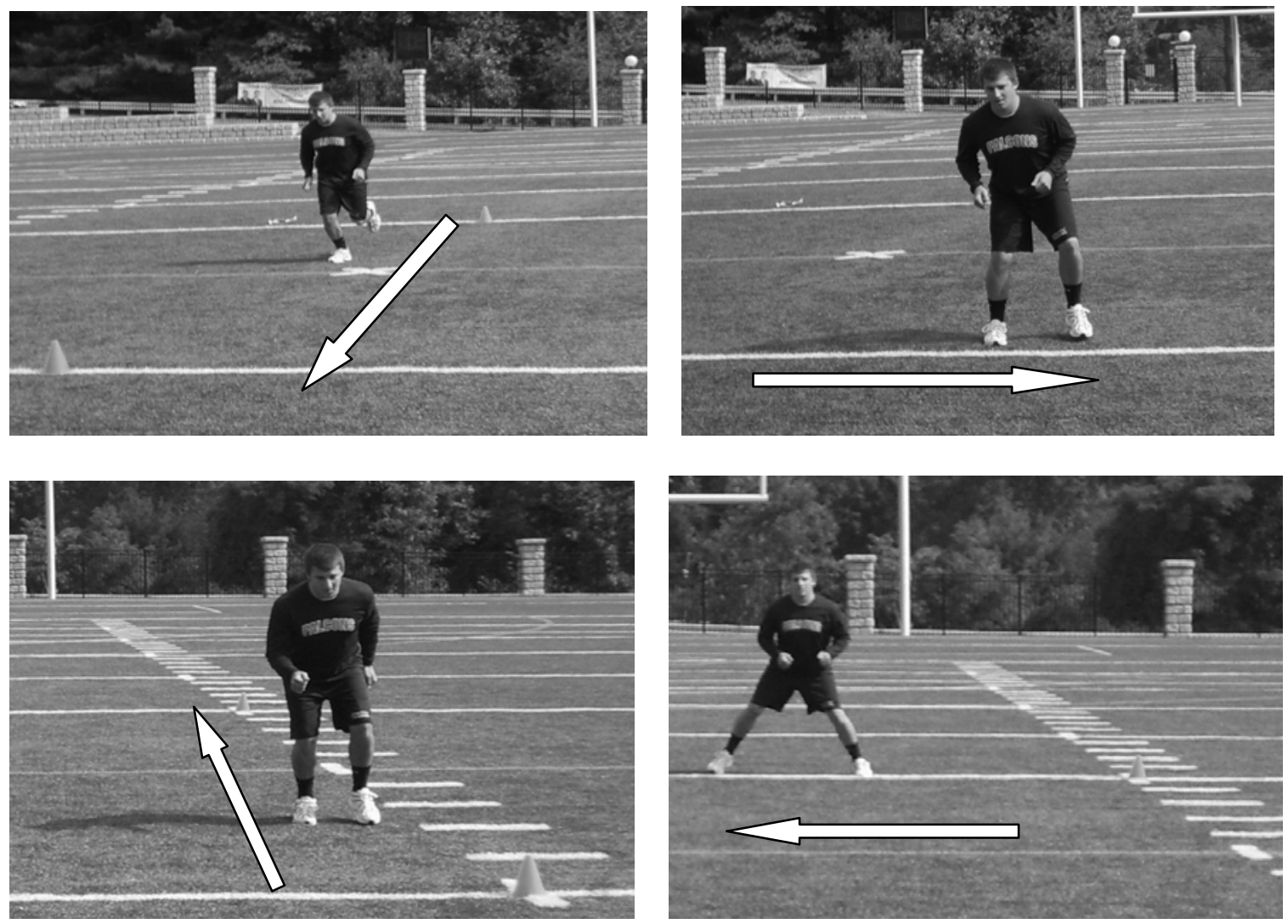

\section{Shuffle Box}

1. Set up: 4 cones outlining a 10 yard $\mathrm{x} 10$ yard Box

2. Test: Athlete was asked to sprint from cone \#1 to cone \#2, shuffle to cone \#3, back pedal to cone \#4 and shuffle back to cone \#1 as fast as they could.

3. Time was recorded to .01 second. Time started on their movement and ended when they returned to the starting position.

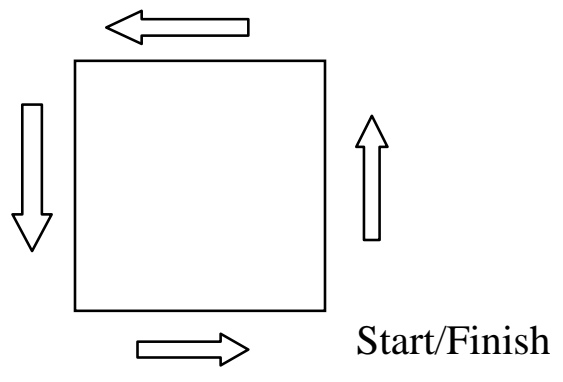



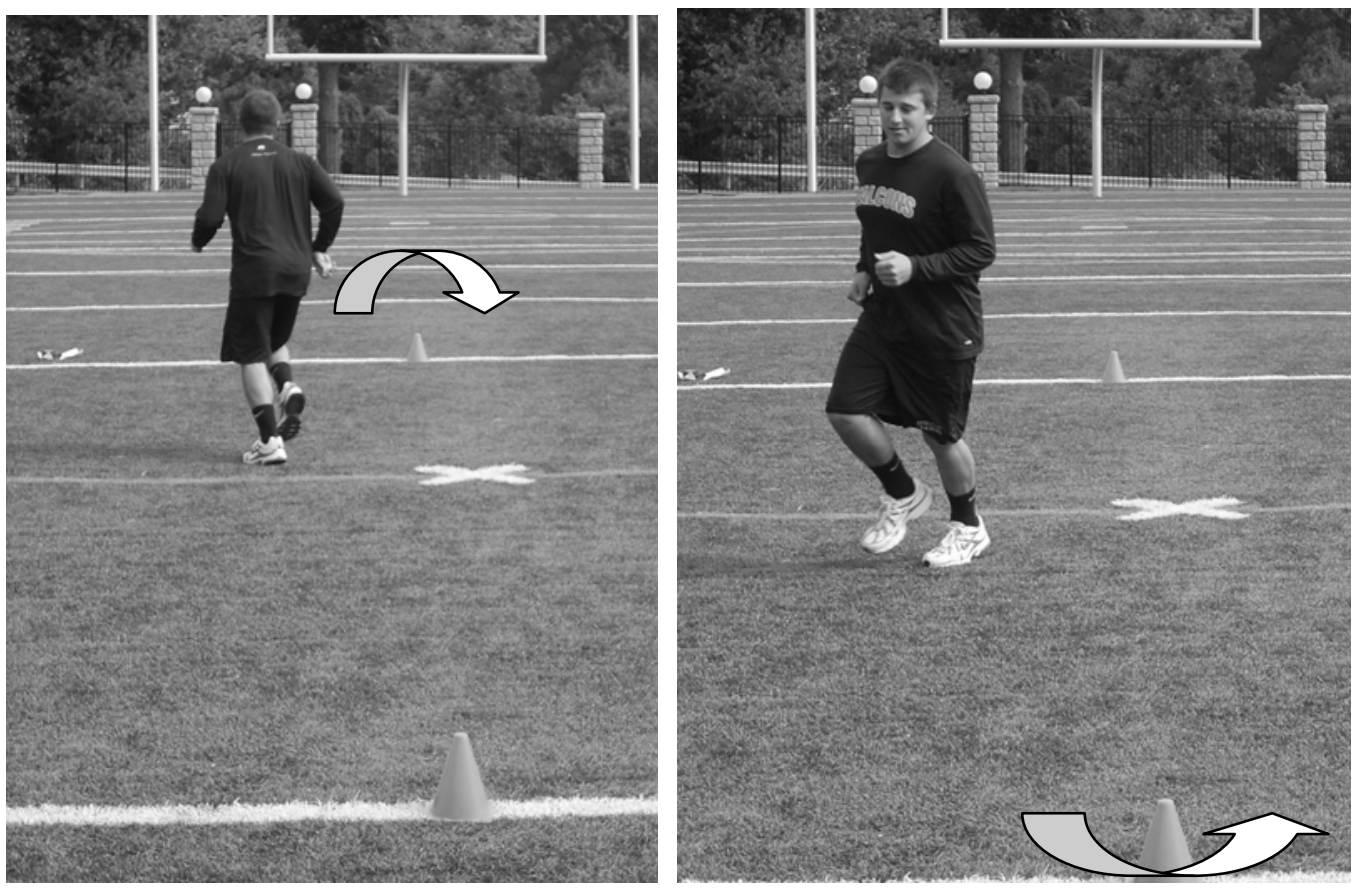

Figure 8:

1. Set up: 2 cones 10 yards apart

2. Test: Athlete ran three consecutive Figure 8 patterns around the cones. Pattern appeared diagonal until turn was made.

3. Recorded to .01 second. Time initiated upon the athlete's first movement and terminated upon return to the starting point on the third series.

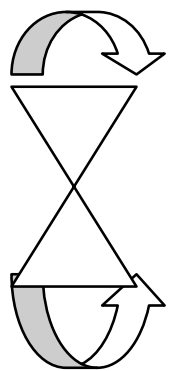

Start/Finish 

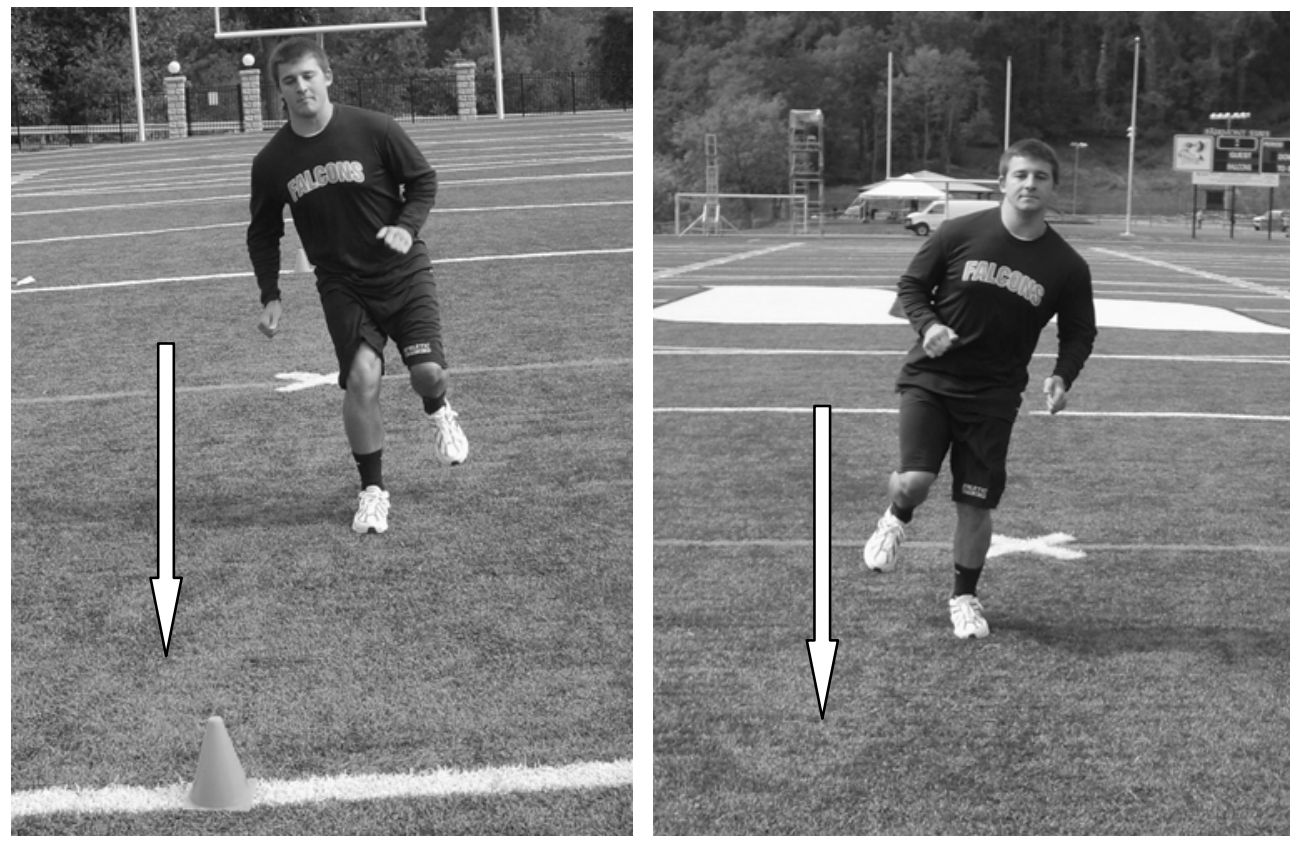

Hop Test:

1. Set up: Two cones 10 yards apart

2. Test: Athlete hopped on one for foot 10 yards then quickly changed directions and hopped back on opposite foot as fast as they could.

3. This task was timed for speed and was recorded to the nearest .01 second. Time started upon the athlete's first movement and ended as they crossed the point in which they started.

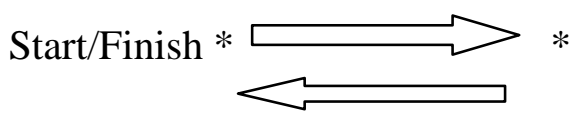



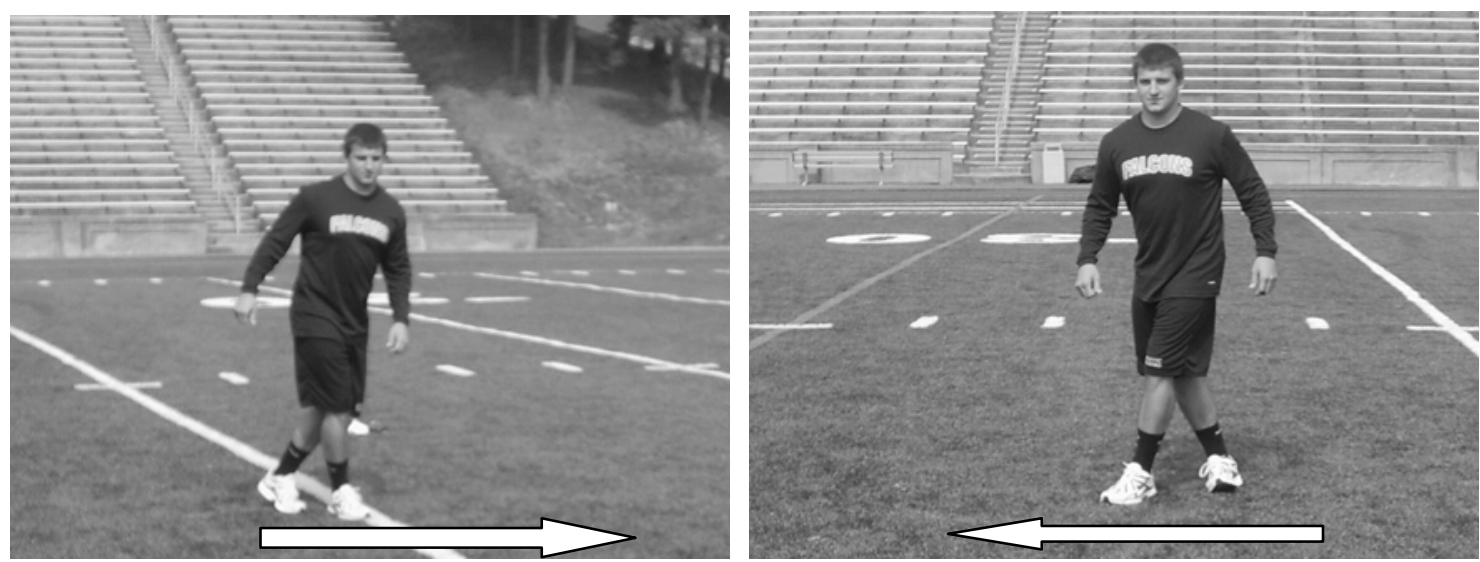

\section{Carioca Test:}

1. Set Up: Two cones 15 yards apart.

2. Test: Athlete performed carioca crossover run from cone \#1 to cone \#2, touched the line with their foot and performed carioca run back to the start cone. (The carioca step is a sideways movement pattern. The left foot crosses in front of the right, the right foot steps right, the left foot crosses behind the right, and the right foot steps right. The pattern was repeated in a continuous manner for fifteen yards.)

3. The athlete touched the line and returned to the starting cone completing the carioca step with a different lead foot. The athlete faced the same direction the entire time.

4. Timed to nearest .01 second and was initiated upon the first movement made by the athlete and ended as they returned to their starting position.

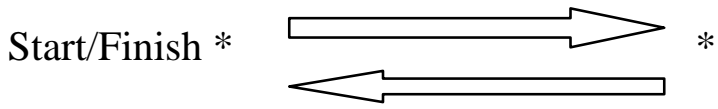



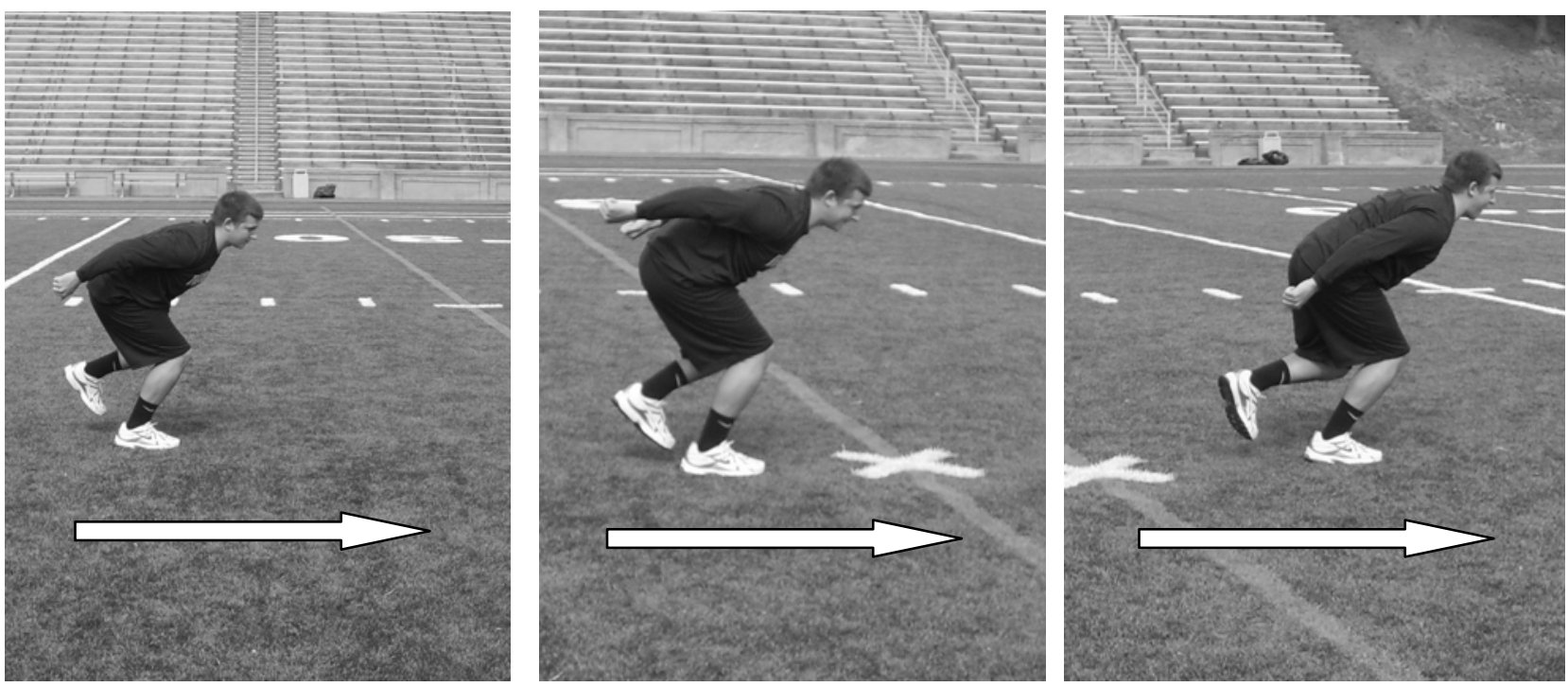

Single Leg Triple Hop:

1. Set Up: Measured for distance from starting cone

2. Test: Athlete performed SL triple hop by remaining on the same leg for three consecutive jumps.

3. Test was repeated again on opposite foot to allow for bilateral comparison.

4. Distance was measured to nearest inch. Distance covered was assessed as initial toe position at the start of the athlete's first jump to the position of the toe upon the completion of the third jump. (Athlete was not allowed to use hands as this generated momentum.) 


\section{APPENDIX D}

\section{ADDITONAL RESULTS}

Table D1. Descriptive Statistics by Position Group

\begin{tabular}{ll}
\hline GROUP & TOTAL \\
Offensive Line & 10 \\
Tight End/Wide Receivers & 12 \\
Quarterbacks & 1 \\
Running Backs & 6 \\
Defensive Tackles/Defensive Ends & 5 \\
Linebackers & 6 \\
Defensive Backs & 4 \\
Special Teams & 3 \\
TOTAL & 47 \\
\hline
\end{tabular}

Table D2. ICC Scores, Percent of Methodological Error, and SEM of Components of UNCFPT

\begin{tabular}{lccccc}
\hline & $\begin{array}{c}\text { ICC } \\
\text { SCORE } \\
(95 \% \mathrm{CI})\end{array}$ & $\begin{array}{c}\text { LOWER } \\
\text { BOUND }\end{array}$ & $\begin{array}{c}\text { UPPER } \\
\text { BOUND }\end{array}$ & $\begin{array}{c}\text { METHODOLOGICAL } \\
\text { ERROR }\end{array}$ & $\begin{array}{c}\text { SEM } \\
\text { Standard Error of the } \\
\text { Measurement }\end{array}$ \\
Shuffle Box & .933 & .880 & .963 & $.117 \%$ & \pm .202 secs \\
Figure 8 & .892 & .806 & .940 & $.213 \%$ & \pm .329 secs \\
SL Hop & .873 & .772 & .929 & $.011 \%$ & \pm .211 secs \\
Carioca & .930 & .874 & .961 & $.074 \%$ & \pm .173 secs \\
SL Triple Hop & .956 & .931 & .973 & $\mathrm{R}=6.56 \%$ & $\pm(\mathrm{R}) 5.975$ in \\
& & & & $\mathrm{L}=4.26 \%$ & $\pm(\mathrm{L}) 5.890$ in \\
\hline
\end{tabular}

Table D3. Best Trial Descriptive Statistics by Week

\begin{tabular}{lcc}
\hline & MEAN & Standard Error of the Mean \\
SHUFFLE BOX & 9.61 secs \pm .773 & .113 \\
Wk 2 & 9.50 secs \pm .786 & .115 \\
Wk 3 & & .141 \\
FIGURE 8 & 15.25 secs \pm .967 & .157 \\
Wk 2 & 15.45 secs \pm 1.078 & \\
Wk 3 & & .092 \\
SL HOP & 5.81 secs \pm .631 & .081 \\
Wk 2 & 5.82 secs \pm .554 & .094 \\
Wk 3 & & .096 \\
CARIOCA & 6.61 secs \pm .646 & \\
Wk 2 & 6.54 secs \pm .659 & 4.331 \\
Wk 3 & & 3.979 \\
SL TRIPLE HOP & 229.26 in \pm 29.694 & \\
Wk 2 (R) & 235.43 in \pm 27.276 & \\
Wk 3 (R) & &
\end{tabular}



Wk 2 (L)
232.06 in \pm 27.647
4.033
Wk $3(\mathrm{~L})$
236.06 in \pm 28.510
4.159

Table D4. Shuffle Box Descriptive Results by Week and Position Group

\begin{tabular}{lccccc}
\hline & $\mathrm{N}$ & \multicolumn{1}{c}{$\begin{array}{c}\text { MEAN } \\
\text { Week } 2\end{array}$} & $\begin{array}{c}\text { Standard } \\
\text { Error of the } \\
\text { Mean } \\
\text { Week } 2\end{array}$ & $\begin{array}{c}\text { MEAN } \\
\text { Week } 3\end{array}$ & $\begin{array}{c}\text { Standard } \\
\text { Error of } \\
\text { the Mean } \\
\text { Week 3 }\end{array}$ \\
Offensive Line & 10 & $10.17 \pm .662$ secs & .209 & $10.01 \pm .627$ secs & .198 \\
TE/WR & 12 & $9.47 \pm 1.02$ secs & .295 & $9.42 \pm 1.052$ secs & .304 \\
QB & 1 & 8.53 secs &. & 8.81 secs &. \\
RB & 6 & $9.10 \pm .417$ secs & .170 & $9.01 \pm .448$ secs & .183 \\
DT/DE & 5 & $9.71 \pm .487$ secs & .218 & $9.44 \pm .347$ secs & .155 \\
LB & 6 & $9.51 \pm .132$ secs & .054 & $9.42 \pm .397$ secs & .162 \\
DB & 4 & $9.67 \pm .860$ secs & .430 & $9.34 \pm 1.054$ secs & .527 \\
Special Teams & 3 & $9.62 \pm .910$ secs & .525 & $9.86 \pm .987$ secs & .570 \\
\hline
\end{tabular}

Table D5. Figure 8 Descriptive Results by Week and Position Group

\begin{tabular}{lccccc}
\hline & N & $\begin{array}{c}\text { MEAN } \\
\text { Week } 2\end{array}$ & $\begin{array}{c}\text { Standard } \\
\text { Error of the } \\
\text { Mean } \\
\text { Week } 2\end{array}$ & $\begin{array}{c}\text { MEAN } \\
\text { Week 3 }\end{array}$ & $\begin{array}{c}\text { Standard } \\
\text { Error of } \\
\text { the Mean } \\
\text { Week 3 }\end{array}$ \\
Offensive Line & 10 & $16.44 \pm .446$ secs & .141 & $16.57 \pm .684$ secs & .216 \\
TE/WR & 12 & $15.06 \pm 1.159$ secs & .334 & $15.16 \pm 1.088$ secs & .314 \\
QB & 1 & 15.38 secs &. & 14.16 secs &. \\
RB & 6 & $14.59 \pm .516$ secs & .210 & $14.61 \pm .523$ secs & .213 \\
DT/DE & 5 & $15.32 \pm .377$ secs & .169 & $15.69 \pm .645$ secs & .288 \\
LB & 6 & $15.12 \pm .358$ secs & .146 & $15.46 \pm 1.360$ secs & .555 \\
DB & 4 & $14.47 \pm .380$ secs & .190 & $14.63 \pm .530$ secs & .265 \\
Special Teams & 3 & $14.48 \pm 1.130$ secs & .652 & $15.61 \pm .609$ secs & .352 \\
\hline
\end{tabular}

Table D6. SL Hop for Distance Descriptive Results by Week and Position Group

\begin{tabular}{lccccc}
\hline & $\mathrm{N}$ & \multicolumn{1}{c}{$\begin{array}{c}\text { MEAN } \\
\text { Week 2 }\end{array}$} & $\begin{array}{c}\text { Standard } \\
\text { Error of the } \\
\text { Mean } \\
\text { Week } 2\end{array}$ & $\begin{array}{c}\text { MEAN } \\
\text { Week 3 }\end{array}$ & $\begin{array}{c}\text { Standard } \\
\text { Error of } \\
\text { the Mean } \\
\text { Week 3 }\end{array}$ \\
Offensive Line & 10 & $6.57 .484 \pm$ secs & .153 & $6.37 \pm .354$ secs & .112 \\
TE/WR & 12 & $5.60 .566 \pm$ secs & .163 & $5.74 \pm .608$ secs & .175 \\
QB & 1 & 5.12 secs &. & 5.44 secs &. \\
RB & 6 & $5.29 \pm .465$ secs & .190 & $5.30 \pm .452$ secs & .184 \\
DT/DE & 5 & $5.90 \pm .491$ secs & .220 & $6.06 \pm .347$ secs & .155
\end{tabular}




\begin{tabular}{llllll} 
LB & 6 & $5.81 \pm .249$ secs & .102 & $5.70 \pm .473$ secs & .193 \\
DB & 4 & $5.68 \pm .623$ secs & .311 & $5.42 \pm .300$ secs & .150 \\
Special Teams & 3 & $5.41 \pm .363$ secs & .210 & $5.91 \pm .230$ secs & .133 \\
\hline
\end{tabular}

Table D7. Carioca Descriptive Results by Week and Position Group

\begin{tabular}{|c|c|c|c|c|c|}
\hline & $\mathrm{N}$ & $\begin{array}{l}\text { MEAN } \\
\text { Week } 2\end{array}$ & $\begin{array}{c}\text { Standard } \\
\text { Error of the } \\
\text { Mean } \\
\text { Week } 2\end{array}$ & $\begin{array}{c}\text { MEAN } \\
\text { Week } 3\end{array}$ & $\begin{array}{c}\text { Standard } \\
\text { Error of } \\
\text { the Mean } \\
\text { Week } 3\end{array}$ \\
\hline Offensive Line & 10 & $7.12 \pm .320$ secs & .101 & $6.95 \pm .467$ secs & .148 \\
\hline TE/WR & 12 & $6.40 \pm .428$ secs & .123 & $6.36 \pm .511$ secs & .147 \\
\hline QB & 1 & 6.53 secs & . & 6.22 secs & • \\
\hline $\mathrm{RB}$ & 6 & $6.16 \pm .455 \mathrm{secs}$ & .186 & $6.08 \pm .277$ secs & .113 \\
\hline $\mathrm{DT} / \mathrm{DE}$ & 5 & $6.60 \pm .519$ secs & .232 & $6.67 \pm .336$ secs & .150 \\
\hline LB & 6 & $6.50 \pm .276 \mathrm{secs}$ & .113 & $6.34 \pm .463$ secs & .189 \\
\hline DB & 4 & $6.93 \pm 1.678 \mathrm{secs}$ & .839 & $6.83 \pm 1.674$ secs & .837 \\
\hline Special Teams & 3 & $6.46 \pm .436$ secs & .251 & $6.65 \pm .586$ secs & .338 \\
\hline
\end{tabular}

Table D8. SL Triple Hop-Right Side Descriptive Results by Week and Position Group

\begin{tabular}{lccccc}
\hline & N & $\begin{array}{c}\text { MEAN } \\
\text { Week 2 }\end{array}$ & $\begin{array}{c}\text { Standard } \\
\text { Error of the } \\
\text { Mean } \\
\text { Week } 2\end{array}$ & $\begin{array}{c}\text { MEAN } \\
\text { Week 3 }\end{array}$ & $\begin{array}{c}\text { Standard } \\
\text { Error of } \\
\text { the Mean } \\
\text { Week 3 }\end{array}$ \\
Offensive Line & 10 & 198.40 in \pm 18.210 & 5.758 & 210.50 in \pm 17.444 & 5.516 \\
TE/WR & 12 & 241.00 in \pm 25.107 & 7.248 & 245.25 in \pm 26.585 & 7.674 \\
QB & 1 & 206.00 in & $\cdot$ & 216.00 in &. \\
RB & 6 & 251.67 in \pm 33.969 & 13.868 & 254.67 in \pm 24.574 & 10.032 \\
DT/DE & 5 & 229.80 in \pm 33.395 & 14.935 & 228.60 in \pm 37.461 & 16.753 \\
LB & 6 & 229.00 in \pm 12.696 & 5.183 & 237.00 in \pm 13.038 & 5.323 \\
DB & 4 & 232.75 in \pm 28.441 & 14.221 & 245.50 in \pm 23.587 & 11.793 \\
Special Teams & 3 & 243.00 in \pm 30.265 & 17.474 & 242.00 in \pm 30.050 & 17.349 \\
\hline
\end{tabular}


Table D9. SL Triple Hop - Left Side Descriptive Results by Week and Position Group

\begin{tabular}{lccccc}
\hline & N & \multicolumn{1}{c}{$\begin{array}{c}\text { MEAN } \\
\text { Week 2 }\end{array}$} & $\begin{array}{c}\text { Standard } \\
\text { Error of the } \\
\text { Mean } \\
\text { Week } 2\end{array}$ & $\begin{array}{c}\text { MEAN } \\
\text { Week 3 }\end{array}$ & $\begin{array}{c}\text { Standard } \\
\text { Error of } \\
\text { the Mean } \\
\text { Week 3 }\end{array}$ \\
Offensive Line & 10 & $203.90 \pm 19.958$ in & 6.311 & $208.00 \pm 16.938$ in & 5.356 \\
TE/WR & 12 & $242.08 \pm 21.576$ in & 6.229 & $242.50 \pm 25.525$ in & 7.369 \\
QB & 1 & 249.00 in & . & 251.00 in & . \\
RB & 6 & $260.83 \pm 29.742$ in & 12.142 & $261.83 \pm 25.600$ in & 10.451 \\
DT/DE & 5 & $226.40 \pm 24.224$ in & 10.833 & $233.20 \pm 30.409$ in & 13.599 \\
LB & 6 & $227.00 \pm 19.586$ in & 7.996 & $234.33 \pm 20.559$ in & 8.393 \\
DB & 4 & $239.50 \pm 24.556$ in & 12.278 & $249.75 \pm 25.838$ in & 12.919 \\
Special Teams & 3 & $232.33 \pm 22.723$ in & 13.119 & $237.33 \pm 39.716$ in & 22.930 \\
\hline
\end{tabular}




\section{APPENDIX E}

\section{RECOMMENDATIONS FOR FUTURE RESEARCH}

1. Obtain data when not in the post season. Pre-season would be best due to the conflict of class scheduling and no formal lifting protocol as was the case during post-season.

2. Avoid exercise induced muscle injury during testing by conducting data collection on off-lifting days.

3. Be consistent with time of day that data is collected for week two and three.

4. Avoid change in seasons due to increased sickness. As a result of the high rate of sickness, actual participation dropped significantly compared to those who volunteered to be in the study. Furthermore, some tried to continue in the study when they were not well negatively impacting results.

5. Increase the time period between weeks for the re-test portion. Several weeks will be more accurate to see if speed and power change throughout season. One would expect larger differences between pre-season and mid-season performance.

6. Obtain a recorder. It would be easier to have assistance with recording time and obtaining distance measurements to expedite the process. This will help with participation as well because it can cut down on testing time.

7. Establish validity of the UNC Functional Performance Test.

8. Conduct test re-test reliability at other locations.

9. Conduct the test pre-season for baseline measurement. Use measurement as part of the return to play decision and keep track of re-injury rate after clearance for the remainder of the season. This will help determine the UNCFPT's actual clinical relevance in regard to function. 


\section{ADDITIONAL REFERENCES}

28. Clark NC. Functional performance testing following knee ligament injury. Phys Ther Sport. 2001;2:91-105.

29. Greenberger HB, Paterno MV. Comparison of an isokinetic strength test and a functional performance test in the assessment of lower extremity function. J Orthop Sports Phys Ther. 1994;19:61.

30. Arnheim DD, Prentice WE. Principles of Athletic Training, Tenth Edition. New York; NY: McGraw Hill; 2000:446-453, 482, 515-521, 565-568.

31. Beam JW. Rehabilitation including sport-specific functional progression for the competitive athlete. J Bodywork Mov Ther. 2002;6(4), 205-219.

32. Saladin KS. Anatomy \& Physiology, The Unity and Form of Function: Second Edition. New York; NY: McGraw Hill; 2001: 312, 386.

33. Moore KL, Dalley AF. Clinically Oriented Anatomy: Fourth edition. Lippincott Williams \& Wilkins: Philadelphia. 2003:715, 726, 730.

34. Torry MR, Schenker ML, Martin HD, Hogoboom D, Philippon MJ. Neuromuscular hip biomechanics and pathology in the athlete. Clin Sports Med. 2006;25(2):179-97.

35. Juhn MS. Patellofemoral pain syndrome: review and guidelines for treatment. Am Fam Phys. 1999;60:2012-22.

36. Gross MT. Lower quarter screening for skeletal malalignment suggestions for orthotics. Foot/Ankle Ther Res 1995;21:398-405.

37. Wikstrom EA, Tillman MD, Chmielewski TL, Borsa PA. Measurement and evaluation of dynamic joint stability of the knee and ankle after injury. Sports Med. 2006;36(5):393-410.

38. Magee DJ. Orthopedic Physical Assessment, Fourth Edition. Philadelphia; PA: Saunders; 2002: 567-568, 607, 661, 765, 847-850.

39. Starkey C, Ryan J. Evaluation of Orthopedic and Athletic Injuries, Second Edition. Phliadelphia; PA: F. A. Davis Company; 2002:87-88, 136-138, 186- 187, 24-245, 272-273, 303-314.

40. McPoil T, Cornwall MW. The relationship between neutral subtalar joint position and pattern of rearfoot motion during walking. Foot Ankle. 1994;15:141-145.

41. Harmon KG. The ankle examination. Prim Care. 2004;31(4):1025-37.

42. Norkin C, White D. Measurement of Joint Motion: A guide to Goniometry, Third Edition. Philadelphia, PA: FA Davis, 2003:30-33, 42-45, 51-56. 
43. Towers JD, Deible CT, Golla SK. Foot and ankle biomechanics. Sem in Musculo Rad. 2003;7(1):67-75.

44. Rockar PA. The subtalar joint: anatomy and joint function. J Orthop Sports Phys Ther. 1995;21(6):361-372.

45. Gollnick PD, Karpovich PV. Electromagnetic study of locomotion and some athletic movements. Res Q. 1964;35:357-369.

46. Macera CA. Lower extremity injuries in runners: advances in prediction. Sports Med. 1992;13:50-57.

47. Bartold SJ. The role of orthoses in the treatment of patellofemoral pain in runners. Int Sportmed J. 2001;2(1):1-10.

48. Laudon J, Jenkins W, Loudon K. The relationship between static posture and ACL injury in female athletes. J Orthop Sports Med. 1995;24:91-97.

49. Witvrouw E, Bellmans J, Lysens R, Daniels L, Cambier D. Intrinsic factors for the development of patellar tendonitis in the athletic population; a two year prospective study. Am J Sports Med. 2001;29:190-195.

50. Glover B, Shepard J, Glover FS. The Runner's Handbook. New York; NY: Penguin Books, 1996:554-578.

51. Hoppenfeld S. Physical Examination of the spine and extremities. New York; NY: AppeltonCentury-Crofts; 1976:164-166.

52. Root ML, Orien WP, Weed JH. Normal and Abnormal Function of the Foot. Los Angeles; CA: Clinical Biomechanics Corp; 1997:127-163.

53. Senavongse W, Amis AA. The effects of articular, retinacular, or muscular deficiencies on patellofemoral joint stability. J Bone Joint Surg. 2005;87(4):577-582.

54. Hreljac A. Impact and overuse injuries in runners. Med Sci Sport Exerc. 2004;2:1-5.

55. Taunton JE, Ryan MB, Clement D, McKenzie DC, Lloyd-Smith DR, Zumbo BD. A retrospective case-control analysis of 2002 running injuries. Brit J Sport Med. 2002;36:95-101.

56. Riegger-Krugh C, Keysor JJ. Skeletal malalignments of the lower quarter: correlated and compensatory motions and postures. J Orthop Sports Phys Ther 1996;23(2):164-170.

57. Hertel J. Functional anatomy, pathomechanics, and pathophysiology of lateral ankle instability. $J$ Athl Train. 2002;37:364-375. 
58. Noyes FR, Dulworth LA, Andriacchi TP, Andrews M, Hewett TE. Knee hyperextension gait abnormalities in unstable knees. Am J Sports Med. 1996;24:34-45.

59. Manske RC, Davies GJ. A nonsurgical approach to examination and treatment of the patellofemoral joint: part one evaluation of the patellofemoral joint. Phys Rehab Med. 2003;15(2):141-166.

60. Piva SR, Fitzgerald K, Irrang JJ, Jones S, Hando B, Browder DA, Childs JD. Reliability of measures or impairments associated with patellofemoral pain syndrome. BMC Musculoskeletal Disorders. 2006;7(33):1-13.

61. Tomsich DA, Nitz AJ, Threkeld AJ, Shapiro R. Patellofemoral alignment: reliability. J Orthop Sports Phys Ther. 1996;23:200-208.

62. Hunt AE, Fahey AJ, Smith RM. Static measures of calcaneal deviation and arch angle as indicators of rearfoot motion during walking. Australian J Phys Ther. 2000;46:9-17.

63. Messier SP, Davis SE, Curl WW. Aetiological factors associated with patellofemoral pain in runners. Med Sci Sports Exerc. 1991;21:1008-1015.

64. Neely FG. Biomechanical risk factors for exercise-related lower limb injuries. Sports Med. 1998;26(6):395-413.

65. Donatelli R. Abnormal biomechanics of the foot and ankle. J Orthop Sports Phys Ther. 1987;9:11-16.

66. Akuthota V, Nadler SF. Core strengthening. Arch Phys Med Rehabil. 2004;85(Suppl1):S86-92.

67. Fields KB, Bloom OJ, Priebe D, Foreman B. Basic biomechanics of the lower extremity. Prim Care. 2005;32(1):245-51.

68. Sigward SM, Powers CM. The influence of gender on knee kinematics, kinetics and muscle activation patterns during side-step cutting. Clin Biomech. 2006;21(1):41-8.

69. Besier TF, Lloyd DG, Ackland TR. Muscle activation strategies at the knee during running and cutting maneuvers. Med Sci Sports Exerc. 2003;35(1):119-27.

70. Pennepacker, K. Running in a new direction can prevent injuries. Runner's World. 2006;41(7):54.

71. Levangie PK, Norkin CC. Joint Structure \& Function: A Comprehensive Analysis, Fourth Edition. Philadelphia PA: FA Davis, 2005:98-99, 354-378, 393-428, 437,461.

72. Nordin M, Frankel VH. Basic Biomechanics of the Musculoskeletal System, $3^{\text {rd }}$ edition. Philadelphia PA: Lippincott Williams \& Wilkins. 2001:176-255. 
73. Feeley BT, Kennelly S, Barnes RP, Muller MS, Kelly BT, Rodeo SA, Warren RF. Epidemiology of National Football League training camp injuries from 1998 to 2007. Am J Sports Med. 2008;36(8):1597-603.

74. Shankar PR, Fields SK, Collins CL, Dick RW, Comstock RD. Epidemiology of high school and collegiate football injuries in the United States, 2005-2006. Am J Sports Med. 2007;35(8):1295303.

75. Dompier TP, Powell JW, Barron MJ, Moore MT. Time-loss and non-time-loss injuries in youth football players. J Athl Train. 2007;42(3):395-402.

76. Krackow MS. An analysis of player position group, height, weight, and relative body weight and their relationship to scores on the Functional Movement Screen. Unrestricted dissertation. Virginia Polytechnic Institute and State University. 2001.

77. Wasudev NP, Ho CP. Mechanisms and imaging of football-related injuries. Semin Musculoskelet Radiol. 2005;9(4):302-15.

78. Culpepper MI, Niemann KM. High school football injuries in Birmingham, Alabama. South Med J. 1983;76(7):873-5, 878.

79. Anderson BL, Hoffman MD, Barton LW. High school football injuries: field conditions and other factors. Wis Med J. 1989;88:28-31.

80. Tyler TF, McHugh MP, Mirabella MR, Mullaney MJ, Nicholas SJ. Risk factors for non-contact ankle sprains in high school football players: the role of previous ankle sprains and body mass index. Am J Sports Med. 2006;34(3):471-5.

81. Beardmore AL, Handcock PJ, Rehner NJ. Return-to-play after injury: practices in New Zealand rugby union. Phys Ther Sport. 2005;6:24-30.

82. Maehlum S, Bahr R. Treating sports injuries. In: Bahr R, Maehlum S, eds. Clinical guide to sports injuries. Champaign: Human Kinetics, 2004:25-37.

83. Wilk KE, Romaniello WT, Soscia SM, Arrigo CA, Andrews JR. The relationship between sjubjective knee scores, isokinetic testing, and functional testing in the ACL-reconstructed knee. J Orthop Sports Phys Ther. 1994;20(2):60-73.

84. Hagglund M, Walden M, Ekstrand J. Lower reinjury rate with a coach-controlled rehabilitation program in amateur male soccer. Am J Sports Med. 2007;35:1433-1442.

85. Risberg M, Ekeland A. Assessment of functional tests after anterior cruciate ligament surgery. $J$ Orthop Sports Phys Ther. 1994;19:212-217. 
86. Augustsson J, Thomeé R, Karlsson J. Ability of a new hop test to determine functional deficits after anterior cruciate ligament reconstruction. Knee Surg Sports Traumatol Arthrosc. 2004;12(5):350-6.

87. O'Donnell S, Thomas SG, Marks P. Improving the sensitivity of the hop index in patients with an ACL deficient knee by transforming the hop distance scores. BMC Musculoskelet Disord. 20061;7:9.

88. Eecahute C, Vaes P, Duquet W. Functional performance deficits in patients with CAI: validity of the multiple hop test. Clin J Sport Med. 2008;18(2):124-129.

89. Docherty C, McLeod T, Shultz S. Postural control deficits in participants with functional ankle instability as measured by the balance error scoring system. Clin J Sport Med. 2006;16:203-208.

90. Keays SL, Bullock-Saxton JE, Newcombe P, Keays AC. The relationship between knee strength and functional stability before and after anterior cruciate ligament reconstruction. J Orthop Res. 2003;21(2):231-7.

91. Saal JA. Common American football injuries. Sports Med. 1991;12(2):132-47.

92. McFarland EG. Return to play. Clin Sports Med. 2004;23(3):15-23.

93. Heffner CL. Research Methods: Variables, Validity and Reliability. All Psych Online: Virtual Psychology Classroom. 2004. Available at: http://allpsych.com/researchmethods/validityreliability.html. Accessed September 23, 2008.

94. Denegar C, Ball D. Assessing reliability and precision of measurement: An introduction to intraclass correlation and standard error of measurements. J Sport Rehabil. 1993;2:35-42. 